\title{
OPPORTUNITIES AND CHALLENGES OF COMBUSTION IN MICROGRAVITY
}

\author{
C. K. LAW* and G. M. FAETH $\dagger \ddagger$
}

* Department of Aerospace and Mechanical Engineering, Princeton University, Princeton, NJ 08544-5263, U.S.A. †Department of Aerospace Engineering. The University of Michigan, Ann Arbor, MI 48109-2118, U.S.A.

\author{
Received 21 February 1994
}

\begin{abstract}
This review considers the opportunities for enhanced fundamental combustion understanding from experiments where effects of buoyancy are eliminated, and the new challenges of fire safety considerations in nonbuoyant (spacecraft) environments. The following specific microgravity combustion phenomena are considered: stretched flames, flamefront instabilities, flammability limits and near-limit phenomena of gaseous premixed flames; structure, stability and soot processes in gaseous nonpremixed flames; flame propagation, smoldering and materials synthesis in heterogeneous premixed flames; flame spread, gasification and combustion in heterogeneous nonpremixed flames; flame-inhibiting atmospheres, fire detection and extinguishment in spacecraft environments; and ground-based (drop tower and aircraft), sounding rocket and space-based (shuttle, space station) microgravity combustion research facilities that are either available or anticipated.

The findings of the review highlight how buoyancy has impeded the rational development of combustion science, precluding observations of fundamental one-dimensional configurations, low Reynolds number flows and other limiting conditions that have been invaluable for developing understanding in other areas of science. Thus, experiments at microgravity provide an opportunity to finally merge theories and experiments for classical problems in order to advance the fundamental understanding of combustion phenomena. Additionally, combustion processes have been shown to be very different at normal gravity and microgravity so that improved understanding of combustion at microgravity is needed in order to address fire and explosion safety considerations for spacecraft.
\end{abstract}

\section{CONTENTS}

Notation

1. Introduction

2. Intrusion of Buoyancy

3. Gaseous Premixed Flames

3.1. Introduction

3.2. Stretch

3.3. Flamefront instability

3.4. Flammability limits

3.5. Near-limit phenomena

3.5.1. Self-extinguishing flames

3.5.2. Stationary spherical flames

66

12

Gaseous Nonpremixed Flames

4.1. Introduction

4.2. Flame structure

4.3. Flame stability

4.4. Soot processes

5. Heterogeneous Premixed Flames

5.1. Introduction

5.2. Flame propagation in suspensions

5.3. Smoldering

5.4. Materials synthesis

6. Heterogeneous Nonpremixed Flames

6.1. Introduction

6.2. Flame spreading

6.3. Droplets

7. Spacecraft Fire Safety

7.1. Introduction

7.2. Flame-inhibiting atmospheres

$\begin{array}{ll}\text { 7.3. Fire detection and extinguishment } & 105\end{array}$

8. Microgravity Facilities

8.1. Introduction

8.2. Drop Towers 
8.3. Aircraft

8.4. Sounding rockets 108

$\begin{array}{ll}\text { 8.5. Spacecraft } & 108\end{array}$

$\begin{array}{lr}\text { 9. Concluding Remarks } & 109\end{array}$

Acknowledgements $\quad 109$

$\begin{array}{lr}\text { References } & 109\end{array}$

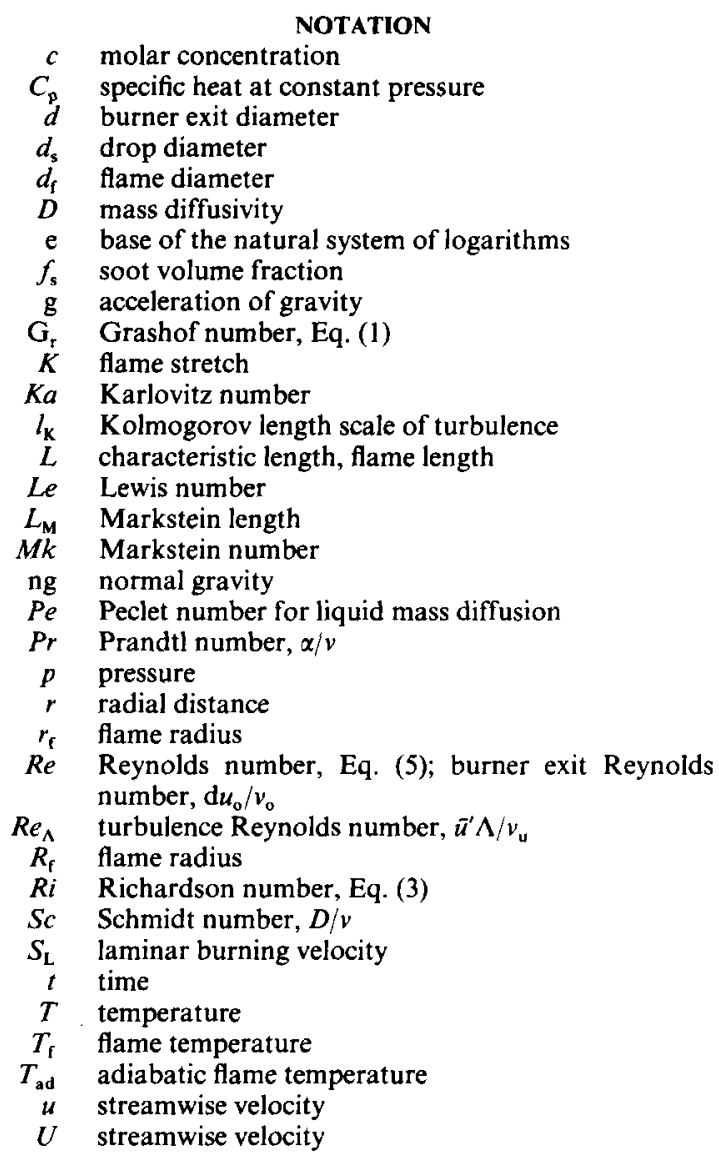

\section{INTRODUCTION}

The availability of improved microgravity $(\mu \mathrm{g})$ facilities and increased manned space activities offer unprecedented opportunities and challenges to combustion science and technology: opportunities to study many combustion phenomena whose fundamental understanding has been handicapped thus far by the buoyant flows that accompany flame processes on Earth, and challenges to develop rational preventive guidelines and control strategies for fire and explosion hazards for spacecraft. ${ }^{1-5}$ The objectives of this review are to discuss progress toward both exploiting the opportunities and meeting the challenges of combustion at $\mu \mathrm{g}$ conditions, concluding with a description of available and anticipated facilities for $\mu \mathrm{g}$ combustion research.

Both terrestrial and space applications provide motivation for advancing fundamental understand-

\author{
characteristic forced convection velocity \\ characteristic natural convection velocity \\ flame spreading velocity \\ reaction rate per unit volume \\ streamwise distance \\ cross stream distance \\ oxidant mass fraction \\ combustion product mass fraction \\ reactant mass fraction \\ streamwise distance \\ thermal diffusivity \\ increment of flame surface area \\ flame thickness \\ density difference \\ rate of dissipation of turbulence kinetic energy \\ thermal conductivity \\ integral scale of turbulence \\ microgravity \\ kinematic viscosity; stoichiometry parameter, \\ $Y_{\mathbf{O} \infty} / \sigma$ \\ density \\ stoichiometric mixture ratio \\ Kolmogorov timescale of turbulence \\ fuel-equivalence ratio \\ characteristic time of a laminar flame \\ transport parameter, $\lambda_{\mathbf{F}} /\left(c D_{\mathrm{F}}\right)$
}

\section{Subscripts}

b combustion products or burned gas property

fuel property

unreacted gas property

burner exit condition; initial condition

ambient condition; negligible stretch condition

\section{Superscripts}

(C) mean value

$\left(^{-}\right)^{\prime}$ rms fluctuating value

ing of combustion science. In particular, we are currently confronted with a long list of either unresolved or emerging combustion problems that have strong economic, social, political and defense-related relevance on Earth. Examples are energy conservation and utilization, air pollution, surface-based transportation, aircraft and spacecraft propulsion, municipal and hazardous waste incineration, materials processing and synthesis, and atmospheric change and global warming. Furthermore, uncontrolled fires and explosions continue to cause loss of life and property-problems that will only become worse as our population and the application of novel technologies increase. Finally, our inadequate understanding of fire and explosion phenomena on Earth is exacerbated by the novel nonbuoyant environment of spacecraft; clearly, combustion research must merit high priority in the space program in order to avoid combustion-related tragedies in the future. 
Several reviews of aspects of $\mu \mathrm{g}$ combustion science have appeared recently. ${ }^{1-5}$ References 1 and 2 are overviews of the U.S. Microgravity Combustion Science Program up to 1989 and 1992, respectively. Law $^{3}$ provides a review emphasizing the advantages of combustion experiments at $\mu \mathrm{g}$ conditions and highlighting the need for studies of spacecraft fire safety due to documented effects of gravity on the properties of flames. Faeth ${ }^{4}$ reviews studies of laminar premixed and nonpremixed gas flames at $\mu \mathrm{g}$, updating aspects of Refs 1 and 2. Finally, Sacksteder $^{5}$ describes available ground-based and spacecraft facilities for $\mu \mathrm{g}$ combustion research and provides a summary of current experiments using these facilities. The present paper synthesizes and updates these reviews up to 1993, emphasizing accomplishments and issues for both homogeneous and heterogeneous flames. The discussion is limited to fundamental laminar flame processes, basic to both laminar and turbulent flames, because practical turbulent flames will remain an empirical aspect of combustion science for some time to come due to computational and experimental limitations. ${ }^{6}$

The paper begins with a discussion of the intrusion of buoyancy during normal gravity (ng) measurements of flame properties, in order to highlight potential research opportunities using $\mu \mathrm{g}$ environments. Completed and active studies of the following combustion phenomena at $\mu \mathrm{g}$ are then considered in turn: stretch, flamefront instabilities, flammability limits and near-limit phenomena of gaseous premixed flames; structure, stability and soot processes in gaseous nonpremixed flames; flame propagation, smoldering and materials synthesis in heterogeneous premixed fiames; flame spread, gasification and combustion in heterogeneous nonpremixed flames; and flame-inhibiting atmospheres, fire detection and fire extinguishment in spacecraft environments. The paper concludes with a description of available ground-based (drop tower and aircraft), sounding rocket and space-based (shuttle, space station) $\mu \mathrm{g}$ combustion research facilities and a summary of recommendations for future $\mu \mathrm{g}$ combustion research based on the needs of combustion-related technologies and the capabilities of available $\mu \mathrm{g}$ combustion research facilities.

\section{INTRUSION OF BUOYANCY}

The intrusion of gravitational forces is a greater impediment to combustion studies than most other areas of science. By its nature, combustion involves chemical energy releases which typically cause the temperature of reactive mixtures to increase from an unreacted ambient state of roughly $300 \mathrm{~K}$ to totally reacted states at $2000-3000 \mathrm{~K}$. These large temperature differences yield corresponding density differences, which in the presence of gravity invariably cause buoyant motions that vastly complicate both the execution and interpretation of measurements. Buoyant motion also prevents some fundamental phenomena-like most laminar one-dimensional premixed and diffusion flames, low Reynolds number heterogeneous flames, flame spread in dispersed heterogeneous media, etc.-from being observed at all. Perversely, the problems of buoyancy are greatest for fundamental laboratory experiments where accurate temporal and spatial resolution are important factors.

Simple phenomenological considerations help to quantify the limitations caused by buoyancy during fundamental flame experiments and provide insight concerning the focus of current $\mu \mathrm{g}$ combustion research. Molecular transport (as manifested by the diffusion of mass, momentum and thermal energy) and forced motion are the relevant collateral properties to chemical energy release for most combustion phenomena; in contrast, buoyant motion generally is an unwanted intrusion. The relative importance of the collateral properties and buoyancy can be represented by two dimensionless parameters: the ratio of buoyant to molecular transport, called the Grashof number, and the ratio of buoyant to forced convective transport, called the Richardson number. ${ }^{7}$

The Grashof number, $G r$, is defined as follows:

$$
G r=(\Delta \rho / \rho) g L^{3} / \nu^{2}
$$

where $\Delta \rho$ and $\rho$ are the characteristic density difference and mean density of the process, respectively, $g$ is the acceleration of gravity, $L$ is a characteristic length scale of the process, and $v$ is a mean kinematic viscosity. Noting that $\Delta \rho / \rho \approx 1$ for flames, because the density of the reactants is generally large in comparison with the density of the combustion products, and that $\mathrm{Gr}<\mathrm{O}\left(10^{-1}\right)$ for effects of buoyancy to be small, ${ }^{7}$ we find that

$$
L<\mathrm{O}(100 \mu \mathrm{m})
$$

for typical values of $v$ (ca. $10 \mathrm{~mm}^{2} / \mathrm{s}$ ) in atmospheric pressure flames. Unfortunately, it is not possible to resolve experiments on such scales using either existing or anticipated combustion apparatus and instrumentation. Experiments at subatmospheric pressures can increase allowable flame sizes before buoyancy intrudes, and this has been exploited by some workers, for example, Law et al. ${ }^{8}$ for studies of droplet burning in quiescent environments. However, reduced rates of chemical reaction at low pressures, even with oxygen enrichment, allow only small increases in scales $\left(L \sim p^{-2 / 3}\right.$ from Eq. (1), where $p$ denotes pressure) before flame extinction eventually occurs. Furthermore, subatmospheric tests generally have reduced relevance because most applications involve pressures equal to or greater than atmospheric pressure, while extrapolation of low-pressure results to the range of interest is uncertain due to complex effects of pressure on the large number of individual reaction steps normally involved in combustion chemistry. 
Experiments in the presence of finite flow velocities offer a way of circumventing the Grashof number limitations. The Richardson number, $R i$, is a measure of the relative importance of buoyancy and a characteristic velocity associated with the flame, such as the laminar burning velocity of premixed flames, $S_{\mathrm{L}}$, or the forced convection velocity of nonpremixed flames, $u_{\mathrm{F}}$. The physical basis for this parameter can be seen by finding the characteristic natural convection velocity, $u_{\mathrm{N}}=(\Delta \rho g L / \rho)^{1 / 2}$, when a low-density gas rises a distance $L .{ }^{7}$ This characteristic natural convection velocity is based on a balance between buoyant and inertial forces; the effects of viscous forces will be considered subsequently. Forming the ratio of the square of these velocities we have:

$$
R i=(\Delta \rho / \rho) g L /\left(S_{\mathrm{L}} \text { or } u_{\mathrm{F}}\right)^{2} .
$$

In the following, we will consider the implications of Eq. (3) for premixed and nonpremixed flames in turn.

Reasonable flame dimensions to provide adequate spatial resolution for measurements within premixed laminar flames are in the range $10-100 \mathrm{~mm}$, while $R i<\mathrm{O}\left(10^{-1}\right)$ for effects of buoyancy to be small. We then find that

$$
S_{\mathrm{L}}>0(1 \mathrm{~m} / \mathrm{s})
$$

is required to avoid significant effects of buoyancy. This regime is comparable with maximum laminar burning velocities. However, it is not possible to study the region of small laminar burning velocities near flammability limits on Earth (typically a few centimeters per second as discussed later) without the intrusion of buoyancy. Additionally, studies of flamefront instabilities, which tend to be most important near flammability limits and for turbulent flames, are constrained by the criterion of Eq. (4) because effects of instabilities tend to be weak near high burning velocity conditions. ${ }^{9-12}$ We will return to this issue later.

The convective limitation due to buoyancy also affects nonpremixed flames. Effects of diffusional transport of heat and mass are central issues for nonpremixed (diffusion) flames. We can conveniently interpret these effects in terms of momentum transport, however, because ratios of heat, mass and momentum diffusivities are nearly unity for gaseous environments of interest to combustion, that is, the Prandtl, Pr, and Schmidt, Sc, numbers are nearly unity for gases. It is then convenient to interpret transport effects through the kinematic viscosity by defining a characteristic Reynolds number of these flames, $R e$, as follows:

$$
R e=L u_{\mathrm{F}} / v=(G r / R i)^{1 / 2}
$$

where $G r$ and $R i$ have been introduced from Eqs (1) and (3). Noting that $\mathrm{Gr}=\mathrm{O}\left(10^{3}\right)$ for a flame length of $10 \mathrm{~mm}$ (which provides reasonable spatial resolution for measurements) from Eq. (1), while
$R i<\mathrm{O}\left(10^{-1}\right)$ for forced motion to dominate buoyancy, ${ }^{7}$ we have as a consequence

$$
R e>10^{2} \text {. }
$$

This implies that the Stokes flow regime $(\operatorname{Re}<1)$, which is a natural limit that has been invaluable for understanding fluid mechanics, cannot be reached for flame studies on Earth without the intrusion of buoyancy. Thus, buoyant, nonpremixed flames are a common experimental configuration, for lack of an alternative, although buoyancy causes complications and introduces phenomena that have little relevance to most studies. Furthermore, the large buoyant velocities cause flames to develop thin boundary layerlike structures typical of large $R e$ conditions that can significantly limit the spatial resolution of measurements, in comparison with low Re conditions achievable at $\mu \mathrm{g}$.

The effect of buoyancy is so ubiquitous that we generally do not appreciate the enormous negative impact that it has had on the rational development of combustion science. For example, aside from limited exploratory work at $\mu \mathrm{g}$ conditions, we have never observed the most fundamental processes of combustion without substantial disturbances of buoyancy-precluding simple one-dimensional configurations, low Reynolds number flows and other limiting conditions that have been invaluable for developing understanding in other areas of science. This prevents the rational merging of theory, where buoyancy is frequently of little interest, and experiments, which are always contaminated by effects of buoyancy at ng conditions.

Turbulent flames, one of the most important unresolved problems of combustion science, provide graphic examples of the impediment that buoyancy causes to the parallel development of theory and experiment. Three-dimensional time-dependent numerical simulations of turbulent flames offer a logical way to study some of the phenomena of turbulence; however, due to computer limitations, such calculations can only consider low-speed flows having a relatively limited range of length scales, that is, low Reynolds number flows. ${ }^{6}$ Unfortunately, such conditions cannot be duplicated in the laboratory at $\mathrm{ng}$ because buoyancy immediately accelerates the flow from any initial low-speed condition, resulting in high-speed flows with a large range of length scales, that is, high Reynolds number flows. The inability to measure combustion properties in low-speed twophase flows, because particles and drops settle at ng conditions, is another obvious example of the experimental limitations caused by buoyancy. In these circumstances, theory and experiment tend to go their own way-to the detriment of both. Furthermore, even the most optimistic estimates of rates of computer development imply no merger of theoretical capabilities and experimental conditions for simulations of turbulence and practical multiphase flows for the foreseeable future. ${ }^{6}$ These are only examples, and 
similar buoyancy-induced gaps between theory and experiment exist in virtually ever area of combustion science. With no massive breakthrough in computer technology in the offing, rapid expansion of combustion experiments at $\mu \mathrm{g}$ conditions offers the most promising approach toward resolving this theoretical/experimental dichotomy of combustion science.

The same features that make the $\mu \mathrm{g}$ environment attractive for fundamental combustion experiments introduce hazards of fires and explosions that have no counterpart on Earth. Thus far, activities in space have been limited and have only involved carefully selected and highly trained individuals. As the space environment is exploited, however, a larger range of activities and individuals will be involved-vastly increasing the potential for unwanted fires and explosions in a highly public arena. The main concern is that virtually all existing information concerning design procedures to control fires and explosions is based on experience with ng environments. Of necessity, current qualification procedures for materials used in space involve tests at $\mathrm{ng}$, justified by rather limited measurements from $\mu \mathrm{g}$ environments. ${ }^{5}$ Since we know that combustion processes are very different at $\mathrm{ng}$ and $\mu \mathrm{g}$ conditions, there is little basis for confidence that this practice is sufficient.

Thus, the Earth's gravity has impeded combusion science, somewhat analogously to the way that the Earth's atmosphere has impeded optical astronomy; additionally, there is virtually no technology base for fire and explosion safety considerations for spacecraft. To circumvent these difficulties, a variety of facilities for reduced gravity combustion research have been developed, including drop towers providing 1-10 $\mathrm{s}$ at $10^{-4}-10^{-6} \mathrm{~g}$, aircraft-based facilities providing $5-15 \mathrm{~s}$ at $10^{-1}-10^{-3} \mathrm{~g}$, sounding rockets providing up to 200-900 $\mathrm{s}$ at $10^{-4} \mathrm{~g}$ and spacecraft facilities providing times of $10^{3}-10^{4} \mathrm{~s}$ at $10^{-5} \mathrm{~g} .{ }^{5}$ In the following sections we shall discuss some combustion phenomena that are strongly influenced by the presence of buoyancy, the progress using available $\mu \mathrm{g}$ facilities to study fundamental combustion processes, and some issues that remain to be resolved.

\section{GASEOUS PREMIXED FLAMES}

\subsection{Introduction}

The large reaction rates per unit volume required for efficient and compact combustion in flowing premixed gases, as well as the large velocities caused by buoyancy for flames in still gases, imply that most practical gaseous premixed flames are turbulent. Thus, an important issue that must be addressed is the relevance of laminar premixed flame studies to applications involving turbulent premixed flames. This issue has been resolved by the development of the laminar flamelet concept in recent years and the finding that most practical combustion systems are in the laminar flamelet regime. ${ }^{13.14}$ The laminar flamelet concept implies that premixed turbulent flames can be considered to consist of quasi-steady premixed laminar flamefronts, that is, flame surfaces that are distorted by turbulence when certain conditions are met as discussed in the following. ${ }^{13-15}$ First, the laminar flamelet concept applies when the smallest scales of turbulence (which can be represented by the Kolmogorov microscale, $l_{\mathrm{K}}$, because scales relevant to mass, momentum and energy transport are comparable in gases, as noted earlier) are larger than the characteristic flame thickness, of $\delta_{\mathrm{L}}$, that is, when $l_{\mathbf{K}}>\delta_{\mathrm{L}}$. This criterion can be expressed in terms of the velocity fluctuations of turbulence in the unburned gas relative to the laminar burning velocity, $\bar{u}^{\prime} / S_{\mathrm{L}}$, and the turbulence Reynolds number of the unburned gas, $\bar{u}^{\prime} \Lambda / v_{\mathrm{u}}$, where $\Lambda$ is the integral scale of the turbulence, as follows: ${ }^{13}$

$$
\tilde{u}^{\prime} / S_{\mathrm{L}}<R e_{\Lambda}^{1 / 2} \text {, laminar flamelet regime. }
$$

Additionally, the quasisteady requirement can be met when the Kolmogorov microtime scale of the unburned gas, $\tau_{\mathrm{K}}=\left(v_{\mathrm{u}} / \varepsilon\right)^{1 / 2}$, where $\varepsilon$ is the rate of dissipation of turbulence kinetic energy, is greater than the characteristic residence time of the flame, $\tau_{\mathrm{L}}=\delta_{\mathrm{L}} / S_{\mathrm{L}}$, or $\tau_{\mathrm{K}}>\tau_{\mathrm{L}}$. It is easy to show, using an argument similar to Bray, ${ }^{13}$ that the quasisteady approximation also requires the conditions specified by Eq. (7). Thus, the laminar flamelet regime involves distortion of the laminar flame sheet at scales that are larger than the thickness of the flame and at rates that are slow in comparison with the response capabilities of the flame. When these conditions are satisfied, the properties of laminar flames are relevant to turbulent flames. Furthermore, the flame thickness requirement expressed by Eq. (7) is not very restrictive; for example, even the intense turbulent premixed flames found within automotive spark-ignition engines are largely within the laminar flamelet regime. ${ }^{16}$ Thus, the effects of turbulence for a significant range of practical conditions can be viewed in terms of enhanced or retarded (quenched) laminar flamelet propagation due to turbulence-induced flame distortion. These distortions involve wrinkling of the propagating laminar flamefront by the nonuniformities of the turbulent flow field, which introduces variations in the curvature of the flamefront, as well as regions where the flamefront is compressed or expanded (strained) along its surface. These dynamical effects of turbulence on thin laminar flamefronts are reviewed by Peters ${ }^{14}$ and Law, ${ }^{15}$ where it is shown that the combined effects of curvature and strain on a propagating thin laminar flamefront can be conveniently represented by the flame stretch. Flame stretch, which was introduced by Karlovitz et al. ${ }^{17}$ is defined as the local fractional rate of increase of flame surface area. Thus, effects of distortion of laminar premixed flames, characterized as effects of flame stretch, are receiving significant attention, including work at $\mu \mathrm{g}$ conditions. 


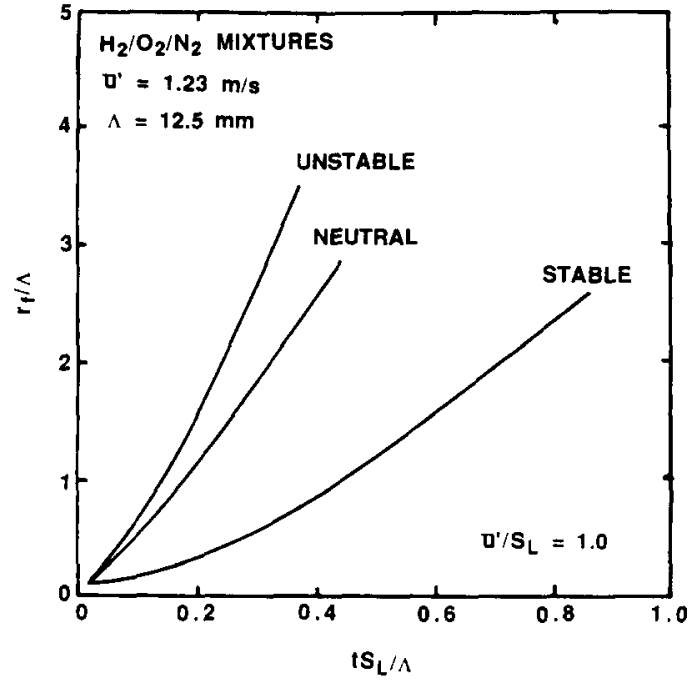

FIG. 1. Variation of the properties of freely propagating turbulent premixed flames in $\mathrm{H}_{2} / \mathrm{O}_{2} / \mathrm{N}_{2}$ mixtures due to effects of preferential diffusion. From Tseng and Faeth. ${ }^{18}$

Another aspect of the relevance of properties of laminar flamefronts to turbulent premixed flames involves potential effects of laminar flamefront instabilities. As discussed subsequently, the interaction between flow nonuniformities in a turbulent flow field and a laminar flamefront generally is not passive, with effects of flamefront instability acting to either enhance or retard the turbulent distortion of the flame surface for unstable and stable conditions, respectively. There are three main mechanisms of laminar flamefront instability, as reviewed by Clavin $^{18}$ and these will be discussed in more detail subsequently. These three mechanisms include: (i) hydrodynamic instability, which is caused by acceleration of low-density combustion products toward a high-density reactant mixture; (ii) preferential-diffusion instability, which is caused by different heat and mass transport rate response to effects of flame stretch; and (iii) Rayleigh-Taylor instabilities, which are caused by accelerations, mainly due to gravity, normal to a density discontinuity such as a flame. All three mechanisms are present to some extent for laminar flamefronts at ng, however, the preferentialdiffusion mechanism appears to be most important for premixed turbulent flames.

Recent observations for a variety of turbulent premixed flames suggest that effects of preferential diffusion, analogous to those associated with preferential-diffusion instability of laminar flamefronts, generally affect the properties of turbulent premixed flames. For example, Clavin and coworkers $^{18}$ have found that flamefront stability phenomena, due to effects of preferential diffusion, influence turbulent flames having large length scales and low turbulence intensity, with unstable and stable conditions, respectively, causing chaotic enhancement and damping of flame surface distortion by turbulence.
While these findings were for weak turbulence, recent experimental work supports similar behavior for highly turbulent, rim-stabilized and freely-propagating flames. ${ }^{9-12.19}$ An example of this behavior is illustrated in Fig. 1, which is a plot of mean flame position as a function of time for freely propagating flames in $\mathrm{H}_{2} / \mathrm{O}_{2} / \mathrm{N}_{2}$ mixtures within the laminar flamelet regime at $R e_{\mathrm{\Lambda}}=1200$ and $\bar{u}^{\prime} / S_{\mathrm{L}}=1 .^{19} \mathrm{Re}$ sults are illustrated for three flames having nearly identical laminar burning velocities and unburned gas turbulence properties, which involve unstable, nearly-neutral and stable preferential-diffusion stability conditions, respectively. Barring effects of preferential-diffusion instability, these flames should have identical properties because test conditions were remote from quenching limits; instead, the unstable (stable) flame propagates substantially faster (slower) than the neutrally-stable flame. This behavior clearly shows that effects of preferential diffusion are important even for highly turbulent conditions. Although effects of preferential diffusion in turbulent flames are just beginning to receive attention in the literature, they are important for most practical applications. For example, premixed flames in spark ignition automotive engines and aircraft propulsion systems all are within the strongly stable preferential-diffusion regime where distortion of the flame surface by turbulence is damped. Coupled with the laminar flamelet concept, this has motivated new interest in the classical problem of laminar flamefront instability.

The preceding discussion suggests that laminar premixed flames are relevant to turbulent premixed flames and has highlighted the importance of stretch, flamefront instability and limits (quenching) for practical flames. Studies of these topics at $\mu \mathrm{g}$ will be considered in the following, concluding with some near-limit phenomena-self-extinguishing flames (SEF) and stationary spherical flames (SSF)-that appear to be unique to $\mu \mathrm{g}$ conditions.

\subsection{Stretch}

Effects of flame stretch, $K$, are important for understanding flamefront stability and aspects of limits; they will, therefore, be discussed in this section. As noted earlier, flame stretch collectively represents the effects of flow nonuniformity, flame curvature and flame motion. It is defined in the context of a laminar flame surface element of incremental area, $\delta A$, as follows: ${ }^{17}$

$$
K \equiv d \ln (\delta A) / \mathrm{d} t
$$

where changes of $\delta A$ are observed in a Lagrangian reference frame that moves with the flame surface, that is, the boundary of $\delta A$ moves in a tangent to the flame surface at the local tangential velocity of the gas, and normal to the flame surface at the sum of the local normal velocity of the gas and the local 


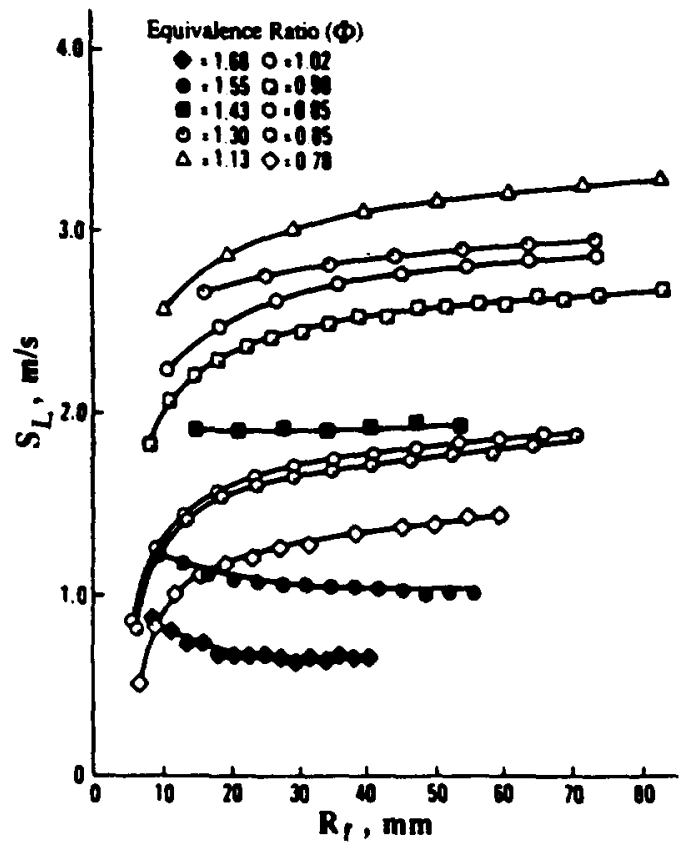

FIG. 2. Variation of laminar burning velocity with flame radius for positively-stretched propane-air flames. Data from Palm-Leis and Strehlow ${ }^{27}$ as replotted by Law. ${ }^{15}$

laminar burning velocity of the flame. ${ }^{14,15}$ Dynamic effects due to stretch and the extent of preferential diffusion alter the relative rates of transport of gas species and thermal energy within the preheat zone of the flame structure, consequently modifying the temperature, composition and reaction rates within the reaction zone. The corresponding modification of laminar burning velocities yields the response of the flame to stretch.

Simplified theories of stretched laminar flames ${ }^{15,18-23}$ frequently adopt a global one-step reaction whose rate is controlled by the stoichiometrically-deficient reactant: the fuel for fuel-lean conditions or the oxidant for fuel-rich conditions. Preferential diffusion of heat and mass is allowed by considering a nonunity Lewis number, $L e$, which is interpreted to be the ratio of the thermal diffusivity of the bulk mixture to the mass diffusivity of the stoichiometrically-deficient reactant. For nearstoichiometric mixtures an effective $L e$ can also be identified. ${ }^{24}$ For these approximations, the flame temperature, $T_{\mathrm{f}}$, in the linearized limit of $K a(1-$ $L e) / L e \ll 1$, is related to the adiabatic flame temperature, $T_{\text {ad }}$, as follows: ${ }^{15}$

$$
T_{\mathrm{f}} T_{\mathrm{ad}}=1+K a_{\infty}(1-L e) / L e .
$$

The parameter $K a$ in Eq. (9), is the Karlovitz number which is the stretch of the flame surface normalized by the characteristic residence time of the flame:

$$
K a=K / \tau_{\mathbf{L}}=K S_{\mathbf{L}} / \delta_{\mathbf{L}}
$$

and the subscript ${ }_{\infty}$ designates conditions near the unstretched state of $K=0$. The use of $K a_{\infty}$ instead of $K a$ in Eq. (9) indicates the linearized nature of the solution. Equation (9) implies increased flame temperatures $\left(T_{f}>T_{a d}\right)$ for either $K a_{\infty}>0$ and $L e<1$ or $K a_{\infty}<0$ and $L e>1$, and reduced flame temperatures $\left(T_{\mathrm{f}}<T_{\mathrm{ad}}\right)$ otherwise. This result has been extensively verified experimentally ${ }^{15}$ for both counterflow and Bunsen flames, for which the stretch effect is manifested through flow straining and flame curvature, respectively.

Modification of the flame temperature through stretch implies a corresponding modification of the reaction rate, $\dot{w}$, and hence the laminar burning velocities, flammability limits and quenching conditions. In particular, phenomenological analysis shows that $S_{\mathbf{L}} \sim \dot{w}^{1 / 2}$, where $\dot{w}$ increases with increasing temperature in the Arrhenius manner (see Ref. 23). This behavior is illustrated by measurements of laminar burning velocities for free spherical flames propagating radially outward from a centrally located spark source in an initially motionless combustible mixture. If the burned gas has negligible motion, if the flame is thin in comparison with its radius, $\delta_{\mathrm{L}} \ll r_{\mathrm{f}}$, and if the rate of change of flame thickness with flame radius is small, $\mathrm{d} \delta_{\mathrm{L}} / \mathrm{d} r_{\mathrm{f}} \ll 1$, which usually is the case, Eq. (8) yields: ${ }^{15,25,26}$

$$
K=\left(2 / r_{\mathrm{f}}\right) \mathrm{d} r_{\mathrm{f}} / \mathrm{d} t
$$

where $r_{f}$ is the radius of the flame surface. Furthermore, a simple mass balance between the rate of consumption of the unburned mixture $\left(\sim S_{\mathrm{L}} \rho_{\mathrm{u}}\right)$ and the rate of growth of the burned mixture $\left(\sim \rho_{\mathrm{b}} \mathrm{d} r_{\mathrm{f}} / \mathrm{d} t\right)$ yields:

$$
S_{\mathrm{L}}=\left(\rho_{\mathbf{b}} / \rho_{\mathbf{u}}\right) \mathrm{d} r_{\mathrm{f}} / \mathrm{d} t .
$$

Then, eliminating $\mathrm{d} r_{\mathrm{f}} / \mathrm{d} t$ between Eqs (11) and (12), we have:

$$
K=2\left(S_{\mathrm{L}} / r_{\mathrm{f}}\right)\left(\rho_{\mathrm{u}} / \rho_{\mathrm{b}}\right)
$$

For the outward propagation of a spherical flame, $K$ is positive and decreases monotonically toward zero as $r_{\mathrm{f}}$ increases. Then Eqs (9) and (10) imply that $T_{\mathrm{f}}>T_{\mathrm{ad}}$ for $L e<1$, and vice versa for $L e>1$.

While the transition $L e$ for $T_{\mathrm{f}}$ is unity, the transition $L e$ for the laminar burning velocity deviates from this value. ${ }^{15}$ Thus, flame curvature and flow nonuniformity still have an influence on the laminar burning velocity when $L e=1$ and $T_{\mathrm{f}}=T_{\mathrm{ad}}$. To further illustrate this effect, early measurements of the laminar burning velocities of spherical outwardly propagating flames, due to Palm-Leis and Strehlow, ${ }^{27}$ are plotted as a function of flame radius in Fig. 2. These results are for propane-air flames at various fuel-equivalence ratios, $\varphi$. For these conditions, the laminar burning velocity increases with increasing flame radius when $\varphi<1.43$ and decreases with increasing flame radius otherwise. Since the experimental transition $\varphi$ for $T_{\mathrm{f}}$ is near unity for propane-air flames, the fact that the experimental burning velocity changes its behavior for $\varphi>1$ supports the theoretical result that its transition $L e$ also deviates from one. 


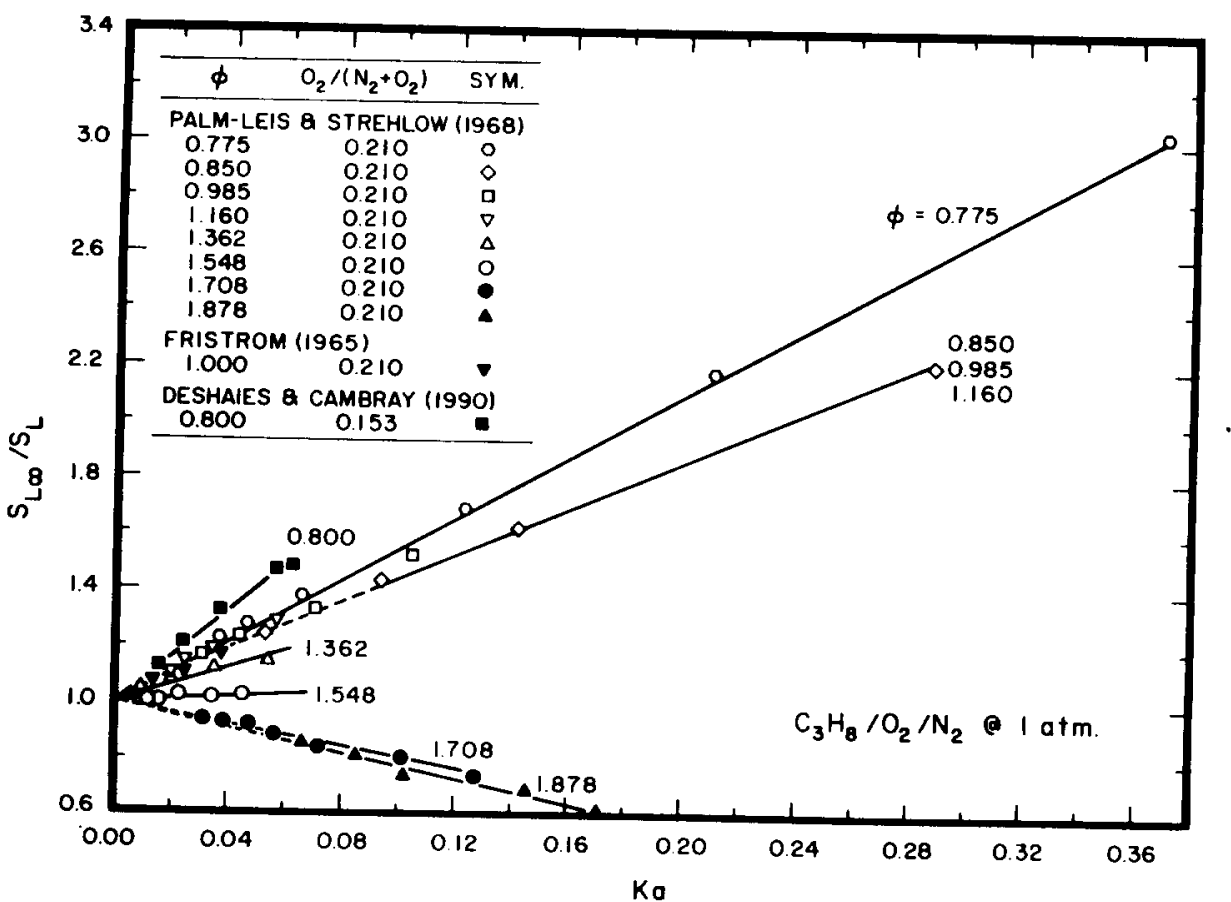

FIG. 3. Variation of laminar burning velocity with Karlovitz number for propane-air flames. Data from Palm-Leis and Strehlow, ${ }^{27}$ Fristrom ${ }^{29}$ and Deshaies and Cambray ${ }^{30}$ as plotted by Kwon et al. ${ }^{25}$

While theories ${ }^{15,20-23}$ of stretched flames yield basically the same result concerning the flame temperature response, differences exist concerning the predicted response for the laminar burning velocity. However, recent experimental measurements of the effects of flame stretch on laminar burning velocities using outwardly-propagating spherical flames, ${ }^{25.26}$ have been found to correlate conveniently, based on an early proposal of Markstein, ${ }^{28}$ as follows:

$$
S_{\mathrm{L}}=S_{\mathrm{L} \infty}-L_{\mathrm{M}} K
$$

where $S_{\mathrm{L} \infty}$ is the laminar burning velocity for an unstretched flame $(K=0)$ and $L_{\mathrm{M}}$ is a measure of the response of the flame to stretch called the Markstein length. Then, basing the characteristic flame thickness on a characteristic mass diffusivity of the unburned gas, $\delta_{\mathrm{L}}=D_{\mathrm{u}} / S_{\mathrm{L}}$, and introducing the Karlovitz number, Eq. (14) becomes: ${ }^{25,26}$

$$
S_{\mathrm{Loo}} / S_{\mathrm{L}}=1+M k K a
$$

where $M k$ is the Markstein number which is defined as the Markstein length normalized by the current characteristic flame thickness, that is, the flame thickness at the local stretched condition, as follows:

$$
M k=L_{\mathrm{M}} / \delta_{\mathrm{L}}=L_{\mathrm{M}} S_{\mathrm{L}} / D_{\mathrm{u}} .
$$

The Karlovitz number in Eq. (15) is defined in a corresponding manner, based on current flame properties, as follows:

$$
K a=K D_{\mathrm{u}} / S_{\mathrm{L}}^{2} .
$$

The stretched burning velocities of propane-air mixtures are plotted according to Eq. (15) in Fig. 3, from Kwon et al. ${ }^{25}$ Results are shown for the measurements of Palm-Leis and Strehlow, ${ }^{27}$ Fristrom, ${ }^{29}$ and Deshaies and Cambray. ${ }^{30}$ (Note that questions raised in Ref. 25 about the Palm-Leis and Strehlow ${ }^{27}$ data have been resolved by recent measurements, ${ }^{26}$ as discussed later.) It is seen that over the range of the measurements, which do not approach either quenching conditions with $K a=0(1),{ }^{15}$ or flammability limits, the correlation between $S_{\mathrm{L} \infty} / S_{\mathrm{L}}$ and $K a$ is linear for a given $\varphi$, implying a constant $M k$ from Eq. (15). As pointed out earlier, the neutral-stability condition, $M k=0$, is reached near $\varphi=1.4$, with laminar burning velocities decreasing with increasing $K a(M k>0)$ for $\varphi<1.4$ and increasing with increasing $K a(M k<0)$ otherwise.

The large variations of laminar burning velocities with stretch is a striking feature of the results of Fig. 3 , for example, $S_{\mathrm{L} \infty} / S_{\mathrm{L}}$ varies in the range 0.6-3.1 even though $K a<0.37$ for the test range. Applying Eq. (15), $M k$ ranges from -2.2 at $\varphi=1.878$ to 5.5 at $\varphi=0.775$ for the measurements of Palm-Leis and Strehlow; ${ }^{27}$ notably, recent results for $\mathrm{H}_{2} / \mathrm{O}_{2} / \mathrm{N}_{2}$ and hydrocarbon-air flames also yield comparable values of $M k .^{25,26}$ These large values of $M k$ show that effects of preferential diffusion cause laminar premixed flames to be very sensitive to modest levels of stretch, even well away from quenching conditions: this helps explain the importance of preferential-diffusion effects for strongly turbulent flames discussed earlier (see Fig. 1 and Refs 9-12). Additionally, $M k$ is significantly greater than unity for hydrocarbons at $\varphi \leqslant 1$ (methane is an exception 


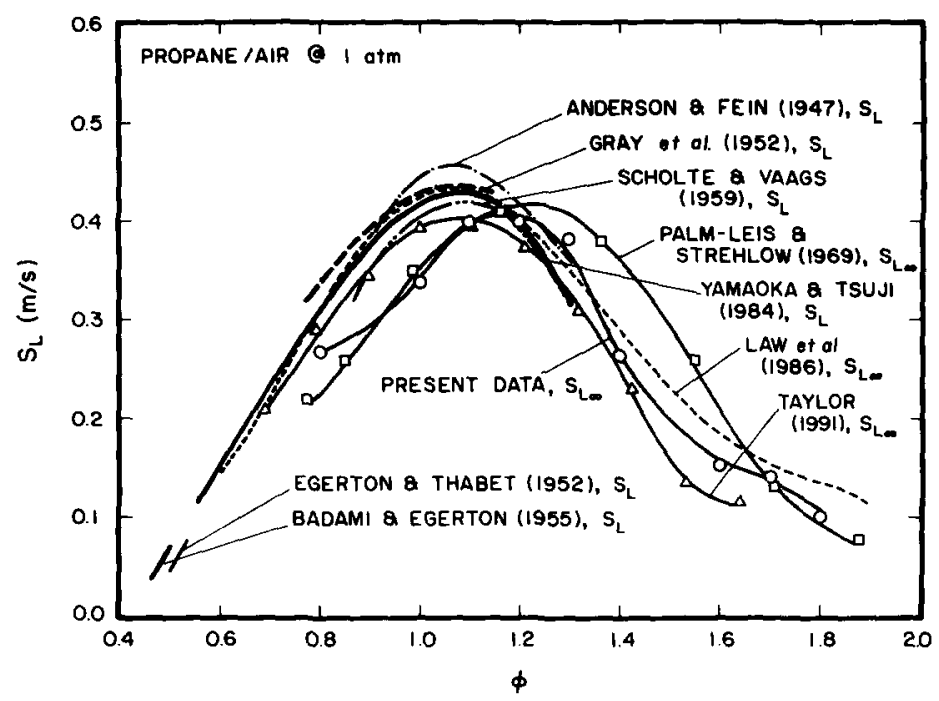

FIG. 4. Laminar burning velocities as a function of fuel-equivalence ratio for propane-air flames at normal temperature and pressure as plotted by Tseng et al. ${ }^{26}$

where unstable conditions are in the range $\varphi<0.7^{26}$ ), suggesting strong effects of preferentialdiffusion stability on flamefront properties for practical applications at these conditions, for example, furnaces, automobile engines and aircraft propulsion systems.

The large effects of stretch on laminar burning velocities also raise questions about existing data in the literature for this important fundamental property. In particular, the laminar burning velocity for an unstretched (planar) flame, $S_{\mathrm{L} \infty}$, is the fundamental property of interest, however, in spite of efforts to minimize and correct for stretch, the database generally involves finite and unspecified values of $K a$. Thus, effects of stretch combine with other experimental uncertainties to yield considerable uncertainties about $S_{\mathbf{L}_{\infty}}$.

An indication of potential problems with existing measurements of fundamental laminar burning velocities can be obtained by comparing measurements from various sources. Results of this type for methane, ethane, ethylene and propane-air flames are presented by Tseng et al.; ${ }^{26}$ a typical example for propane-air flames is illustrated in Fig. 4. Results that are plotted include measurements for outwardly propagating spherical flames from Tseng et al. ${ }^{26}$ Palm-Leis and Strehlow ${ }^{27}$ and Taylor $^{31}$ (the latter two re-analyzed in Ref. 26 as discussed in connection with Fig. 3), measurements for stagnation point flames from Law and coworkers ${ }^{32-35}$ and Yamaoka and Tsuji, ${ }^{36}$ and several other measurements using a variety of techniques: original sources cited in Ref. 26 should be consulted for the details of these experiments. The outwardly-propagating spherical flame results of Tseng et al., ${ }^{26}$ Palm-Leis and Strehlow ${ }^{27}$ and Taylor ${ }^{31}$ have been corrected as discussed in connection with Fig. 3 in order to provide estimates of $S_{\mathrm{L} \infty}$. Similarly, the stagnation point measurements of Law and coworkers ${ }^{32-35}$ involve techniques where effects of stretch are quantified and subtracted out so that $S_{L_{\infty}}$ can be estimated (see Ref. 35 for a complete compilation of measurements based on this approach). The remaining measurements have not been corrected for stretch.

The results illustrated in Fig. 4 are not very encouraging with respect to current knowledge concerning fundamental laminar burning velocities, even considering results where corrections for stretch have been made. Among the corrected measurements, the results of Palm-Leis and Strehlow ${ }^{27}$ probably involve an error in reported fuel-equivalence ratios, as discussed in Ref. 26, and will not be considered further. The remaining measurements only are in fair agreement for $\varphi$ near 1.4, which corresponds to near-neutral conditions for propane-air flames where values of $M a$, and thus effects of stretch, are small (see Fig. 3 and Ref. 26). At both fuel-lean and fuelrich conditions where $M a$ is large for propane-air flames, ${ }^{26}$ there are substantial differences between the various measurements which are probably mainly attributable to effects of stretch and the procedure through which the stretch effects are subtracted out (see Refs 26, 32-35 and 38, and references cited therein, for discussions of this methodology). Clearly, resolving the uncertainties of laminar burning velocities must have high priority because this fundamental property impacts the interpretation of a variety of flame phenomena. Additionally, these uncertainties compromise the development of methods to numerically simulate premixed laminar flames using detailed chemical-kinetic and transport models because they generally are calibrated using laminar burning velocity data (see the recent review by Warnatz, ${ }^{39}$ and references cited therein). 


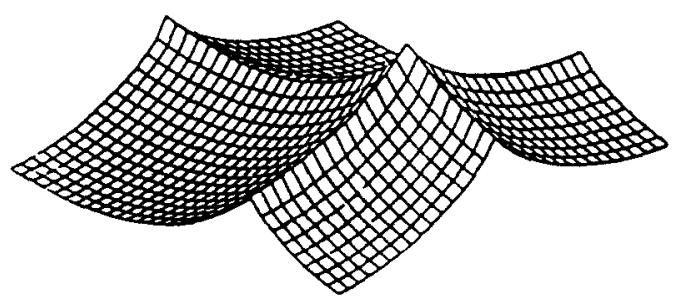

FIG. 5. Thermal-expansion-induced steady folds of fullydeveloped hydrodynamic instability. Predictions from Sivashinsky. ${ }^{43}$

Measurements at $\mu \mathrm{g}$ offer opportunities to resolve problems of laminar burning velocities. For example, effects of buoyancy-induced stretch for the outwardly-propagating spherical flame technique can be eliminated in this manner, increasing the reliability of determinations of both $S_{\mathbf{L} \infty}$ and $M k$. Work along these lines has been carried out by Ronney and coworkers, and will be discussed in connection with near-limit phenomena, but much remains to be done. An alternative approach involves consideration of one-dimensional premixed flames around porous cylindrical and spherical burners at $\mu \mathrm{g}$. This configuration is attractive because the flames are steady and the flow is normal to flame, which implies that the flames are stretchless. ${ }^{15}$ Work with cylindrical flames of this type has been initiated. ${ }^{40}$

Other implications of effects of stretch on reaction intensity, flamefront instability and flammability limits are addressed in the following.

\subsection{Flamefront Instability}

Laminar premixed flames do not always exhibit smooth flame surfaces. Various types of instabilities can develop over flame surfaces, causing wrinkling and fundamental changes of flame topography and structure. ${ }^{25,26,41-48}$ When effects of instabilities are present, the burning intensity varies over the flame surface, leading to local regions of high reactivity (or hot spots) as well as extinguished regions through which reactants can leak. It has also been suggested that flamefront instabilities could lead to self-turbulization of flames. ${ }^{43}$ Other interactions between stability phenomena and turbulent flamefronts have already been discussed in connection with Fig. 1.

As briefly noted earlier, there are three major mechanisms of flamefront instability of interest to laminar and turbulent premixed flames: hydrodynamic, preferential-diffusion and Rayleigh-Taylor instabilities. Hydrodynamic (or Landau-Darrieus) instability involves the growth of disturbances due to pressure fields caused by density changes across the flame surface. The linear stability analysis of Landau and Darrieus treats the flame like a structureless density discontinuity propagating through an other- wise incompressible medium and shows that the flame is unstable to perturbations of all wavelengths. ${ }^{28}$ This analysis presents a dilemma, however, because smooth flames are routinely observed in the laboratory. A nonlinear analysis has shown that such instabilities will evolve into folds having substantial dimensions relative to the disturbances as illustrated in Fig. $5 .^{43}$ This mechanism has been observed for large-diameter spherical laminar flames, ${ }^{25,44}$ but it is probably not of primary interest for either laminar premixed flame studies, where flame sizes are generally smaller, or most practical applications involving turbulent flames, where momentum fiuctuations from turbulence tend to dominate the distortion of flame surfaces.

Preferential-diffusion instability is the mechanism of major interest for turbulent flames, due to its capability to enhance or retard turbulent distortion of the flame surface in the laminar flamelet regime. ${ }^{5-12,19}$ Two classes of preferential-diffusion instabilities have been analyzed in the past: diffusive-thermal and diffusive-diffusive instabilities. The diffusive-thermal instability mechanism was first described by Zel'dovich and coworkers, ${ }^{45,46}$ and has received substantial subsequent theoretical attention using activation-energy asymptotics of a one-reactant flame. ${ }^{18,43,47}$ Diffusive-thermal instabilities involve preferential diffusion of mass and heat, affecting flame temperatures as discussed in connection with Eq. (9), and accordingly the local burning velocities. In this case, the flame bulges into the reactant yield $K a>0$, similar to freely propagating spherical flames, while the flame bulges into the combustion products yield $K a<0$, similar to the tips of Bunsen burner flames. ${ }^{15}$ Then for $L e<1$, bulges into the reactant (product) have $T_{\mathrm{f}} / T_{\mathrm{ad}}>1(<1)$ through Eq. (9), causing the bulges to grow and the flame to be unstable. The opposite behavior occurs for $L e<1$. Thus, fuel-lean premixed flames of heavy hydrocarbons are stable, as noted earlier, because the fuel is the deficient reactant and its large molecular weight implies a low mass diffusivity so that $L e>1$. More detailed analysis shows that diffusivethermal effects are stabilizing for small wavelengths, thereby partially resolving the Landau-Darrieus dilemma. ${ }^{43,47}$ At longer wavelengths, the diffusive-thermal effect is destabilizing for small $L e$, leading to the formation of cellular flames, stabilizing for intermediate values of $L e$, and destabilizing for large $L e$, leading to pulsating flames or travelling waves over smooth flame fronts. A nonlinear analysis further shows that the cells evolve in time in a chaotic manner (see Fig. $6 .^{43}$ ).

Diffusive-diffusive instability was first described by Manton et al: $:^{48}$ it involves the preferential diffusion of reactant species. Figure 7 is a sketch illustrating the mechanism, involving a perturbed thin flame propagating at its local burning velocity with respect to the unreacted mixture. The flame surface is a sink for reactants; therefore, the relative mass flux of the 


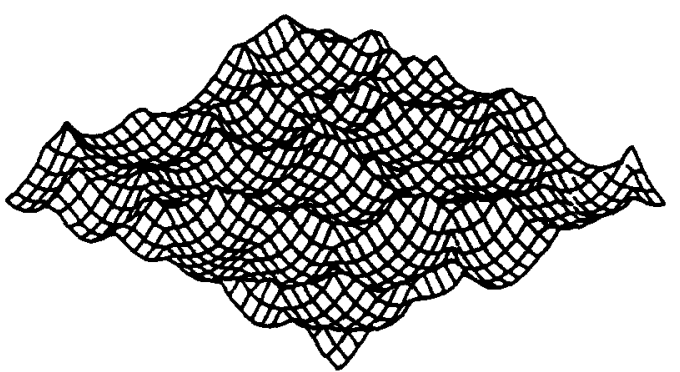

FIG. 6. Diffusive-thermal unstable cellular flames in a state of chaotic self-motion. Predictions from Sivashinsky. ${ }^{43}$

PRODUCTS

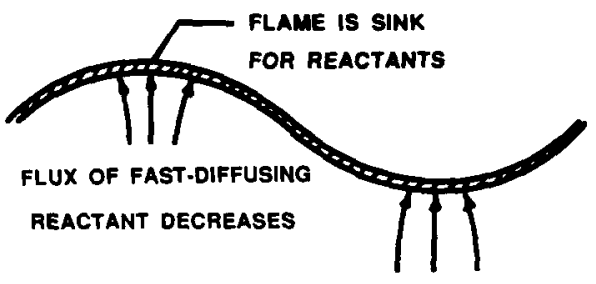

FLUX OF FAST-DIFFUSING

REACTANT INCREASES

\section{REACTANTS}

Fig. 7. Sketch of the diffusive-diffusive preferential-diffusion instability mechanism.

fast-diffusing reactant increases at bulges projecting into the reactant and decreases at bulges projecting into the combustion products, modifying the reactant mixture ratio at bulges accordingly. If the laminar burning velocity increases (decreases) with increasing concentrations of the fast-diffusing reactant, the bulges projecting into the reactant have larger (smaller) burning velocities than the bulges projecting into the product so that the bulges grow (decay) yielding an unstable (stable) flame. For example, hydrogen is the fast-diffusing reactant in $\mathrm{H}_{2} / \mathrm{O}_{2} / \mathrm{N}_{2}$ flames which have a maximum burning velocity near $\varphi=1.8$ : therefore, these flames should be unstable for $\varphi<1.8$ and stable for $\varphi>1.8$ according to diffusive-diffusive stability theory. ${ }^{10-12}$ However, diffusive-diffusive theories do not predict the transition condition between stable-unstable conditions very well since recent observations find this transition near $\varphi=1.4{ }^{25}$

The deficiencies of simplified diffusive-thermal and diffusive-diffusive instability mechanisms arise because preferential-diffusion instability generally involves combined effects of preferential diffusion of the various species with respect to one another and with respect to thermal energy. This combined behavior can be related to effects of stretch through Eq. (15) if $M k$ is known. For $K a>0, M k$ can be found from results such as Fig. 3. In contrast, $K a<0$ is problematical due to the difficulties of reliably measuring $S_{\mathrm{L}}$ for these conditions. On the other hand, limited existing measurements suggest that plots for $K a>0$ at a particular $\varphi$ can be extrapolated at least qualitatively into the region where $K a<0 .{ }^{30}$ Thus, bulges into the reactant have $K a>0$ so that for $M k<0$ (>0) the burning velocity increases (decreases), the bulges grow (decay), and the flame is unstable (stable). However, additional theoretical and experimental studies are needed to resolve preferential-diffusion behavior and the properties of $M k$ when $K a<0$ and when flammability limits and quenching conditions are approached. As discussed earlier, experiments at $\mu \mathrm{g}$ are particularly valuable to study behavior near limits and quenching conditions, where $S_{\mathrm{L}}$ is small in comparison with the criterion of Eq. (4); existing results of this type will be discussed in Section 3.5.

Rayleigh-Taylor instability involves accelerations normal to a density discontinuity like a flame. ${ }^{28}$ In general, acceleration of the heavier fluid toward (away from) the lighter fluid is unstable (stable). This kind of instability has been observed for flames in shock tubes, where gravity has little effect, ${ }^{28}$ but it is most significant for gravitational acceleration. Thus, upward (downward) propagating flames, where the heavier reactant gas is above (below) the lighter combustion products, are unstable (stable) to gravitationally-induced Rayleigh-Taylor instability. Such instabilities yield a convex shape to upward propagating flames and a somewhat planar shape for downward propagating flames, for flames that are otherwise stable. ${ }^{49.50}$ This mechanism influences burning velocities and limits, and obscures other instability mechanisms at ng. Eliminating the gravitationally-induced Rayleigh-Taylor instability is an additional motivation for combustion experiments at $\mu \mathrm{g}$.

Studies have shown that the gravity-induced Rayleigh-Taylor instability interacts strongly with the preferential-diffusion instability. The classical example $^{51}$ is shown in Fig. 8 which is an illustration of the observed flame shapes of upward propagating flames in very lean hydrogen-oxygen mixtures with inerts having different molecular diffusivities. It is seen that the flame can either form a closed surface covered by brightly luminous streaks (Fig. 8a), or is composed of a large number of flamelets rising in a zig-zag motion (Fig. 8b), or assumes a 'jelly-fish' like structure (Fig. 8c), as the mixture mass diffusivities are varied. The corresponding downward propagating flames do not exist in these situations because the mixtures are too lean.

Kailasanath and coworkers ${ }^{52-58}$ have completed several computational studies of the interactions between Rayleigh-Taylor and preferential-diffusion instabilities. These studies considered a flame tube configuration, like that of Strehlow et al., ${ }^{59}$ where flames propagate upward or downward at $\mathrm{ng}$, or propagate at $\mu \mathrm{g}$ (taken to be $0 \mathrm{~g}$ ). The computations 

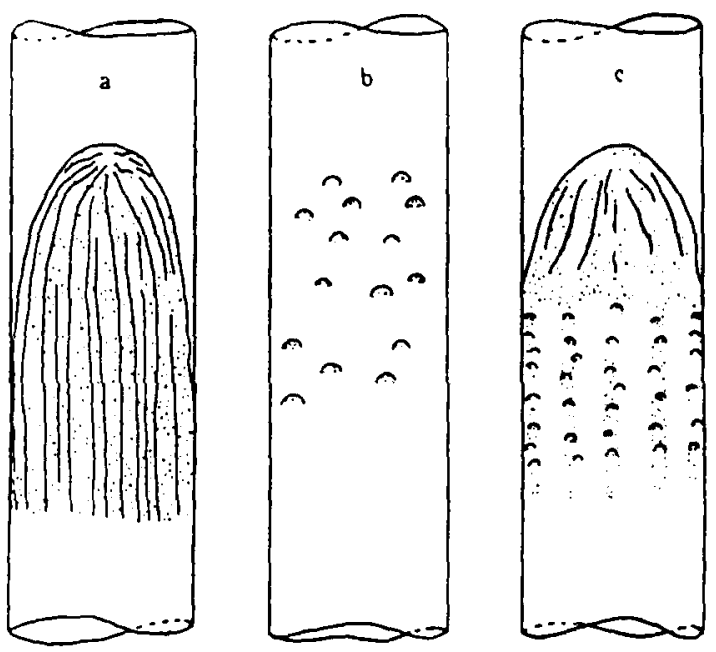

FiG. 8. Sketches of lean hydrogen flames propagating upward in a closed vertical tube, demonstrating the effects of preferential diffusion interacting with Rayleigh-Taylor instability. Reactant concentrations by volume are: (a) $6 \%$ $\mathrm{H}_{2}, 94 \%$ dry air; (b) $6 \% \mathrm{H}_{2}, 20 \% \mathrm{O}_{2}, 74 \% \mathrm{SO}_{2}$; (c) $6 \% \mathrm{H}_{2}$, $84 \% \mathrm{O}_{2}, 10 \% \mathrm{SiCl}_{4}$. From Böhm and Clusius. ${ }^{51}$

were limited to the two-dimensional, time-dependent propagation of flames in $\mathrm{H}_{2} / \mathrm{O}_{2} / \mathrm{N}_{2}$ mixtures, with chemistry involving 24 reversible reactions, diffusion using Fick's law, and consideration of variable thermochemical and transport properties. The initial conditions were found by computing the properties of a purely one-dimensional flame and then perturbing the solution by displacing the central portion toward the reactant side of the flame.

Typical results from the computations of Kailasanath and coworkers ${ }^{52-57}$ are illustrated in Figs 9 and 10. The premixed flame sheet is indicated by contours of the radical $\mathrm{OH}$ because radial species generally are confined to regions where chemical reaction is significant, for example, near the hot boundary of the flame surface. The contours are illustrated at various times after perturbation of the flame surface for upward and downward propagation at $\mathrm{ng}$ and at $\mathrm{0g}$, for lean $\mathrm{H}_{2} / \mathrm{O}_{2}$ flames that are subject to preferential-diffusion instability. Conditions illustrated in Fig. 9 are for a rapidly propagating flame with strong preferential-diffusion instability. In this case, the effects of Rayleigh-Taylor instability are relatively unimportant during the period of the computations (up to $60 \mathrm{~ms}$ ), although they would become important at longer times. The effects of preferential-diffusion instability are seen by the flame surface breaking up into cells with negligible reaction between the cells due to both reduced $\mathrm{H}_{2}$ concentrations and temperature levels caused by stretch within the cusp-like regions projecting into the combustion products. Depending upon the mixture ratio, the time of propagation and the width of the computational domain, the cells can divide and their number will vary.
The effect of Rayleigh-Taylor instability at $\mathrm{ng}$ is much more dramatic for the more slowly propagating flame illustrated in Fig. 10. To begin with the $0 \mathrm{~g}$ results, the cell structure due to preferential-diffusion instability is qualitatively similar to Fig. 9; however, evolution of the cell structure is slower due to the lower reactivity of this flame. For upward propagation, however, Rayleigh-Taylor effects remain about as strong as before so that a strong buoyant cell is produced. Regions of negative stretch near the cusps into the burned gas cause the flame to quench or extinguish, behavior that also is associated with flame extinction due to buoyancy near the flammability limits at ng. ${ }^{15}$ Conversely, Rayleigh-Taylor effects act to stabilize the flame during downward propagation at ng, completely eliminating the growth of diffusional instabilities for the conditions of Fig. 10. More extended calculations for the conditions of Fig. 10 show that preferential-diffusion instability cells are overwhelmed by Rayleigh-Taylor effects at ng: upward propagating flames evolve into a bubble-like surface while downward propagating flames oscillate between mildly concave and convex flame surfaces. ${ }^{53}$ These studies have also shown that the diffusive-thermal mechanism has a much stronger effect on flamefront instability than the diffusive-diffusive mechanism for this reactant mixture.

The work described above ${ }^{52-57}$ clearly establishes the importance of diffusive instabilities near limits. $A$ recent study $^{58}$ has further shown that chemical oscillation can also occur for near-limit rich hydrogen-air flames, causing pulsating instability. Specifically, as the hydrogen concentration in a rich mixture is gradually increased for a planar flame, damped and then undamped oscillations in the flame velocity appear (Fig. 11). This persists until the mixture becomes too rich to support flame propagation. This oscillation is thought to be caused by the crucial $\mathrm{H}-\mathrm{O}_{2}$ branching-termination chain, although the precise mechanism has not been explained. The potential influence of such chemical instability on flamefront cellular instability, especially for near-limit mixtures, merits further study. Furthermore, the chemicalkinetic and transport aspects of the computations described above involve more approximations than contemporary simulations of this type ${ }^{33,60}$ and realworld processes are three dimensional. Thus, more work is needed, involving both numerical predictions as computational capabilities increase and experiments to provide direct measurements of preferential-diffusive instability effects at $\mu \mathrm{g}$. These results will be useful for developing and evaluating approximate numerical predictions of these processes. In particular, because buoyancy interactions are most prominent for near-limit mixtures, experiments at $\mu \mathrm{g}$ eliminate the buoyancy interaction and allow detailed study of the preferential-diffusion effects that are most relevant for practical premixed flames. ${ }^{1,42,61-63}$ 
Upward
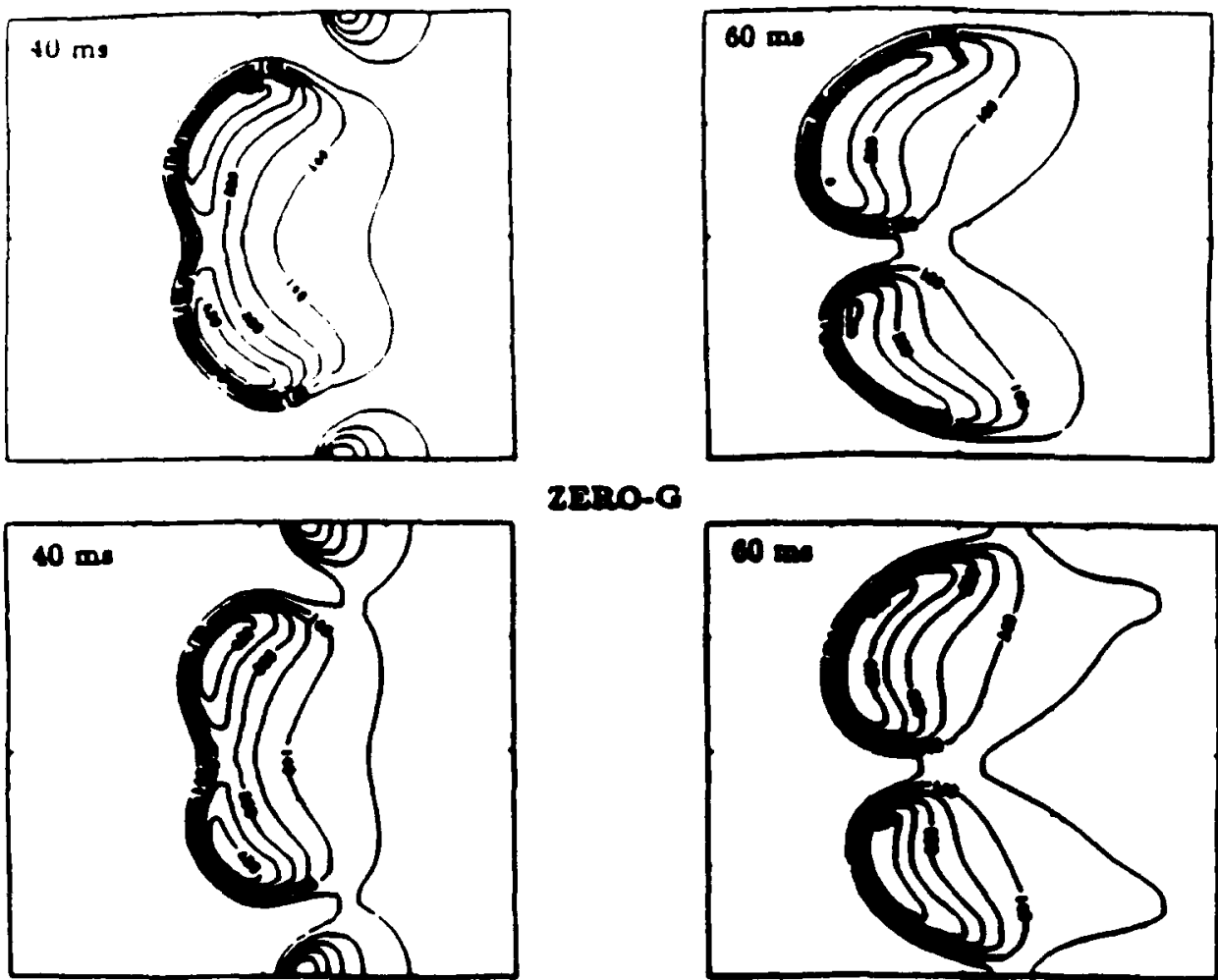

25no-0

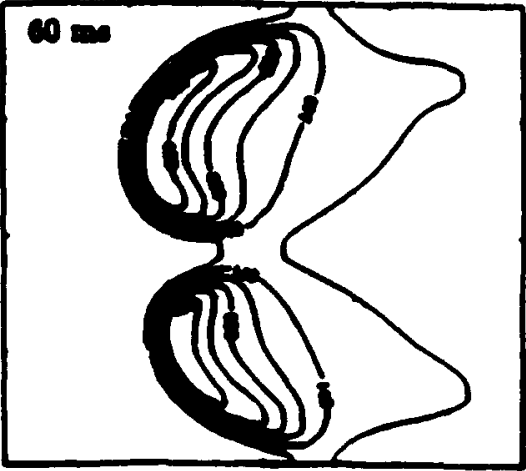

\section{DOWNWARD}
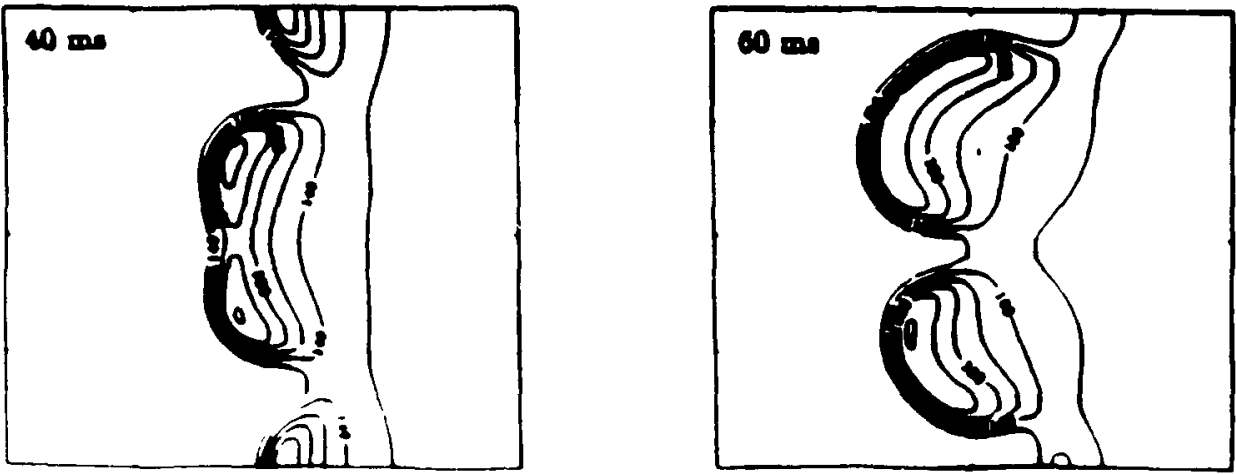

FIG. 9. OH radical number density contours $\left(\times 10^{14}\right)$ for rapidly propagating $\mathrm{H}_{2} / \mathrm{O}_{2}$ flames $\left(\mathrm{H}_{2}: \mathrm{O}_{2}: \mathrm{N}_{2} / 1.5: 1: 10\right.$ mixture by volume). Reactants are toward the left-hand side. Predictions from Kailasanath et al. ${ }^{52}$

\subsection{Flammability Limits}

Flammability limits are a fundamentally and practically important concept in combustion..$^{41,42}$ Empirically, it has been found that sufficient dilution of a combustible mixture with excess fuel, oxidant, or inert gas can render the mixture nonflammable. The critical composition at which this occurs is the flammability limit. When there is a fixed relationship between the concentrations of the inert gas and the fuel or oxidant, for example, the fixed relative oxygen and nitrogen concentrations in air, there are only two flammability limits at a particular pressure and temperature: the lean flammability limit where there is excess oxidant and the rich flammability limit where there is excess fuel. Naturally, a knowledge of the lean and rich flammability limits of a given fuel in air is important for assessing fire and explosion hazards in, for example, mine galleries, chemical refineries, and manned spacecraft. This information also is relevant to the design of lean-burn engines and the use of low-BTU gases. 

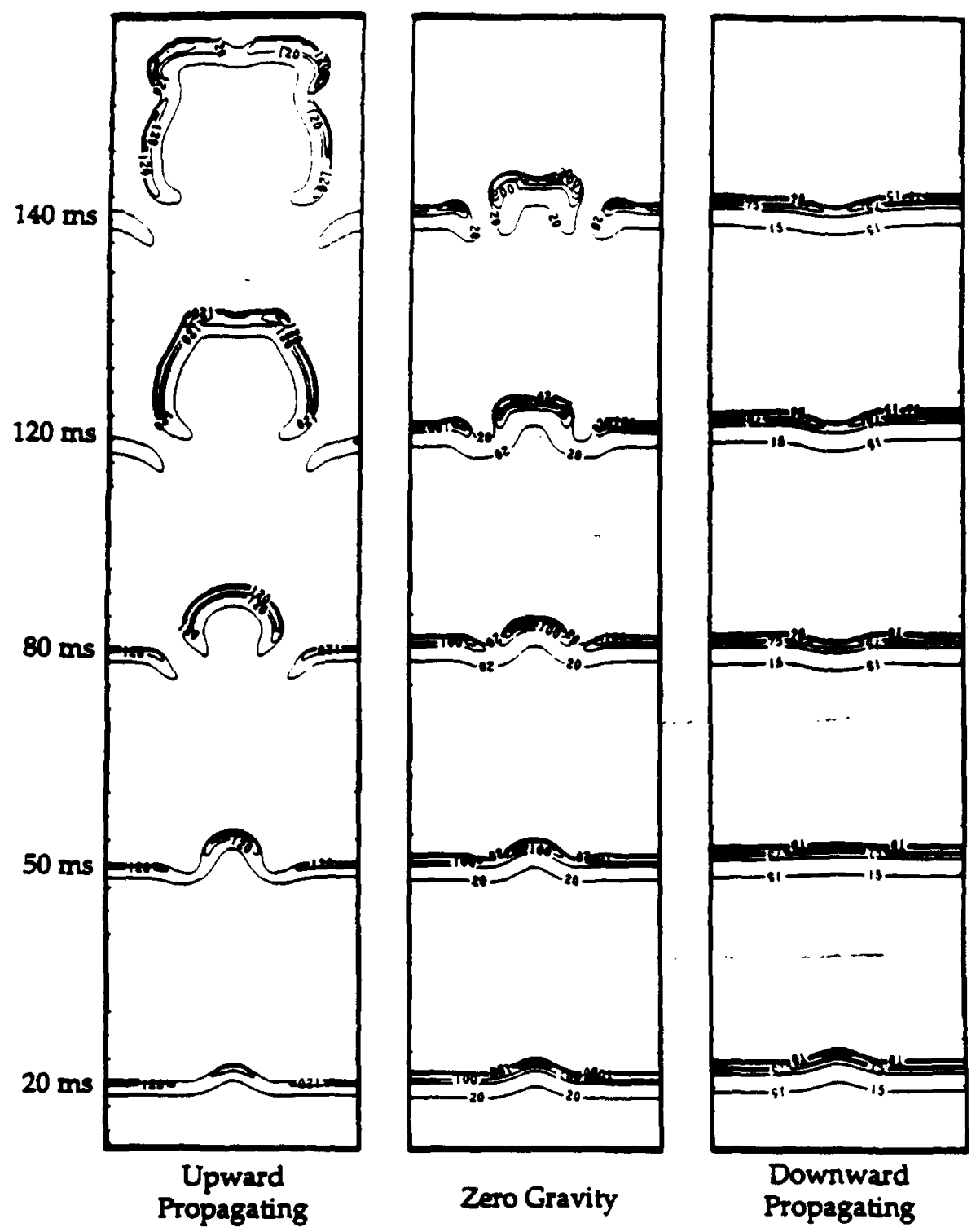

FIG. 10. $\mathrm{OH}$ radical number density contours $\left(\times 10^{14}\right)$ for near-limit $\mathrm{H}_{2} / \mathrm{O}_{2}$ flames $\left(10 \% \mathrm{H}_{2} /\right.$ air by volume). Reactants are toward the top. Predictions from Patnaik et al. ${ }^{53}$

Studies of flammability limits generally are concerned with the numerical values of these limits and the mechanism(s) responsible for their existence. Flammability limits determined at ng exhibit significant effects of buoyancy, causing much wider limits for upward-propagating flames than for downwardpropagating flames, and limits are different from both at $\mu \mathrm{g}$. Experimental studies addressing this issue include Strehlow et al. ${ }^{59}$ and Ronney and coworkers. ${ }^{64-72}$ Strehlow et al. ${ }^{59}$ used a configuration where the flame is ignited by a spark and propagates inside a tube, either upward or downward at $\mathrm{ng}$ or $\mu \mathrm{g}$, similar to the results illustrated in Figs 9 and 10 . Ronney and coworkers ${ }^{64-70}$ consider spark-ignited flames propagating from the center of a chamber, in an initially still gas, as a more or less spherical flame.
In the latter work, upward and downward propagation limits at ng were defined differently than for tubes: the upward limit implied flame propagation to the top of the vessel, the downward limit implied flame propagation throughout the vessel. These measurements employed a drop tower to reach $\mu \mathrm{g}$, except for recent experiments in aircraft. ${ }^{69}$

Typical lean flammability limits at $\mathrm{ng}$ and $\mu \mathrm{g}$, from Ronney and Wachman, ${ }^{64}$ are plotted as a function of pressure in Fig. 12. The results are for lean methane-air flames so that $M k<0 .{ }^{26}$ The results indicate that flammability limits at $\mu \mathrm{g}$ generally fall between those for downward and upward propagation at ng: downward propagation is the most difficult because buoyancy sweeps the flame to the top of the chamber at the low burning velocities near 


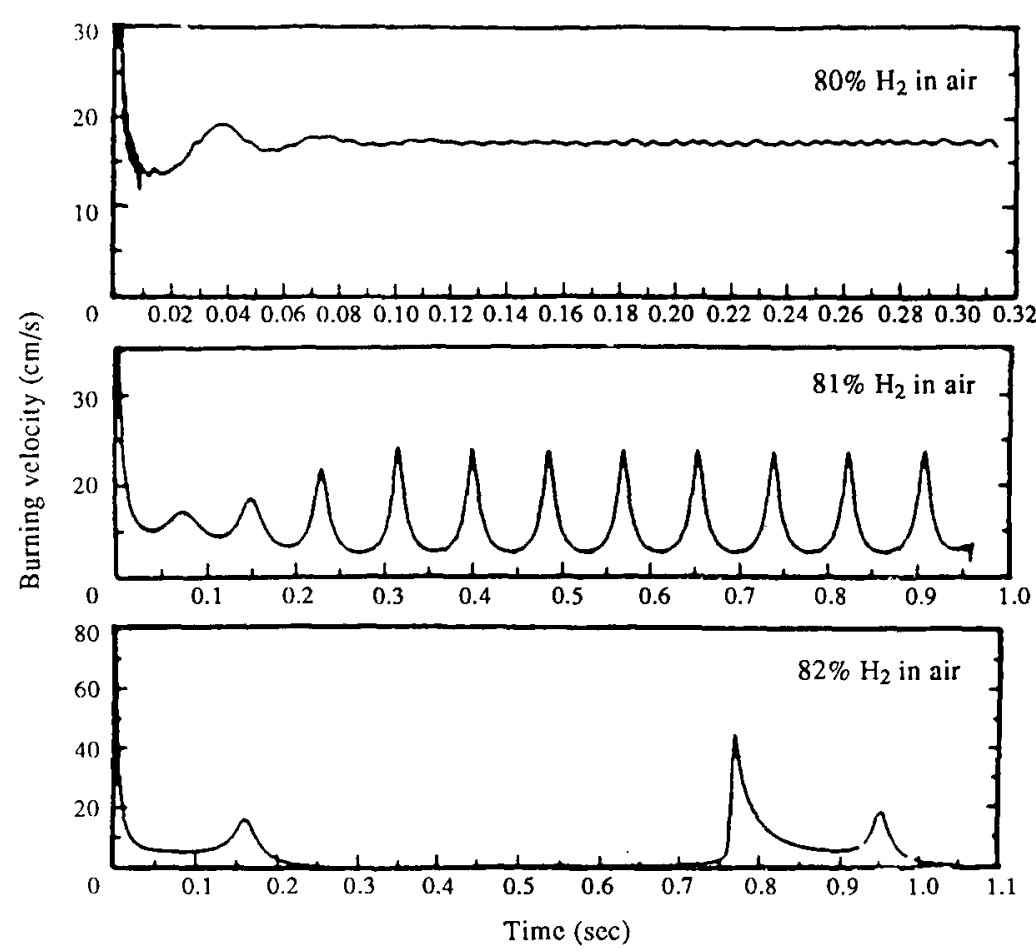

FIG. 11. Laminar burning velocity as a function of time, illustrating oscillatory near-limit behavior for rich hydrogen-air flames. From Kailasanath et al. ${ }^{58}$

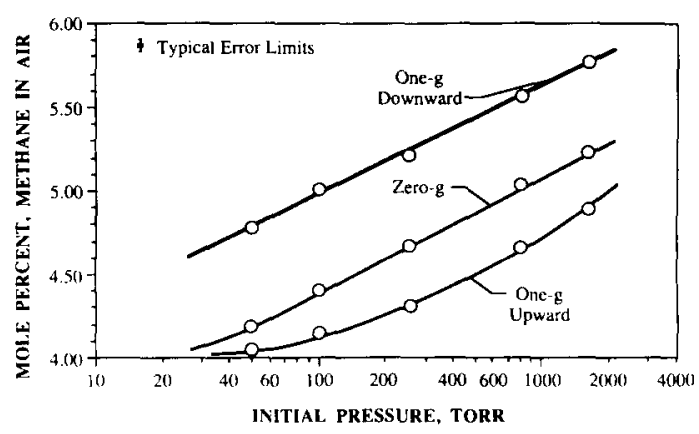

Fig. 12. Lean flammability limits of methane-air mixtures as a function of pressure for upward and downward propagation at $\mathrm{ng}$ and $\mu \mathrm{g}$. From Ronney and Wachman. ${ }^{64}$

limits so that the chamber walls quench the flame. The different flow conditions and flammability definitions for the flame tube experiments of Strehlow et $a l .{ }^{59}$ yielded somewhat different results: lean limits for methane-air mixtures at atmospheric pressure were $5.25,5.25$ and $5.85 \%$ for upward, $\mu \mathrm{g}$ and downward propagation, which are higher with less difference between upward and $\mu \mathrm{g}$ propagation than for the results shown in Fig. 12. Additionally, Strehlow et $a .^{59}$ find conditions where lean limits at $\mu \mathrm{g}$ are outside those at ng; for example, propane-air flames at atmospheric pressure had lean limits of $2.15,2.06$ and $2.20 \%$ for upward, $\mu \mathrm{g}$ and downward propagation. This probably occurs because $M k>0$ for lean propane-air flames, as seen in Fig. 3, so that posi- tively stretched upward propagation of the propane-air flames causes reduced burning velocities and flame temperatures, in contrast with the lean methane-air flames where $M k<0$ and burning velocities and flame temperatures increase. ${ }^{26}$ Then increased stretch rates for upward propagation at $\mathrm{ng}$ in comparison with $\mu \mathrm{g}$, due to buoyant motion, causes a correspondingly higher lean flammability limit. The same argument implies that rich flammability limits for methane-air mixtures, where $M k>0$, would be broader at $\mu \mathrm{g}$ than at $\mathrm{ng}$, but measurements in this region have not been reported.

Other observations supporting effects of stretch on near-limit behavior will be discussed subsequently. However, the broader lean flammability limits at $\mu \mathrm{g}$ for reactants with $M k>0$ have important implications for spacecraft fire and explosion hazards because most lean hydrocarbon-air flames are in this regime, as noted earlier. Thus, any notion that flammability limits for gases at ng are applicable to conditions at $\mu \mathrm{g}$ is erroneous. Additional measurements of lean flammability limits for a wider range of reactants are clearly needed to provide the technology base required for safe spacecraft operation with respect to fires and explosions.

The fact that flammability limits do seem to exist at $\mu \mathrm{g}$ resolves a controversy regarding the role of buoyancy in limit phenomena. That is, previous theories relating such limits to natural convection predict that no limits should exist in the absence of gravity. Thus, the $\mu \mathrm{g}$ experiments that have just been dis- 
cussed have ruled out buoyancy as a controlling mechanism for the occurrence of flammability limits.

There also have been disagreements about whether the flame should have a finite or vanishing speed at the flammability limit. Previous studies at ng cannot answer this question satisfactorily due to the large buoyant flow velocities or heat loss to the burner. Recent $\mu \mathrm{g}$ experiments, however, show that these flame speeds assume finite, albeit very small, values of around a few centimeters per second. ${ }^{66,67}$

The fundamental controlling mechanism(s) of flammability limits are as yet unidentified, although valuable insights have been gained in some recent studies. $^{23,73.74}$ Clearly, if the flammability limit is a viable concept, and its value is a unique property of a given combustible, then the mechanism(s) should be independent of external influences and thereby predictable from first principles. At present it appears that there ar two major classes of fundamental flammability limits that can be defined from first principles, depending on whether the flame is stretched or not. For the unstretched flame, the relevant phenomenon is the failure of propagation of the one-dimensional, planar flame in the doubly-infinite domain. The intrinsic, omnipresent mechanisms which can cause extinction of such a flame are radiative heat loss and chemical-kinetic chain termination. Radiative heat loss decreases the flame temperature which in turn exponentially reduces the heat generation rate in the flame. Extinction can be expected when the heat loss rate becomes excessive. On the other hand, chemicalkinetic flammability is based on the consideration that the two-body chain-branching reactions are temperature sensitive while the three-body chain-termination reactions are usually temperature insensitive. Thus, by continuously reducing the concentration of the lean reactant, the corresponding reduction of the flame temperature progressively weakens the intensity of the branching reactions relative to that of the termination reactions. It is therefore reasonable to expect that at a certain concentration the overall reaction rate would have been so weakened that the flame is readily extinguished by unavoidable perturbations in the system.

Recently, the separate concepts of flammability due to heat loss and chain termination have been unified through a numerical simulation of the nonbuoyant (planar) flame in the doubly-infinite domain, with radiative heat loss and detailed chemistry, for methane-air and hydrogen-air flames. ${ }^{74}$ It is shown that as the flammability limit is approached, the flame response exhibits an extinction turning point which is characteristic of extinction due to heat loss. Furthermore, near this turning point, the normalized sensitivity of the rate of the dominant chaintermination reaction to that of the dominant chainbranching reaction becomes $O(1)$, indicating that the chain-termination reaction starts to have a controlling influence on the flame response. These results therefore suggest that at the flammabillity limit, the branching reaction is so weakened relative to the termination reaction that the overall heat release rate is rapidly reduced. Extinction occurs when the heat release rate cannot keep up with the radiative heat loss rate. The theory also shows that the laminar flame speed has a finite value at the flammability limit.

Since practically all realistic flames are subjected to stretch, it is then necessary to consider whether fundamental flammability limits can also be defined for stretched flames. For these stretch-affected limits the intrinsic mechanisms of heat loss and chain termination identified for the nonstretched flames should obviously still be operative. In addition, it is reasonable to conjecture that a unique stretch rate may also exist at such a limit. The flammability condition could therefore be expressed as a critical flame diameter for spherically propagating or stationary flames, or a critical strain rate for aerodynamically stretched flames. The possibility of defining flammability limits through spherical flames will be discussed next.

\subsection{Near-Limit Phenomena}

Due to their ability to sustain extremely weak flames having small propagation rates, $\mu \mathrm{g}$ experiments have identified some premixed flame phenomena that have not been previously observed. These include self-extinguishing flames (SEF) and stationary spherical flames (SSF). Both SEF and SSF are associated with conditions near flammability limits and involve preferential-diffusion effects. Thus, SEF and SSF have the potential to provide insight concerning the mechanism of flammability limits and to highlight the unique combustion properties of nonbuoyant $\mu \mathrm{g}$ conditions.

\subsubsection{Self-extinguishing flames}

Ronney ${ }^{65-67}$ made the first observations of SEF during his experiments on outwardly propagating spherical flames near flammability limits. The nature of SEF can be seen from the plots of flame radius as a function of time for lean ammonia-air mixtures illustrated in Fig. 13. The two cases shown are for conditions just above and just below the lean flammability limit, both ignited using sparks having similar energies. This reactant system involves $M k<0$ with a progressively decreasing positive stretch as the flame radius increases. Thus, in agreement with the discussion associated with Eq. (9), and the results illustrated in Figs 2 and 3, the slope of the flame radius as a function of time, which is proportional to the burning velocity through Eq. (12), decreases with increasing radius as the flame temperature, and thus its reactivity, decreases. Propagation continues for the normal flame, with the burning velocity eventually approaching a constant value at large radii where the effects of stretch become small because the flame 


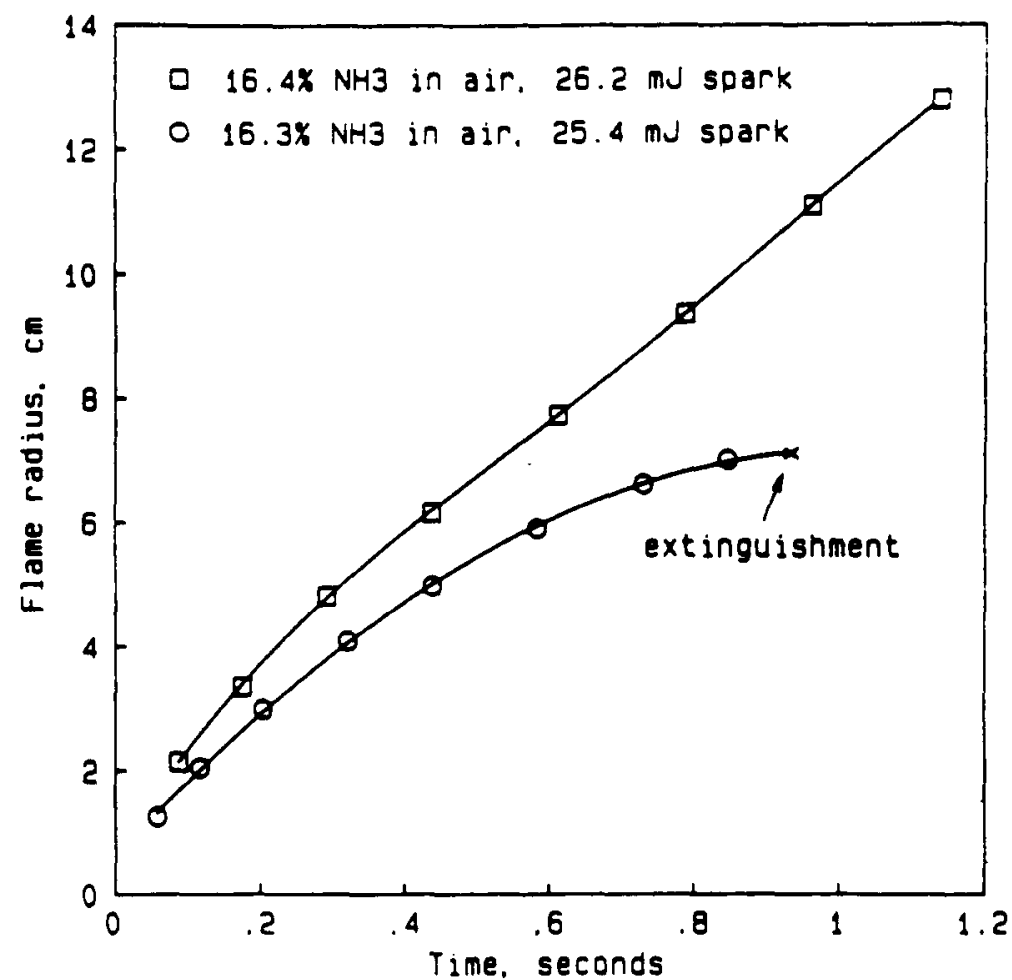

FIG. 13. Measured flame radius as a function of time for near-limit ammonia-air flames at $\mu \mathrm{g}$. From Ronney. ${ }^{67}$

is nearly planar. In contrast, propagation ends abruptly before a constant burning velocity is reached for the SEF. Notably, SEF are not caused by the added energy of the spark. Conventional nonpropagating flames normally consume some reactant due to the thermal disturbance of the spark before extinguishing, typically releasing reaction energies roughly 10 times larger than the spark energy. SEF, however, release 100-1000 times more chemical energy than the spark energy before extinguishing, so that their presence is not solely associated with initial overheating of combustion products by the spark.

Theoretical studies of SEF indicate that they are due to the interaction of stretch and radiative heat losses from the flame. ${ }^{67,70-72}$ First, SEF are observed for conditions where $M k<0$, for example, fuel-lean ammonia, methane or hydrogen-air flames, or fuel-rich propane-air flames. This suggests that the tendency for positive flame stretch to increase the flame reactivity for $M k<0$ compensates for the tendency of radiative heat losses to reduce flame temperatures. Since the effect of stretch decreases with increasing flame radius, radiative heat losses eventually dominate the process and the flame is quenched. Thus, for these conditions, the normal flammability limit can be attributed to thermal effects. However, whether such limits are a fundamental property of the reactants, which would be helpful for establishing universal limits, is still an open issue due to the numerous effects that influence radiative heat losses from flames, for example, the dimensions of the combustion products, the radiative boundary conditions, etc.

Predictions of flame propagation and SEF behavior are currently based on approximate theories invoking simplifed descriptions of the chemical and transport processes. ${ }^{67,70-72}$ Thus, their quantitative accuracy is limited. Nevertheless, the theories do provide support for the thermal mechanism of extinction, and represent the qualitative behavior of SEF. Typical predictions for lean methane-air flames are illustrated in Fig. 14 where the flame radius is plotted as a function of time for various mixtures near the flammability limit. By definition, all SEF operate outside the normal flammability limits. Additionally, reduced concentrations of the fuel near this lean limit (reduced $\varphi$ ) cause the SEF to extinguish at a progressively smaller radius. Thus, the normal lean limit is the flame where radiative heat losses just remain above critical levels over the entire region in which stretch is finite and flame reactivity exceeds the planar-flame limit.

Other features of SEF are also consistent with interactions between stretch and radiation. In particular, SEF are not observed when $M k>0$, which corresponds to $L e>1$ within the context of the simplified theories of premixed flames, where the discussion of Eq. (9), or the results illustrated in Figs 2 and 3 , indicate that flame temperatures, and thus 


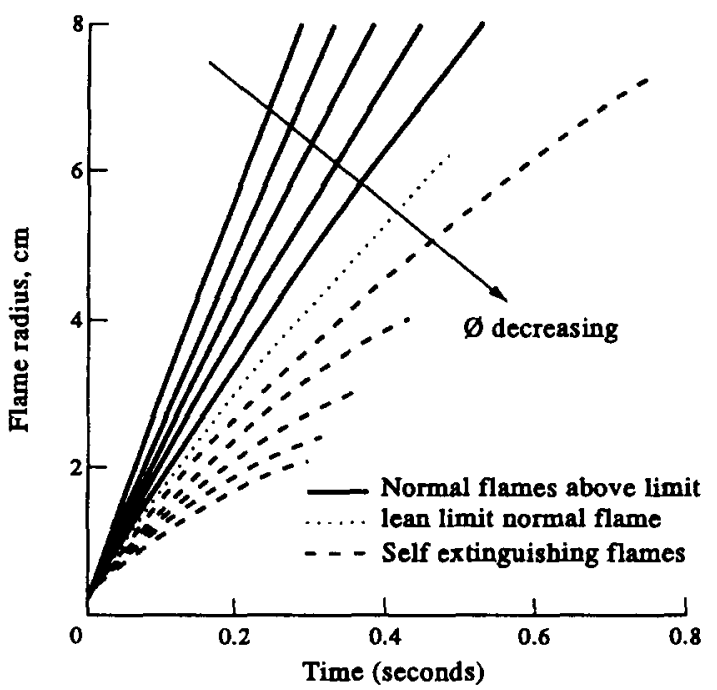

FIG. 14. Predicted flame radius as a function of time for near-limit normal flames and SEF in lean methane-air mixtures at $\mu \mathrm{g}$. Compositions range from $5.64 .6 \%$ methane in $0.1 \%$ steps $(\varphi=0.565-0.459)$. From Ronney. ${ }^{66}$

burning velocities, increase with increasing flame radius. Then the flammability limit becomes strongly influenced by ignition conditions because once the flame is established the flame zone reactivity tends to increase until the flame surface becomes planar. ${ }^{66}$ Due to the variation of ignition properties with the magnitudes and rates of spark energy deposition, whether flammability limits for these circumstances are a fundamental property of the reactants is also an open issue. ${ }^{41,42}$ The absence of intrusive effects of buoyancy at $\mu \mathrm{g}$ provides a useful environment to address this issue and should continue to receive attention by both experiments and analyses.

The previous discussion indicates that the study of SEF provides a new perspective on the interactions between preferential diffusion, stretch and radiative heat losses relating to flame propagation and limits. Notably, SEF behavior was never established at ng because buoyant motion strongly distorts these flames due to their low burning velocities (ca. 1-10 $\mathrm{cm} / \mathrm{s}$ ). Thus, experimental studies at $\mu \mathrm{g}$ clearly provide valuable new directions and insights concerning the properties of homogeneous premixed flames.

\subsubsection{Stationary spherical flames}

Another unique flame configuration experimentally observed at $\mu \mathrm{g}$ - the SSF-also provides valuable insights concerning premixed flame properties. SSF, often called flame balls, are observed in reactant mixtures near limits having very small Lewis numbers, such as lean hydrogen-oxygen flames. For such systems, preferential-diffusion instability occurs even near flammability limits causing the flames to break up into cells, similar to those illustrated in Figs 9 and 10. Examples from experiments at ng are illus- trated in Fig. 8; this involves cap-shaped flamelets that rise through the mixture but do not seem to grow before being quenched by contact with the surfaces of test apparatus-behavior that was attributed to stabilization by convection. ${ }^{41}$ Similar flame systems are encountered at $\mu \mathrm{g}$, however, where they develop into SSF whose radius remains constant, at least for the test times available for study at $\mu \mathrm{g}$ (up to $10 \mathrm{~s}$ during recent work). ${ }^{69,70}$ As will be discussed subsequently, the failure of SSF to continue outward propagation, and instead reach a stable fixed size, occurs due to heat losses in the burned gas. The mechanism involves radiation from the burned gas to the surroundings with steady temperatures maintained in the burned gas due to conduction (and perhaps some contribution from radiation) from the region of the flame surface. In a sense, this behavior is analogous to the stabilization of a premixed flame by heat losses near the surface of a flat flame burner, with the main differences between SSF and burner flames being the direction of energy flow from the flame to the stabilizing heat sink and the fact that SSF attain the unusual limit where mean velocities approaching the flame are zero.

The existence of SSF was proposed many years ago by Zel'dovich, ${ }^{45}$ and subsequently studied by Buckmaster and Weeratunga, ${ }^{75}$ however, SSF were never observed due to buoyant disturbances at $\mathrm{ng}$. A sketch of the structure of these flames, based on current theories, ${ }^{76}$ appears in Fig. 15. The conditions pictured involve a thin reaction zone at a radius, $r_{\mathrm{f}}$, for an overall reaction that is complete, that is, all reactants become products. The mass fractions of reactants and products, $Y_{\mathrm{R}}$ and $Y_{\mathrm{P}}$, the temperature, $T$, and the reaction rate per unit volume, $\dot{w}$, are plotted as a function of radius from the flame center, $r$. The reactant diffuses toward the flame, is converted to product within a thin reaction zone, and finally the product diffuses radially outward into the ambient environment. The SSF postulated by Zel'dovich ${ }^{45}$ did not involve radiative heat losses. Recent analysis shows, however, that adiabatic SSF are unstable at their equilibrium radius, either collapsing or propagating outward for small disturbances. ${ }^{76}$ Thus, radiative heat losses are depicted in Fig. 15, where the temperature decreases within the reacted core of the flame due to the balance between

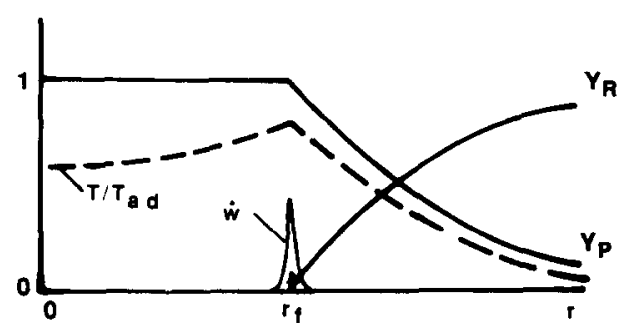

Fig. 15. Sketch of the structure of stationary spherical flames (SSF). 


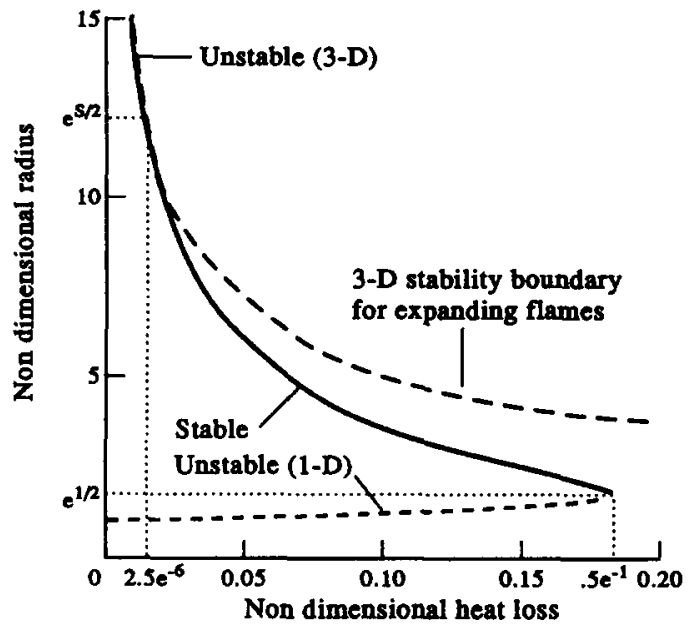

FIG. 16. Stationary dimensionless radius of SSF as a function of nondimensional heat loss. From Buckmaster et al. ${ }^{76}$

radiation to the surroundings and heat conduction from the flame zone. Thus, the thermal energy release at the flame surface divides into two parts: one part flowing into the core to compensate for radiative heat losses to the surroundings, and the other part flowing directly outward toward the unburned gas similar to a conventional premixed flame.

The unique behavior of SSF has prompted analysis of conditions for their existence and stability. ${ }^{75-79}$ The initial theories, ${ }^{75-78}$ while simple in terms of chemistry and transport properties, yield predictions which are consistent with experimental observations. The predicted stability properties of the flames are illustrated in Fig. 16, in which the flame radius normalized by the radius of a corresponding adiabatic SSF, called the Zel'dovich radius, is plotted as a function of dimensionless heat loss (see Ref. 76 for definitions of these variables). There are two branches of the solution of flame radius as a function of heat loss. One is for a dimensionless flame radius less than $e^{1 / 2}$ which is unstable to one-dimensional (radial) disturbances. This branch includes the Zel'dovich SSF, which has a dimensionless radius of unity, highlighting the requirement for finite radiative heat losses to stabilize SSF. Similarly, the flames are unstable to three-dimensional disturbances for values of dimensionless radius greater than $e^{5 / 2}$. However, the branch of the solution with radii between $e^{1 / 2}$ and $e^{5 / 2}$ yields stable SSF with finite radiative heat losses similar to experimentally observed SSF.

Recently, a numerical simulation of SSF in hydrogen-air mixtures with detailed transport, chemistry and radiative loss has been conducted. ${ }^{79}$ The simulation shows lean and rich limits beyond which no solution exists. It has been suggested that these limits can be identified as the corresponding flammability limits of the mixture. However, stability analysis of these numerically-generated flames, especially the rich flame which is believed to be unstable based on Lewis number considerations from simplified analysis, needs to be conducted.

Due to the mathematical simplicity associated with the analysis of SSF, much can be learned about the structure and limits of flames by using SSF as a model flame problem. Furthermore, it has also been suggested that the appearance of SSF in limit situations could precede the onset of flaming combustion of fires in space environments. Thus, the study of SSF commands both fundamental and practical interest in $\mu \mathrm{g}$ combustion research.

\section{GASEOUS NONPREMIXED FLAMES}

\subsection{Introduction}

Studies of gaseous nonpremixed flames at $\mu \mathrm{g}$ have also largely been limited to laminar flames, even though most practical nonpremixed flames are turbulent. This is motivated by a desire to control the complexity of already complicated combustion processes, for experimental circumstances where diagnostics must be rudimentary by ng standards. However, the tactic also is justified to some extent by the evolution of laminar flamelet concepts for nonpremixed flames, somewhat analogous to those developed for premixed flames.

Ideas about laminar flamelet concepts were proposed for turbulent nonpremixed flames by Hawthorne et al. ${ }^{80}$ not very long after the structure of laminar diffusion flames was described by Burke and Schumann. ${ }^{81}$ The main premise was that relationships between scalar properties in turbulent flames were the same as in laminar flames, that is, a turbulent flame corresponded to a distorted or wrinkled laminar flame. It also was assumed that preferentialdiffusion effects were not significant, so that the scalar properties in laminar flames could be described by a variety of conserved scalars, related to the extent of mixing at a point. A popular choice for the conserved scalar is the mixture fraction, which is the mass fraction of elemental fuel species in a sample, independent of the current chemical composition. As a result, relationships between various scalar properties and the mixture fraction, called state relationships, can be found. ${ }^{82-91}$ Then, predictions of the properties of mixture fractions in turbulent flames using a turbulence model, a large-eddy simulation, for example, yield all scalar properties-an approach called the conserved-scalar formalism. ${ }^{82}$

The reason that state relationships can be found is that nonpremixed flames are often diffusion controlled with thin flame sheets, where the fuel and oxidant react to form combustion products. For such conditions, reaction rates are fast enough to approach local thermodynamic equilibrium at various local mixture fractions over a range of stretch 


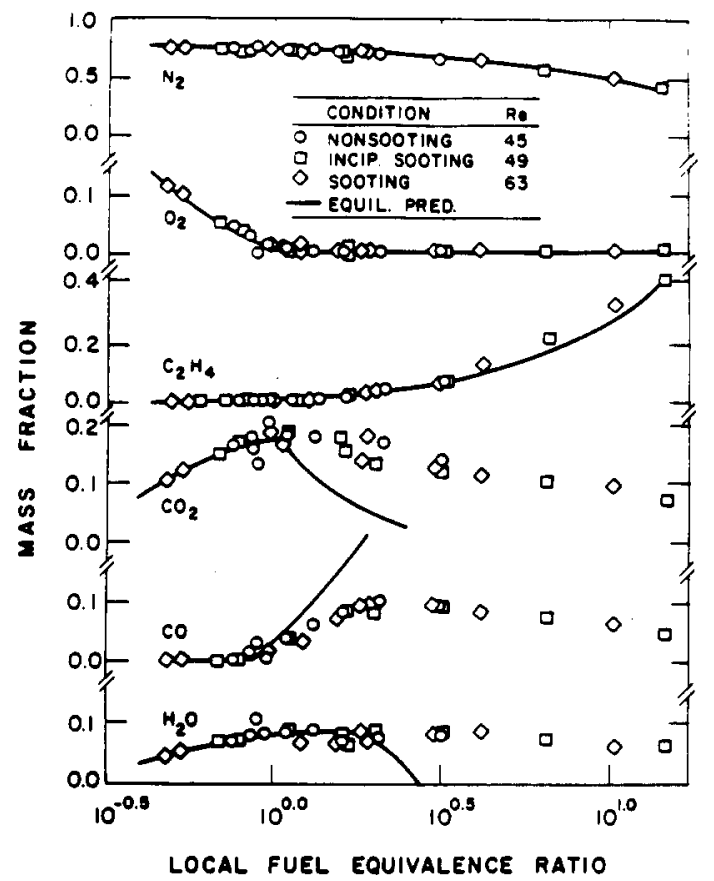

FIG. 17. State relationships for laminar ethylene air flames. From Gore and Faeth. ${ }^{84}$

rates. Thus, reactants involving simple molecules that have fast chemistry, for example, hydrogen-air and wet carbon monoxide-air flames, exhibit reasonably good state relationships, in spite of potential effects of preferential diffusion, that approach estimates assuming local chemical equilibrium for conditions not too near points of flame attachment or extinction..$^{90}$

The existence of state relationships for complex fuels such as hydrocarbons is more questionable due to potential fuel decomposition in the high-temperature region on the fuel-rich side of the flame sheet. However, Bilger ${ }^{82}$ noticed that major gas species in laminar hydrocarbon-air flames also satisfied state relationships. In this case, slow processes of fuel decomposition and soot chemistry caused departures from local thermodynamic equilibrium predictions for fuel-rich conditions; however, these departures are relatively universal over wide ranges of stretch rates. This behavior is illustrated in Fig. 17, where state relationships based on measurements in buoyant coflowing ethylene-air jet flames are shown along with predicted properties based on the assumption of local thermodynamic equilibrium. ${ }^{84}$ These results are for various positions in the flames and burner exit Reynolds numbers, and thus a range of stretch rates, and still yield reasonably universal state relationships for these soot-containing flames. Subsequently, generalized state relationships have been developed for alkane and alkene-air flames, covering molar $\mathrm{H} / \mathrm{C}$ ratios in the range $1-4$, that exhibit relatively small effects of the wide variations of soot concentrations within the flames. ${ }^{86}$ Additionally, the use of state relationships has proved to be effective for estimating the structure and radiation properties of both nonluminous and luminous nonpremixed turbulent flames having modest stretch rates. ${ }^{87}$

Similar to the laminar premixed flames, preferential diffusion could also modify the flame response through its influence on the flame temperature as well as through coupling with stretch. ${ }^{88,89}$ Such influences have not been addressed to the same extent as for premixed flames, possibly due to the fact that the influences are likely to be modest for diffusion flames because, in the limit of near-equilibrium combustion, the bulk flame response is basically decoupled from the reaction rate, which is sufficiently fast in any event, and hence only weakly dependent on the flame temperature. Furthermore, it has also been suggested $^{90}$ that preferential-diffusion effects are frequently being masked by experimental uncertainties even for flames involving $\mathrm{H}_{2}$. Thus, although the limitations of state relationships and laminar flamelet concepts are still being debated, and the fact that the methodology relies on the assumption of equidiffusion and also cannot treat finite-rate processes leading to pollutant emissions, ${ }^{91}$ the relevance of an understanding of laminar nonpremixed flames to turbulent nonpremixed flames of practical importance is widely accepted.

Studies of nonpremixed flames at $\mu \mathrm{g}$ have been limited to the laminar round jet flame. Although spherically symmetric diffusion flames would be simpler geometrically, and a burner-generated steadystate spherical flame is currently being planned for $\mu \mathrm{g}$ experimentation, ${ }^{40}$ research with this configuration has centered on heterogeneous drop combustion which will be discussed later. Nevertheless, the jet flame is a fundamental configuration at $\mu \mathrm{g}$ due to the absence of complications from buoyancy and capabilities to vary stretch and reaction rates by varying burner diameters, jet exit velocities, fuel and ambient compositions, and the ambient pressure. Notably, simplified analyses of forced laminar jet diffusion flames have been available for some time, ${ }^{81,92}$ although measurements needed to evaluate predictions have only appeared recently. ${ }^{93-109}$ Results concerning the structure, stability and soot properties of these flames will be considered in the following sections.

\subsection{Flame Structure}

The earliest measurements of jet diffusion flames emphasized effects of gravity on their structure and stability properties in terms of extinction and stability. ${ }^{93-99}$ These experiments involved round fuel jets directed vertically upward in still air, with the flame ignited by a spark. In some instances, provision was made for a coflowing air stream around the fuel jet. ${ }^{99}$ Tests were conducted at $\mathrm{ng}$ and $\mu \mathrm{g}$, the latter using drop-tower facilities. 


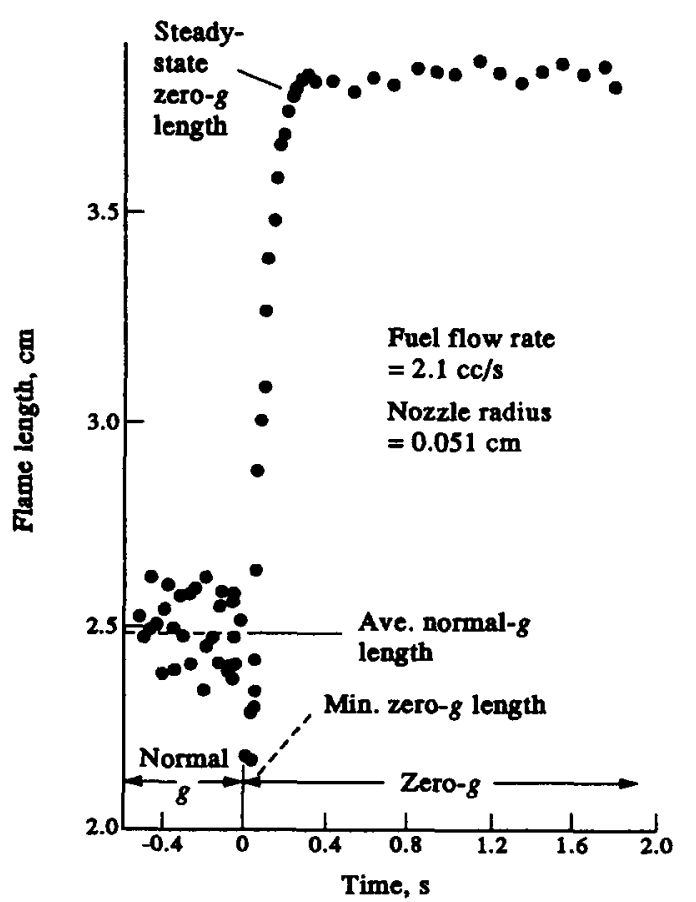

FIG. 18. Length of a methane-air laminar jet diffusion flame as a function of time at $\mu \mathrm{g}$ (near-steady conditions). From Haggard and Cochran. ${ }^{96}$

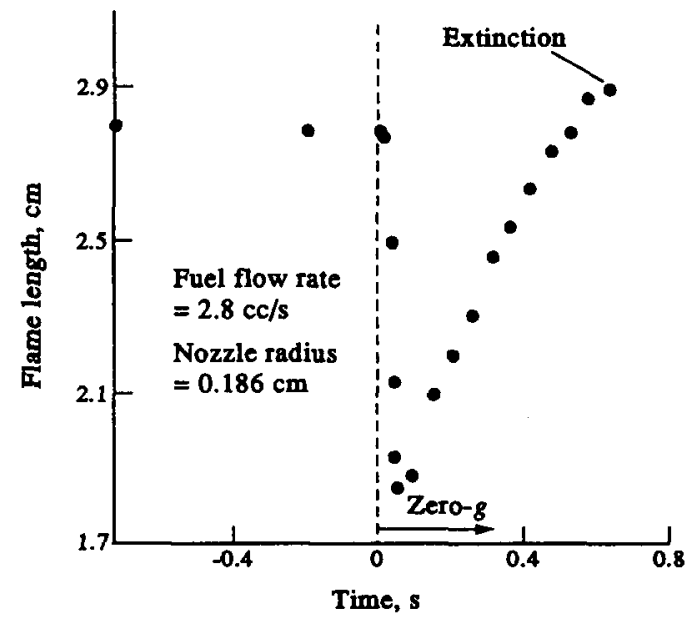

Fig. 19. Length of a methane air laminar jet diffusion flame as a function of time at $\mu \mathrm{g}$ (extinguished conditions). From Cochran and Masica. ${ }^{93}$

Some typical measurements of the properties of jet flames at $\mu \mathrm{g}$ are illustrated in Figs 18 and 19. These tests involved igniting the flames at $\mathrm{ng}$ and then releasing the apparatus to reach $\mu \mathrm{g}$. The adjustment of the flame to $\mu \mathrm{g}$ causes it to become much shorter for a time and then to gradually lengthen toward its nonbuoyant configuration. In some instances, the flame extinguishes during this transient development process (Fig. 19). This behavior has been attributed to the accumulation of combustion products in the flame region, due to loss of the buoyant convective flow, which excessively limits diffusion of oxygen to the flame sheet-particularly at the points of flame attachment near the jet exit. ${ }^{101,103}$ This view is supported by observations that even small levels of air coflow serve to sustain flames that would normally extinguish in the absence of coflow during transition to $\mu \mathrm{g} .{ }^{99}$ For conditions where the flame does not extinguish after entering $\mu \mathrm{g}$, its length increases and eventually approaches a constant value that is consistent with steady flame structure (Fig. 18).

Although theories of nonbuoyant jet diffusion flames have been available since the original studies of Burke and Schumann, ${ }^{81}$ evaluation of predictions even for this fundamental flame configuration has been hampered by the complications of buoyancy at ng. The increasing availability of flame structure measurements at $\mu \mathrm{g}$ is beginning to rectify this situation, however, allowing theories of varying complexity to be evaluated. ${ }^{95,100,108-110}$

The earliest models of nonbuoyant jet diffusion flames, aside from simple constant-property treatments of the qualitative features of the flow, ${ }^{92}$ are typified by the models of Edelman et al.$^{95}$ and Klajn and Oppenheim. ${ }^{100}$ Major assumptions of these models are functionally the same: boundary-layer flow, neglect of radiation, thin flame sheet, equal diffusivities of all species and heat, and state relationships developed assuming complete oxidation of fuel species to products at the flame sheet. Other details differ somewhat, particularly the state relationships (see the original sources for more complete information). Bahadori et al. ${ }^{104}$ report an evaluation of the models of Refs 95 and 100, based on flame length measurements at $\mu \mathrm{g}$ for methane, propane, ethylene and propylene flames burning in air. The results are illustrated in Fig. 20 where flame lengths are plotted as a function of the burner exit Reynolds number. The range of burner exit Reynolds numbers for these results is sufficiently high so that flame lengths increase nearly linearly with Reynolds number, in accord with simple boundary layer treatments of jet diffusion flames. ${ }^{92}$ Additionally, flame lengths in this regime are largely controlled by stoichiometric fuel-oxidant mass ratios, which are not very different for the fuels considered in Fig. 20. The two predictions are similar to each other and yield good results except for propylene-air flames that are considerably shorter than predicted. This difficulty is attributed to larger effects of radiative heat losses from the propylene flames. ${ }^{104}$ This is plausible because propyleneair flames are known to have considerably higher radiative heat losses than the other fuels tested (see Ref. 87 and references cited therein), and increased radiative heat losses tend to decrease flame lengths. ${ }^{108.109}$ However, the effect seen in Fig. 20 is surprisingly large, and experimental difficulties may also be a factor.

More recent theories have addressed the limita- 


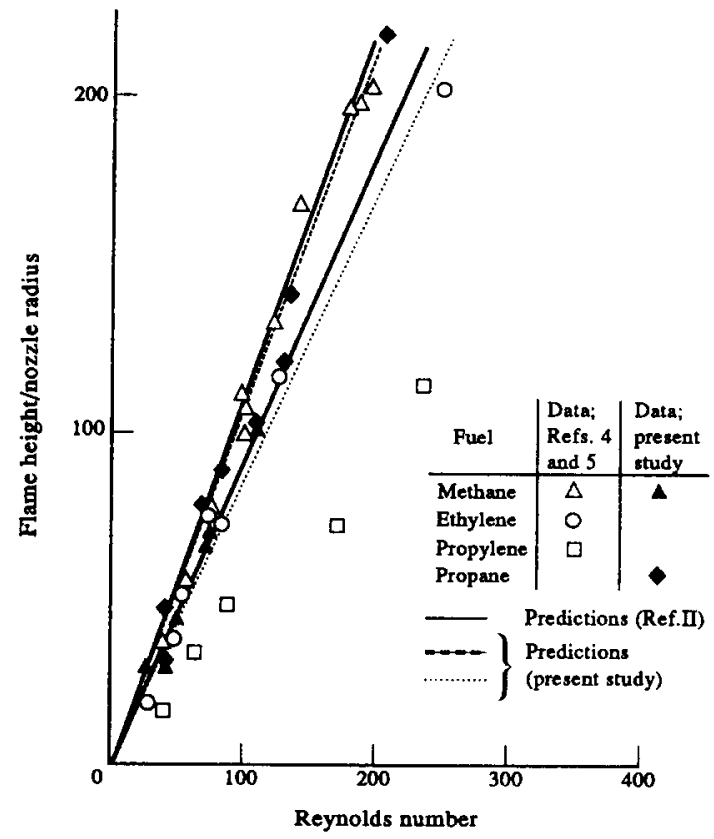

FIG. 20. Predicted and measured flame lengths of nonbuoyant laminar jet flames. Measurements from Haggard, ${ }^{9}$ ? Haggard and Cochran ${ }^{98}$ and Bahadori et al., ${ }^{104}$ predictions from Klajn and Oppenheim ${ }^{102}$ and Edelman et al. $;^{95}$ plot from Bahadori et al. ${ }^{104}$

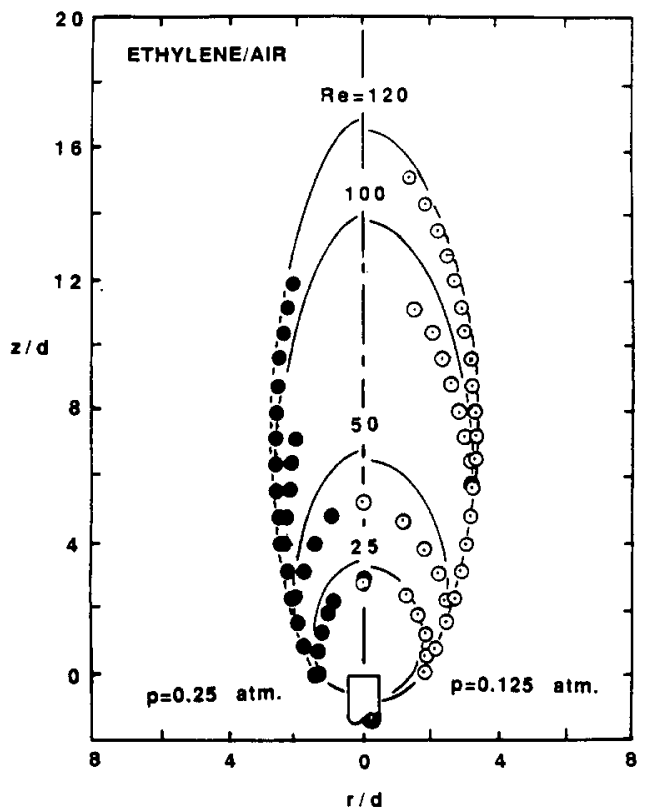

Fig. 21. Predicted and measured shapes of weakly-buoyant ethylene-air laminar jet flames at various burner exit Reynolds numbers. From Mortazavi et al. ${ }^{108}$

tions of the boundary layer and the negligible radiative heat loss approximations. ${ }^{108-110}$ The approach of Mortazavi et al. ${ }^{108}$ and Köylü et al. ${ }^{109}$ attempts to address the difficulties of soot-containing flames by using the conserved-scalar formalism in conjunc- tion with the state relationships discussed in connection with Fig. 17. The flames were taken to be axisymmetric and steady, while radiative heat losses were treated in an approximate way by assuming that they were a fixed fraction of the chemical energy release, similar to treatments used with some success for turbulent diffusion flames. ${ }^{87}$ Measurements to evaluate the predictions were carried out for weaklybuoyant laminar jet flames at $\mathrm{ng}$. This involved measurements at reduced pressures, exploiting the fact that effects of buoyancy for laminar diffusion flames scale like $\left(p / p_{\mathrm{o}}\right)^{2} g$, where $p$ and $p_{\mathrm{o}}$ are the test pressure and normal atmospheric pressure. Thus, flames at pressures of $\mathrm{O}(0.1 \mathrm{~atm}$.) have buoyancy effects of $\mathrm{O}(0.01 \mathrm{~g})$ and can be made weakly buoyant by controlling the jet exit velocity if they are not too long. Predicted and measured flame shapes using a $3 \mathrm{~mm}$ diameter burner for ethylene-air flames are illustrated in Fig. 21; results for acetylene-air flames were similar. The measurements denote the position of the blue portion of the flame and are terminated when yellow soot luminosity obscures the blue flame sheet; the predictions denote the corresponding locus of the stoichiometric mixture fraction. Predictions include effects of buoyancy, but they are nearly negligible for these conditions; this behavior is evident from the small change of flame shape when the pressure is halved. The predictions are reasonably good, including the trends of the flame shape with varying Reynolds number and the attachment of the flames below the burner exit. In particular, capabilities to predict features near the burner exit and the shapes of low Reynolds number flames demonstrate the value of allowing for streamwise diffusion rather than using the boundary layer approximation.

The evaluation of the approximate approach for computing the properties of soot-containing diffusion flames was continued by Köylü et al. ${ }^{109}$ In this study, distributions of velocities, mixture fractions and the concentrations of major gas species were considered for weakly-buoyant laminar jet diffusion flames. Typical predictions and measurements are illustrated in Fig. 22 for an acetylene-air flame at $0.250 \mathrm{~atm}$. The state relationships used for these predictions were drawn from results at atmospheric pressure from Gore and Faeth; ${ }^{85}$ nevertheless, concentration measurements in the low-pressure flames indicated the small effect of pressure on the state relationships over the range of interest. The weakly-buoyant nature of the flame is indicated by the rapid decay of velocity near the burner exit; velocities for more buoyant atmospheric pressure conditions would begin to increase almost immediately. Nevertheless, a gradual increase of velocity is still observed at larger distances from the burner exit which is caused by buoyancy-highlighting problems of $\mathrm{ng}$ observations of flames of reasonable size having negligible effects of buoyancy discussed in Section 2. In any event, the approach of Refs 


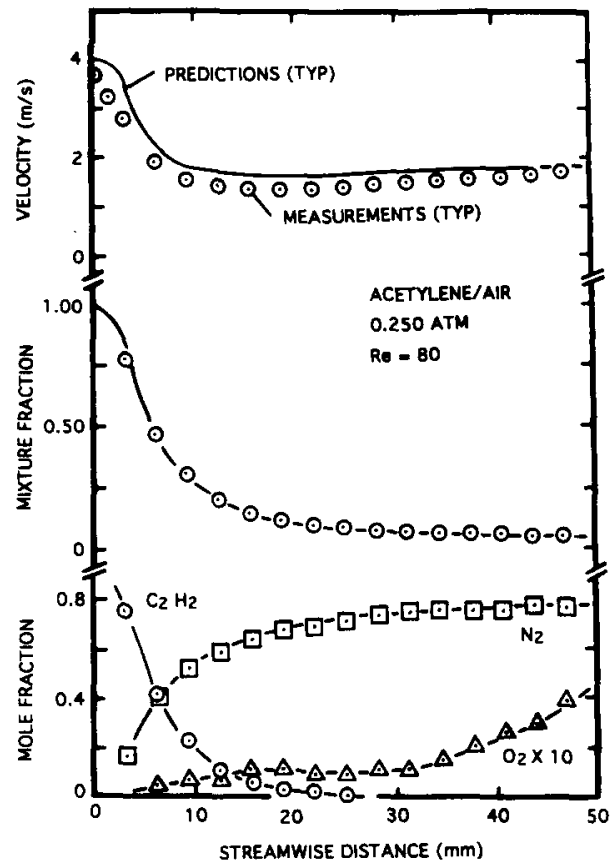

FIG. 22. Predicted and measured velocities, mixture fractions and mole fractions of acetylene, nitrogen and oxygen along the axis of a weakly-buoyant acetylene-air laminar jet diffusion flame at $0.250 \mathrm{~atm}$. From Köylü et al. ${ }^{109}$

108 and 109 handles the mild effect of buoyancy reasonably well, and predictions are in reasonably good agreement with measurements. Evaluations of temperature distributions in the fuel-lean portions of the test flames were also reasonably satisfactory. ${ }^{108,109}$

The results of Refs 108 and 109 are promising; however, predictions of this type still have considerable uncertainties. First, the flame shape is sensitive to radiative heat losses that are crudely modeled; this sensitivity to radiation would present greater difficulties for atmospheric pressure ethylene and acetylene flames that have much higher soot concentrations, and thus much larger continuum radiation heat losses from soot. Second, the variation of soot concentrations with pressure raises questions about the relevance of state relationships measured at atmospheric pressure to these low-pressure conditions, although pressure effects on state relationships have proven to be small for ethylene and acetylene-air flames for pressures in the range $0.125-1.000 \mathrm{~atm} .{ }^{109}$ and the existence of generalized state relationships for hydrocarbons having a wide range of sooting tendencies provides some justification for this procedure. ${ }^{86}$ Finally, additional structure measurements for a wider range of conditions, including effects of coflow, are needed for a definitive evaluation of the predictions.

Interest in reliable predictions of the structure of nonbuoyant laminar jet flames goes beyond the general objective of understanding this fundamental flame configuration. For example, laminar jet diffu- sion flames at $\mu \mathrm{g}$ provide a useful experimental environment, capable of addressing a wide range of pressures, for studies of fuel decomposition, soot processes and pollutant production in diffusion flames. However, diagnostics available to characterize the flame environment at $\mu \mathrm{g}$ will be limited in comparison with typical laboratory conditions at ng for some time to come. As a result, reliable methods to predict the main features of flame structure - concentrations of major species, temperatures and velocities - are needed in order to supplement limited measurements to define the flame environment. Thus, additional experimental and theoretical work for nonbuoyant flames is needed to establish reliable prediction methods. In particular, similar to premixed combustion at $\mu \mathrm{g}$, radiation plays a strong role in the properties of nonbuoyant jet diffusion flames and will require greater attention than in the past to achieve this goal.

\subsection{Flame Stability}

Gaseous diffusion flames involve mixing between fuel-rich and oxidant-rich streams, with a flame zone appearing in the mixing region between the two streams. Various configurations of these streams are used in practice, however, they are canonically similar to the jet diffusion flame configuration. Thus, jet diffusion flames will be used to simplify the discussion of flame stability issues in the following. The main problems of stability for nonpremixed flames involve maintaining the flame attached at the jet exit, local extinction of the flame sheet due to excessive stretch, and transition to turbulence.

The stability of flame attachment determines whether the flame remains attached near the jet exit, whether the flame is lifted or separated to some distance from the jet exit, or whether the flame blows off entirely and is extinguished. In the presence of buoyancy at $\mathrm{ng}$, or for strong forced-convection conditions, the mechanism of attachment is considered to involve local premixing of fuel and oxidant which provides a small premixed flame region. This behavior comes about because the flame attachment point is generally separated from the burner exit, providing a region where the fuel- and oxidant-rich streams can mix without reaction to form a flammable gas mixture. Propagation of the resulting premixed flame is then stabilized by local gas velocities, which must be low enough so that the flame can maintain a fixed position. Additionally, for attached flames, where the premixed flame is close to the burner exit, heat loss to the burner provides an additional stabilization mechanism, similar to the behavior of fully premixed flames stabilized on flatflame burners. Finally, the premixed flame region can be viewed as providing a continuing ignition source that anchors the position of the rest of the flame. 
This traditional view of flame attachment could very well be modified for low Reynolds number flames at $\mu \mathrm{g}$. For example, observations of laminar jet diffusion flames in a stagnant environment at $\mu \mathrm{g}$ show that the points of flame attachment advance below the burner exit, ${ }^{86-88}$ similar to the predicted flame shape plots for weakly-buoyant flames illustrated in Fig. 21. In the complete absence of buoyancy, and for negligible jet momentum, diffusion in all directions is equally probable so that the flame shape would become spherical and the attachment points would move farther down the tube. In this case, conventional attachment is no longer required, any more than it is required for the envelope flame around a motionless burning drop at $\mu \mathrm{g}$, and the attachment points would simply be areas where quenching occurs due to the relatively cool burner surface. Clearly, the evolution between the spherical flame and the more conventional attachment of flames having large velocities involves progressive increases of stabilization due to premixing effects, and can offer useful insights about the mechanism of attachment.

The attachment process is at least two-dimensional; therefore, attachment cannot be described by boundary-layer approximations because streamwise transport acts to fix the attachment point, and attachment involves complications of evolution from a premixed to a diffusion flame. In view of these complexities, current understanding of attachment and extinction is very limited-largely consisting of empirical correlations of measurements based on phenomenological theories. ${ }^{41,42}$ Experimentation at $\mu \mathrm{g}$, however, should advance our understanding of processes of attachment and extinction because the absence of buoyant velocities allows the stretch of the premixed region to be controlled by jet exit velocities, and modified systematically by controlled coflow velocities, while capabilities to operate at low jet exit Reynolds numbers expands the premixed flame region so that adequate spatial resolution for measurements can be provided. Models allowing for streamwise diffusion and finite-rate kinetics (for example, Ref. 110) can potentially treat the attachment regions, but corresponding measurements have not been addressed as yet.

Problems of local extinction of diffusion flame surfaces are important as potential sources of pollutants in turbulent flames. ${ }^{91}$ Thus, stretched laminar flame surfaces are receiving a great deal of attention using experiments at ng. Companion tests at $\mu \mathrm{g}$ would also be helpful, due to the potential for improved spatial resolution and the need to address the low stretch rates of spacecraft environments for fire safety concerns. However, measurements at $\mu \mathrm{g}$ will require development of instrumentation comparable with methods available at $\mathrm{ng}$, as well as extended access to spacecraft $\mu \mathrm{g}$ facilities. Thus, instrument and facility development must precede significant contributions of $\mu \mathrm{g}$ experi- ments to a better understanding of local flame quenching.

Issues of transition from laminar to turbulent flames are long standing due to problems of buoyant disturbances in the transition region. Bahadori et al. ${ }^{111}$ report initial results concerning transition to turbulence in round jet diffusion flames at $\mu \mathrm{g}$, finding significantly different behavior in the transition region for nonbuoyant and buoyant conditions. In particular, large-scale slow-moving wrinkled flame structures are observed near the flame tip at $\mu \mathrm{g}$, rather than the brush-like flame tip seen at ng. Additionally, transition to a turbulent flame at $\mu \mathrm{g}$ is characterized by the appearance of intermittent disturbances that are generated near the flame base and convected downstream, in contrast with ng flames where disturbances are first observed at the flame tip. These fundamental differences are probably related to the different velocity distributions in nonbuoyant and buoyant laminar diffusion flames. In particular, velocities decrease with increasing streamwise distance for nonbuoyant flames (Fig. 22), but increase with increasing distance for buoyant flames. This behavior would tend to move regions of high velocity, which are most unstable to transition, downstream toward the flame tip at ng in agreement with the observed behavior. However, the actual mechanism for different transition behavior at $\mu \mathrm{g}$ and $\mathrm{ng}$ still is unknown. Finally, flame lengths increase monotonically with increasing burner exit Reynolds number at $\mu \mathrm{g}$, rather than the abrupt reduction of the flame length at transition seen at ng. Clearly, existing $\mu \mathrm{g}$ facilities are capable of addressing issues of transition to turbulence in flames and they deserve consideration due to the importance of turbulent flames to practical applications.

\subsection{Soot Processes}

Understanding soot properties in diffusion flames is important because soot affects the performance of propulsion systems and furnaces, the hazards of unwanted fires, and the pollutant emissions from combustion processes. For example, continuum radiation from soot is the main heat load to the combustor components of propulsion systems and controls their durability and life, while it also serves as the main heat transfer mechanism in many furnace designs. ${ }^{112}$ Similarly, continuum radiation from soot is the dominant mechanism for the growth and spread of unwanted fires, particularly for spacecraft conditions where effects of buoyancy are absent, while sootcontaining clouds emitted from these flames obscure fire-fighting efforts. ${ }^{87.113}$ Finally, black soot-containing exhaust plumes and the carbon monoxide emissions intrinsically associated with soot emissions ${ }^{114,115}$ represent objectionable pollutants and are also the main source of fatalities in unwanted fires. ${ }^{116}$ Thus, soot properties within diffusion flames 

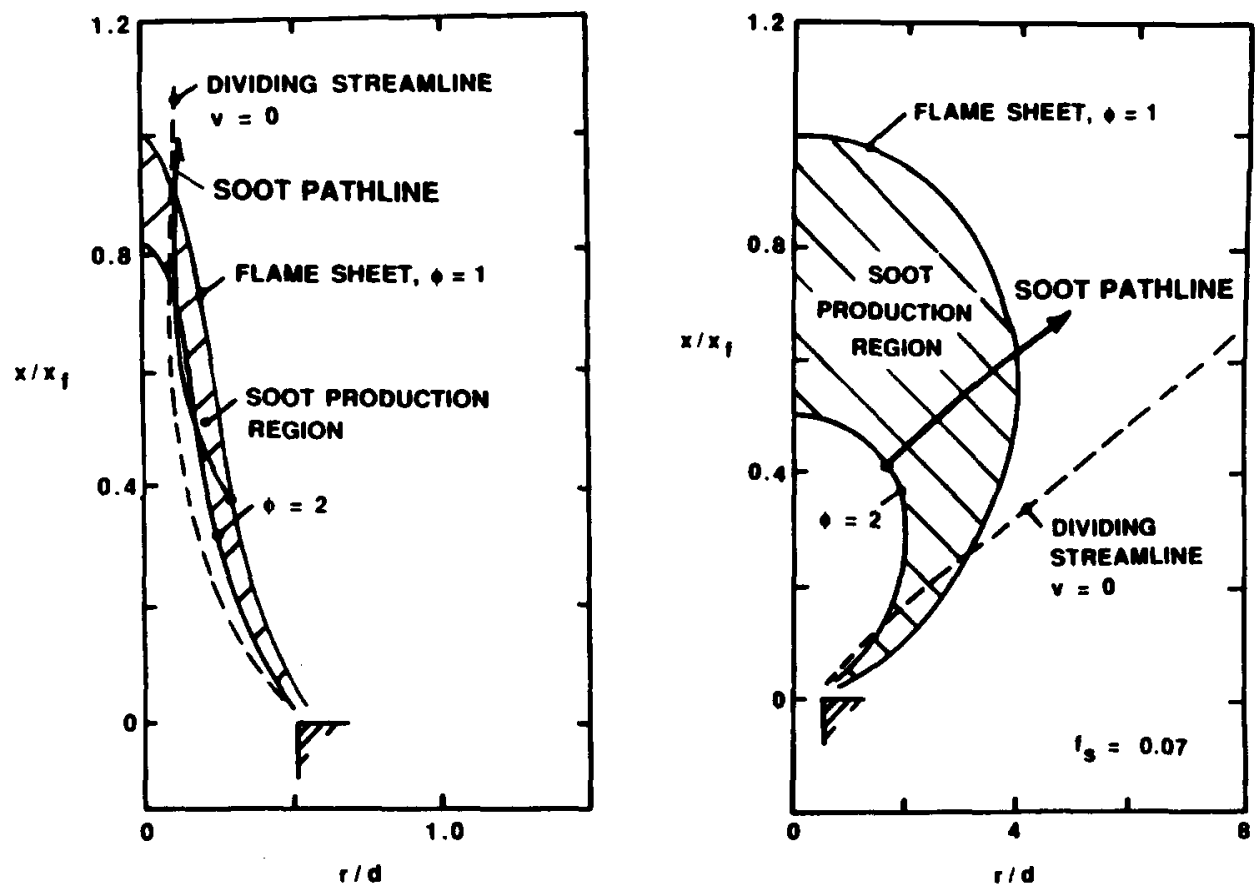

FIG. 23. Schematics of soot formation and oxidation regions for laminar jet diffusion flames at ng and $\mu \mathrm{g}$.

are unusually significant for practical applications, and they represent a major unresolved problem of combustion science in spite of significant efforts in the past. ${ }^{117,118}$

Similar to other flame phenomena, while soot processes in turbulent flames are of greatest practical interest, the direct study of soot in turbulent flames is not feasible using either existing or anticipated technologies. In particular, the unsteadiness and distortion of turbulent flames limit available residence times and spatial resolution in regions where soot properties are most important. Thus, laminar diffusion flames are generally used as more tractable model flame systems to study soot processes relevant to turbulent diffusion flames, justified by the known similarities between the gas-phase processes in these two-flame systems. ${ }^{86,90}$ This is appropriate only if the buoyancy in laminar diffusion flames at the ambient pressures of interest, generally atmospheric pressure and greater, does not directly affect soot processes. Unfortunately, this is not the case because soot particles are too large to diffuse like gas molecules and are primarily transported by local convective flows, modified somewhat by effects of thermophoresis.

The problems associated with using buoyant laminar flames to study soot processes can be seen by comparing the configurations of the soot production regions in buoyant and nonbuoyant laminar jet diffusion flames as illustrated in Fig. 23. Soot production regions occur for fuel-equivalence ratios roughly in the range $\varphi=1-2,{ }^{118}$ which is marked on the plots.
The locus of points where the radial velocity, $v=0$, which approximates the dividing streamline, is also shown on the plots, along with some typical soot pathlines in the flow. Soot particles follow the flow along streamlines, ignoring effects of thermophoresis; therefore, they move toward the dividing streamline in the radial direction. For buoyant flows, the dividing streamline is inside the soot production region except near the flame tip. Thus, except for a small region near the axis, soot particles form near the flame sheet and then move radially inward toward cooler and less reactive regions before finally reversing direction, in mixture fraction space, and eventually crossing the flame sheet close to the flame tip in a narrow soot layer near the dividing streamline. However, the process is completely different for nonbuoyant jet diffusion flames because the dividing streamline crosses the flame sheet close to the burner exit; as a result, soot begins to form near the cooler core of the flame and is drawn directly toward and through the flame sheet for most of the flame. Another important difference between buoyant and nonbuoyant diffusion flames involves the variation of velocities along soot pathlines. For buoyant flames, velocities progressively increase with increasing height above the burner exit, for example, similar to the discussion leading to Eq. (3), $(\Delta \rho g z / \rho)^{1 / 2}$ is roughly the scale of streamwise velocities. Thus, residence times near the upper end of the soot reaction zone are shortest for buoyant flames, which reduces the effectiveness of soot oxidation processes in comparison with soot production processes nearer to the 
burner exit. In contrast, streamwise velocities are roughly inversely proportional to the distance from the burner exit for nonbuoyant flames, as discussed in connection with Fig. 22. ${ }^{108,109}$ This tends to increase the effectiveness of soot oxidation processes relative to soot growth processes for nonbuoyant flames in comparison with buoyant flames. Finally, as will be discussed later, residence times in nonbuoyant flames are significantly longer than for buoyant flames of comparable size, providing longer absolute times for soot nucleation, growth and oxidation. Thus, any resemblance between soot processes within nonbuoyant and buoyant laminar diffusion flames clearly is fortuitous. Additionally, local effects of buoyancy are generally insignificant for turbulent flames; thus, the largely unstudied nonbuoyant laminar jet diffusion flame configuration provides a better simulation of soot processes relevant to the turbulent flames of practical interest than buoyant laminar jet diffusion flames.

Aside from their practical relevance, nonbuoyant jet diffusion flames at $\mu \mathrm{g}$ also provide improved spatial resolution for studying soot processes. This can be seen from the results illustrated in Fig. 23. In particular, the flame surface and the dividing streamline are close to one another for buoyant flames so that soot collects in a narrow layer. Furthermore, soot oxidation is confined to a narrow region where the soot layer crosses the flame tip for buoyant flames, because effects of strain and relatively high velocities in the flow near the flame tip introduce large radial gradients as well as rapid quenching of reactions in the soot layer. In contrast, both soot formation and oxidation are spread along most of the flame surface for nonbuoyant conditions, and these regions are broad with relatively low velocities for the low Reynolds number conditions that are accessible at $\mu \mathrm{g}$. In particular, the breadth of the soot-containing region is evident from the significant flame widths seen in Fig. 21.

Flexibility to control overall flame residence times, defined as the time required for a parcel of fluid to convect from the burner exit to the flame tip, is another advantage of nonbuoyant jet diffusion flames for studying soot processes. For example, flame residence times for buoyant laminar diffusion flames are primarily controlled by effects of buoyancy and are relatively insensitive to burner diameter and initial gas velocity variations, with the residence time roughly proportional to the square root of the flame height. ${ }^{14,115}$ This behavior implies a variation of residence times of approximately $3: 1$ over the range of typical laminar smoke point flame lengths for buoyant flames, for example, $20-200 \mathrm{~mm}$, at atmospheric pressure. ${ }^{117-120}$ In contrast, residence times tend to be proportional to burner diameter and inversely proportional to burner exit velocity for nonbuoyant laminar jet diffusion flames having dimensions typical of laminar smoke point conditions at atmospheric pressure, that is, burner exit Reynolds numbers of $O(100)$ and ratios of flame length to burner exit diameter less than 50. ${ }^{108}$ Based on simple constant property analyses using the boundary layer approximations, the effect of diameter is expected; however, the effect of burner exit velocity is surprising because simplified analyses show that residence times are independent of the burner flow rate. ${ }^{117}$ The difference between the two results is caused by effects of streamwise diffusion and variable properties; actually, due to the large property variations within flames, rather large burner exit Reynolds numbers, $O(1000)$, are required before the boundary layer approximations are appropriate for laminar jet diffusion flames. ${ }^{108}$ Thus, it is a relatively simple matter to vary the residence times of nonbuoyant jet diffusion flames by orders of magnitude through variations of burner exit diameters and velocities for the range of conditions normally considered during studies of soot processes.

Recent studies of soot processes in laminar jet diffusion flames at $\mu \mathrm{g}$ have confirmed the anticipated differences between soot processes at $\mathrm{ng}$ and $\mu \mathrm{g}$ conditions, and have demonstrated the advantages of experiments at $\mu \mathrm{g}$. A portion of these studies was devoted to measurements of the laminar smoke point flame length, which is defined as the length of the luminous portion of the flame at the condition where soot just begins to be emitted from the flame, that is, all longer flames which have larger fuel flow rates will be soot emitting. The laminar smoke point flame lengths of buoyant jet diffusion flames at ng are a valuable global measure of the sooting tendencies of fuels, because these lengths, and the corresponding residence times for a particular length, are relatively independent of burner exit conditions. ${ }^{114-120}$ It was suggested earlier ${ }^{17}$ that laminar smoke point flame lengths might not be observed for nonbuoyant laminar jet flames because simplified boundary layer analysis indicated that their residence times were independent of burner flow rate, or flame length for a particular burner, as discussed earlier. However, laminar smoke point flame lengths were recently observed for nonbuoyant flames at $\mu \mathrm{g}$ which provide a useful contrast to existing observations at ng. ${ }^{121} \mathrm{~A}$ portion of the results is summarized in Table 1 , which provides laminar smoke point luminosity lengths and residence times for ethylene and propane-air flames at atmospheric pressure. Luminosity lengths are somewhat longer than flame lengths because the soot oxidation region is relatively large; however, the ratios between flame and luminosity lengths are comparable at $\mathrm{ng}$ and $\mu \mathrm{g}$, ca. $0.6 .^{121}$ On the other hand, the basis for residence times differ somewhat because they were computed using the approach of Mortazavi et al. ${ }^{108}$ at $\mu \mathrm{g}$, while they were measured as the time required for flame luminosity to disappear after abruptly ending the burner flow at ng. ${ }^{19}$ It is unlikely, however, that the different definitions of residence times significantly affect the following observations. 
TABLE 1. Laminar smoke point properties for nonbuoyant and buoyant diffusion flames

\begin{tabular}{lccc}
\hline $\begin{array}{l}\text { Buoyancy } \\
\text { condition }\end{array}$ & $\begin{array}{c}\text { Burner } \\
\text { diameter } \\
(\mathrm{mm})\end{array}$ & $\begin{array}{c}\text { Luminosity } \\
\text { length } \\
(\mathrm{mm})\end{array}$ & $\begin{array}{c}\text { Residence } \\
\text { time } \\
(\mathrm{ms})\end{array}$ \\
\hline $\begin{array}{l}\text { Ethylene-air flames } \\
\begin{array}{l}\text { Nonbuoyant }(\mu \mathrm{g}) \\
\text { Nonbuoyant }(\mu \mathrm{g})\end{array}\end{array}$ & 1.6 & 32 & 180 \\
$\begin{array}{l}\text { Nonbuoyant }(\mu \mathrm{g}) \\
\text { Buoyant }(\mathrm{ng})\end{array}$ & 2.7 & 25 & 280 \\
Propane-air flames & 5.9 & 24 & 750 \\
$\begin{array}{l}\text { Nonbuoyant }(\mu \mathrm{g}) \\
\text { Nonbuoyant }(\mu \mathrm{g})\end{array}$ & 14.3 & 135 & 41 \\
$\begin{array}{l}\text { Nonbuoyant }(\mu \mathrm{g}) \\
\text { Buoyant (ng) }\end{array}$ & 1.6 & & \\
\hline
\end{tabular}

Nonbuoyant and buoyant round jet flames in air at $298 \pm 3 \mathrm{~K}$ and 1 atm. Nonbuoyant results from Sunderland $e t a l .^{121}$ with residence times estimated from Mortazavi et al. ${ }^{108}$ Buoyant flames from Sivathanu and Faeth ${ }^{19}$ with measured residence times.

There are several interesting features about the comparison between laminar smoke point luminosity lengths and residence times at $\mu \mathrm{g}$ and $\mathrm{ng}$ summarized in Table 1. First, the nonbuoyant flames exhibit laminar smoke point luminosity lengths, in contrast with the implications of simplified theories of flame structure, ${ }^{117}$ because their residence times vary with flame length as discussed earlier. Second, varying the burner exit diameter at $\mu \mathrm{g}$ has little effect on the laminar smoke point luminosity length. While this behavior is superficially similar to buoyant flames, the mechanism must be different. In particular, the residence times increase substantially over the range of burner diameters at $\mu \mathrm{g}$ listed in Table 1; however, similar variations of burner diameter would have little effect on residence times at ng. ${ }^{17}$ Additionally, the smoke point luminosity lengths are roughly four times shorter at $\mu \mathrm{g}$ than ng. Finally, residence times at the laminar smoke point are appreciably larger at $\mu \mathrm{g}$ than at $\mathrm{ng}-180-1310 \mathrm{~ms}$ in comparison with $41-$ $48 \mathrm{~ms}$. About the only feature that is similar for results at $\mu \mathrm{g}$ and $\mathrm{ng}$ is the tendency for luminosity lengths and residence times to be somewhat larger for propane-air than ethylene-air flames. The different soot paths and the different relative residence times and sizes of the soot formation and oxidation regions for nonbuoyant and buoyant jet diffusion flames undoubtedly contribute to this behavior. However, the specific mechanisms are neither adequately quantified nor understood. Furthermore, the greater propensity to soot at $\mu \mathrm{g}$ than $\mathrm{ng}$ is problematical for fire safety in spacecraft. Clearly, much remains to be done to establish the behavior of smoke point properties at $\mu \mathrm{g}$, but it is already evident that experiments at $\mu \mathrm{g}$ provide a valuable new perspective for gaining a better fundamental understanding of the global soot properties of diffusion flames, as well as information needed to address fire safety concerns for spacecraft.

Other experiments carried out at $\mu \mathrm{g}$ further con- firm fundamental differences between soot processes in nonbuoyant and buoyant jet diffusion flames. ${ }^{93-107}$ These experiments involve jet diffusion flames for a variety of hydrocarbon fuels in still air with the measurements limited to flame photographs. The results were generally obtained using drop towers where short available test times preclude reaching fully-developed flame conditions; however, the results are still qualitatively useful. ${ }^{106}$ It was observed that $\mu \mathrm{g}$ conditions yield enhanced sooting, which was attributed to the longer residence times of $\mu \mathrm{g}$ flames than ng flames of comparable lengths. ${ }^{103}$ The region where soot was present was much wider at $\mu \mathrm{g}$ than at ng, with the luminous region due to continuum radiation from soot having a blunt tip, called tip-opening behavior, rather than the familiar conical tip of buoyant flames such as candle flames. Furthermore, the luminosity near the tip of nonbuoyant flames progresses from yellow to red to dull red with increasing distance from the burner exit, near the end of the visible portion of the flame. This behavior can be attributed to the absence of buoyancy as discussed in connection with Fig. 23. For nonbuoyant and weakly-buoyant conditions, soot crosses the flame sheet over a broad region and passes into an extended soot oxidation region where gas temperatures progressively decrease; this yields a blunt appearance to the luminosity emitted from the sootcontaining region with the color shifting toward the infrared as the mixture cools. In contrast, the soot layers in buoyant flames at ng are confined to a region near the axis as the flame tip is approached, which yields a conical tip because the oxidation region is rapidly quenched.

Recent measurements of soot concentrations in weakly-buoyant laminar jet diffusion flames at low pressures help to quantify the structure of the sootcontaining region when the effects of buoyancy are small. ${ }^{108}$ These experiments were feasible because even though soot concentrations are reduced at low 


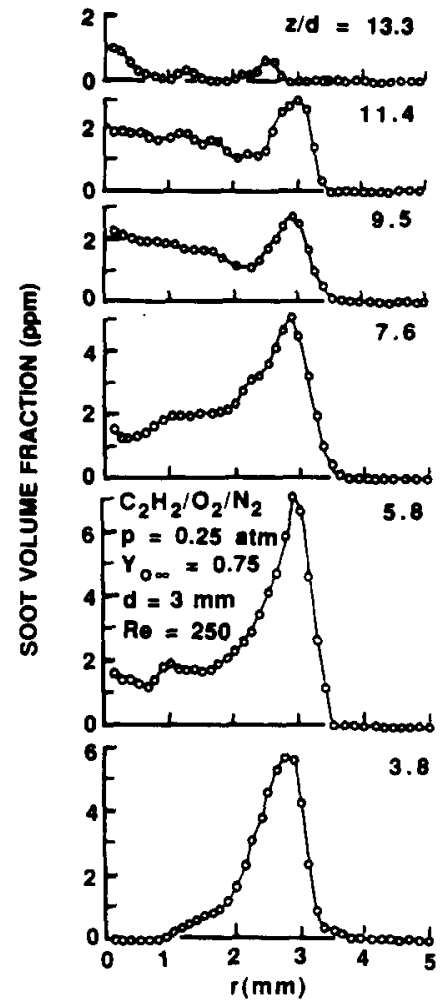

FIG. 24. Soot volume fraction distributions in a weaklybuoyant laminar jet diffusion flame (acetylene $/ \mathrm{O}_{2} / \mathrm{N}_{2}$ mixture at $0.125 \mathrm{~atm}$. and an ambient oxygen mass fraction of 0.75 ). From Mortazavi et al. ${ }^{108}$

pressures, ${ }^{122.123}$ longer residence times in nonbuoyant flames help to compensate for this reduction. A typical example of these results is illustrated in Fig. 24 , which involves an acetylene flame issuing from a $3 \mathrm{~mm}$ diameter burner having a burner exit Reynolds number of 250 , an ambient oxygen mass fraction of 0.75 and an ambient pressure of $0.25 \mathrm{~atm}$. The soot volume fraction is plotted as a function of radial distance at various distances from the burner exit. An annular soot layer is evident near the burner exit, corresponding to the region that is sufficiently heated for soot to form with possibly some additional resistance to the soot crossing the flame sheet due to effects of thermophoresis. However, the soot layer becomes less prominent as soot begins to form along the axis of the flow near the tip of the flame (ca. $x / d=9.35$, based on the stoichiometric mixture fraction). Soot oxidation extends to the axis beyond the flame tip, where soot concentrations become relatively uniform. Finally, the soot is completely oxidized at a nearly constant distance from the burner exit in this nonsooting flame. The large width of the soot-containing region, and its rather uniform disappearance at all radial locations, helps to explain the blunt luminous zone (or tip-opening process) observed for jet diffusion flames at $\mu \mathrm{g}$. Finally, the breadth of the soot-containing region and the large size of the soot-oxidation region clearly provide excellent spatial resolution for studying soot processes.

Behavior similar to Fig. 24 at all pressures at $\mu \mathrm{g}$, coupled with significant flexibility to vary flame residence times, provides unprecedented opportunities for significant progress towards an understanding of soot processes in diffusion flames. The differences in soot behavior at $\mu \mathrm{g}$ and $\mathrm{ng}$ have important implications for spacecraft fire safety because continuum radiation from soot significantly affects fire growth, flame spread and burning rates, ${ }^{87}$ providing an additional incentive to study soot processes in nonbuoyant diffusion flames.

\section{HETEROGENEOUS PREMIXED FLAMES}

\subsection{Introduction}

Aside from the limited case of double-base solid propellant combustion, denoting a class of combustion phenomena as heterogeneous premixed flames is an oxymoron because these flames normally involve nonpremixed combustion on small scales, that is, individual dispersed phases (particles or droplets) are generally dominated by either fuel-like or oxidizerlike reactants. In keeping with normal usage, however, we shall consider a variety of flame phenomena under the heading of heterogeneous premixed flames, where gross mixing between the fuel-rich and oxidizer-rich phases has already occurred before flame propagation begins. This includes flame propagation in suspensions, smoldering and materials synthesis in flames.

\subsection{Flame Propagation in Suspensions}

The propagation and extinction of flames in particle and droplet suspensions are relevant to the combustion of sprays and coal dusts, and to accidental explosions in mine galleries and grain elevators. However, it has proven to be far more difficult to develop reliable information concerning such important fundamental combustion parameters as the minimum ignition energy, flame propagation speeds, flammability limits, and quenching distances in particle and droplet suspensions than in homogeneous gas mixtures. The primary reason for the difficulties is the inability to produce a uniform suspension due to particle settling. This problem is caused by two factors, namely particle settling during combustion, and particle settling during the preparation of a combustible heterogeneous mixture. ${ }^{12-130}$

First consider the effects of particle settling during combustion. The particles of interest to combustion have sizes which typically vary from $10-1000 \mu \mathrm{m}$. This implies terminal velocities within the range 
$10-100 \mathrm{~cm} / \mathrm{s}$. This range, however, basically brackets the rate of flame propagation in particle suspensions so that settling can seriously modify the flame behavior. For example, for a downward-propagating flame, rapid settling may make the suspension too dilute to support combustion. In contrast, an upward-propagating flame may also fail to propagate because the dense particle cloud can either make the heterogeneous mixture too rich for flame propagation and/or can absorb too much heat from the flame and cause extinction. By the same reasoning, there may also exist situations in which settling can make an initially nonflammable suspension combustible. Finally, even if a flame can successfully propagate through the suspension, its motion will be highly transient due to the stratified particle concentration.

The second factor concerns the creation of particle or droplet clouds. Effective methods to mix particles and gases frequently produce strong turbulent motion within the gas (see Kumar et al. ${ }^{130}$ and references therein). Since it is desirable to initiate the experiment only after the turbulent motion has decayed, substantial settling can take place during this decay period. Practical operational compromises imply that measurements at $\mathrm{ng}$ involve combined disturbances of turbulence and settling except for the very smallest particulates or droplets. ${ }^{130}$ In view of these considerations, the need for long duration $\mu \mathrm{g}$ experiments in space is warranted for this class of phenomena. These experiments will provide valuable data for comparison with existing theories based on uniform suspensions (see Seshadri et al. ${ }^{131}$ and references therein), and will serve as new standards for the evaluation of fire hazards in particle suspensions for both Earth- and space-based applications.

Earlier $\mu \mathrm{g}$ studies on flame propagation in suspensions in a tube have focused on a so-called 'chattering flame' phenomenon. ${ }^{125-128}$. Specifically, the structure of near-stoichiometric flames appears to be spatially discontinuous in a rib-like manner, while it is continuous for rich mixtures. It was speculated that the chattering flame propagation was associated with a Kundt's tube-type phenomenon, ${ }^{132}$ which causes the unburnt mixture to segregate into alternate fuel-rich and fuel-lean layers. Upon ignition, the flame would then propagate in a pulsating mode as the layers of particles are ignited in turn through radiation. More recent experiments, however, cast doubt on this mechanism because segregated layers in the unburnt mixture were not observed. ${ }^{133}$ It is now believed that the chattering nature is simply caused by the flame-acoustic interation for flame propagation in a tube.

Theoretical studies for flame propagation in suspensions have been performed for both the steady mode of flame propagation, ${ }^{131}$ and for the acoustic instability characteristics in the tube. ${ }^{133,134}$ In all these analyses the particles are assumed to completely gasify in the preheat zone so that the reaction zone is equivalent to a premixed flame. Results presented for acoustic instability characteristics in Ref. 133 show that the growth of the instability is damped by the particle velocity lag, as is well known, with the damping being stronger for the higher loading cases of stoichiometrically-rich mixtures.

Concerning future research, it seems that if the chattering flame phenomenon is strictly a flameacoustic interaction problem peculiar to the use of the tube as the flame propagation chamber, then investigators can simply use either a homogeneous gaseous mixture for studies on acoustic instability alone, or a gas mixture with inert particle seeding to allow for viscous damping. By the same reasoning, studies of flame propagation in fuel particle suspensions should use a combustion chamber which would not produce such instabilities. In terms of theoretical work, active particle gasification and burning should constitute part of the reaction zone structure, similar to 'spray flame' analysis, ${ }^{24}$ so that the heterogeneous nature of the flame structure is completely incorporated.

\subsection{Smoldering}

Accidental fires and explosions are frequently preceded by smoldering, which is the slow heating and pyrolysis of organic materials with the release of combustible vapor and particles. Without buoyancy for dispersion, the pyrolyzate will stagnantly accumulate so that a flammable concentration can be easily reached. In addition, safe toxicity levels in the environment could be exceeded due to accumulation of these preflame pyrolyzates. Therefore, the formation and dispersion of pyrolyzates for smoldering in $\mu \mathrm{g}$ environments needs to be understood, primarily motivated by spacecraft fire safety concerns. ${ }^{135,136}$

Smoldering frequently takes place in the interior of a porous material through the creeping propagation of a smoldering front supported by the exothermic, heterogeneous reaction that takes place at the surface of the pores. Radiative transport may become important because heat conduction can be relatively ineffective in a porous medium. Furthermore, because the porous material inhibits convective and diffusive transport to the smoldering front, oxygen supply is frequently the rate limiting factor. Smolder front propagation has been studied for cigarettes, polyurethane foams, wood, wood products, coal matrixes in underground coal gasification and fires involving coal heaps. ${ }^{135}$

The influence of gravity on smoldering is primarily through the mechanism and rate of air supply, with past considerations generally limited to downward and upward propagation (see Refs 136-138 and references therein). For example, in a downward-propagation mode, the supply of oxidizer is augmented by the buoyancy-induced upwardly-rising air. Since both the fuel and oxidizer are supplied upstream of the front, the spreading mode is similar to a premixed 
flame and is termed cocurrent spread. On the other hand, for an upwardly-propagating flame, fuel and buoyancy-induced oxidizer are supplied from opposite sides of the flame. Then the spreading mode is similar to a nonpremixed flame and is termed counter-current spread. The above situations are analogous to those of flame propagation in the vertical tube, considered previously, except that the flow is in a porous medium. The spreading of the smoldering front can also take place through natural convection boundary-layer flows over nonporous surfaces for the analogous cocurrent and counter-current situations. It is clear that, in spite of the small pore size of the smoldering material, buoyancy plays an important role in the rates of flame propagation and spreading in these situations. In the absence of buoyancy, the rates of oxidizer supply, and thereby front propagation, are expected to be considerably reduced. Detection of smoldering occurrence will also be more difficult when buoyancy is absent, leading to greater danger of transition to flaming combustion.

The $\mu \mathrm{g}$ environment also provides an opportunity for systematic study of smoldering processes that cannot be carried out at ng. For example, detailed measurements of the locally heterogeneous combustion processes of smoldering requires reasonable spatial resolution. However, this is difficult at $\mathrm{ng}$ because gas passage sizes must be small to prevent effects of natural convection flows that are not relevant to practical smoldering processes (see Section 2 for a discussion of these limitations). This difficulty is circumvented at $\mu \mathrm{g}$ because the size of both the fuel elements and the gas passages can be scaled up so that conventional temperature and gas sampling probes can be used to determine flame structure. Unfortunately, smoldering processes are normally slow, and become even slower upon scale-up. Thus, ground-based $\mu \mathrm{g}$ facilities, that have test times in the range $1-100 \mathrm{~s}$, do not offer much potential for studies of smoldering. However, progress in this area should be rapid when spacecraft environments become available for smoldering experiments.

\subsection{Materials Synthesis}

Materials synthesis in flames is a growing field due to potential applications for a wide range of novel and useful products. There are three general classes of materials synthesis in flames: film deposition, condensation of nanoparticles and self-propagating high-temperature synthesis (SHS). Flame deposition of films has a long history and is commonly used to produce coatings of refractory materials, including recent interest in the production of industrial diamonds. Significant effects of buoyancy on deposition processes are normally not a factor, however, because relatively high flow velocities are used in order to minimize the boundary layer thickness along surfaces so that high deposition rates can be achieved.
Thus, deposition will not be considered in the following discussion. However, materials synthesis by condensation of nanoparticles and SHS will be considered because they are related to flame propagation in suspensions and smoldering so that $\mu \mathrm{g}$ environments can impact these processes as discussed in Sections 5.2 and 5.3.

A common method of materials synthesis in flames involves condensing the desired product in the postflame region, somewhat analogous to the way that soot is formed in premixed flames. This tactic can be used to produce highly purified refractory materials like silicon dioxide or technological fumes like carbon black and fullerenes. ${ }^{139}$ In a general way, this is the inverse process of flame propagation in suspensions and it involves similar limitations. First of all, the growth of dispersed-phase elements is limited by settling and available flame residence times at $\mathrm{ng}$. At $\mu \mathrm{g}$ conditions, both these restrictions are modified, thereby allowing for the production of larger dispersed-phase elements, providing a range of properties of the materials that is beyond current capabilities, and reducing problems of phase separation (or product collection). However, the properties of these processes are not understood at $\mu \mathrm{g}$; in particular, it is likely that available residence times will ultimately be limited by radiation effects, rather than convection effects which control residence times at ng. Thus, the kinds of products that can be made, and the structure and stability of the flame environments used for their production, will require extensive experiments at $\mu \mathrm{g}$.

SHS is related to thermite processes that have a long history, and is receiving new interest due to capabilities to produce novel and valuable products (see Refs 140-142 for a summary of recent work in this field). SHS involves mixing and compacting controlled amounts of solid phases of reactant materials and igniting the mixture, with the final product produced upon flame propagation through the mixture. A desired shape of the product also can be achieved by appropriate shaping of the compacted reactant. There are two main classes of SHS processes: (i) solid-fluid and (ii) solid-solid. Solid-fluid processes involve one reactant as a solid matrix that is submerged in a second reactant that is fluid. An example is the suspension of titanium particles in liquid nitrogen to produce titanium nitride. ${ }^{143}$ Solid-solid processes involve mixtures of solid phases, typically of a metal and a nonmetal, with the surrounding gas playing a minor role, or with operation even in a vacuum, yielding a unique class of combustion phenomena. Solid-solid SHS processes are sometimes called gasless reactions because both reactants and products are solids; however, one of the reactants frequently melts or gasifies upon passage of the flamefront so that the resulting combustion process could resemble heterogeneous flame propagation in sprays and dusts. ${ }^{144}$ Including both classes, there is a rich variety of SHS processes of interest, and the 


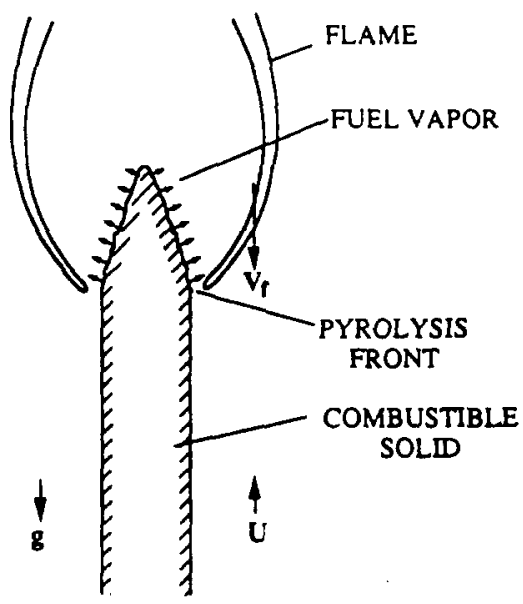

(a)

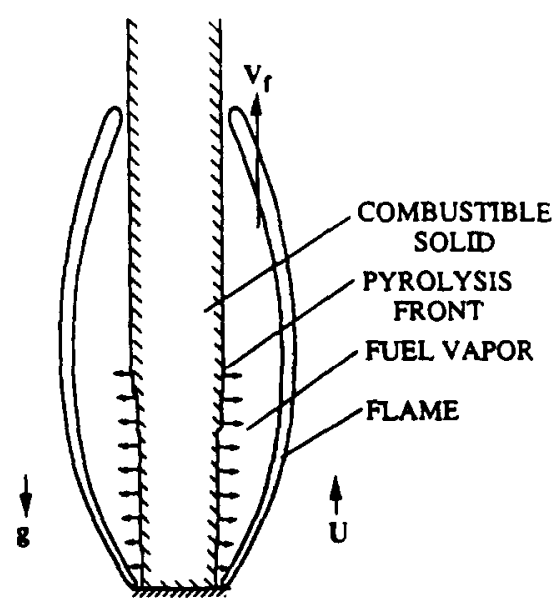

(b)

Fig. 25. Schematic of (a) a downward-propagating opposed flow flame, and (b) an upward-propagating concurrent flame.

mechanisms of SHS are not well understood. In fact, most past work has been limited to general thermodynamic considerations to define conditions needed to achieve SHS having appropriate properties, and studies of the mechanical properties of the product for various reactant properties. ${ }^{140-142}$ Thus, there is substantial scope for fundamental experimental studies of SHS, with the advantages of experimentation at $\mu \mathrm{g}$ being very similar to those already discussed in connection with heterogeneous premixed flames. There are some additional distinct advantages of conducting the SHS process at $\mu \mathrm{g}$. For example, for solid-solid synthesis in which the flame speed could be low (say $0.1 \mathrm{~cm} / \mathrm{s}$ ), and one of the solids melts upstream of the reaction front, the melt could drip due to gravity and consequently modify the unreacted mixture composition. Furthermore, for liquidsolid synthesis involving a suspension, the problem of settling could be circumvented at $\mu \mathrm{g}$ in the same manner as for gas-particle suspensions discussed in Section 5.2 , provided a uniform dispersion can be initially achieved. ${ }^{143}$

\section{HETEROGENEOUS NONPREMIXED FLAMES}

\subsection{Introduction}

As noted earlier, the combustion process of heterogeneous flames generally involves nonpremixed combustion between a gaseous phase and a solid or liquid phase. Therefore, heterogeneous nonpremixed flames include many classical problems that have had significant attention in the past. In the following we shall consider two main classes of heterogeneous nonpremixed combustion, namely, flame spread along solid and liquid surfaces and the combustion of droplets. The corresponding problems of the combustion of solid particles has attracted surprisingly little attention at $\mu \mathrm{g}$ conditions, and will not be considered.

\subsection{Flame Spreading}

Flame spreading over fuel surfaces is a crucial process in fires both on Earth and in space. The relevant issues are understanding the mechanisms governing spreading, determining the spreading rate as a function of the fuel properties and environmental parameters, and identifying the limiting situations when spreading is not possible.

Flame spreading can be classified into two broad categories; ${ }^{146}$ namely, opposed-flow spread (Fig. $25 a$ ), in which the spreading direction is opposite to that of the external flow, and concurrent-flow spread (Fig. 25b), in which the spreading direction is the same as that of the external flow. For a verticallyoriented fuel surface in the presence of gravity, the flame induces a buoyant flow and these two spreading modes correspond to downward and upward flame spread, respectively. In concurrent spread, the hot combustion products form a plume that bathes the unburnt fuel, leading to rapid rates of flame spreading. If the fuel plate is also thermally thick, ${ }^{146}$ then spreading is generally accelerated as a greater depth of the solid fuel becomes heated. For a thermally thin fuel, a steady rate of spread may be possible when complete fuel burnout can be achieved near the leading edge. Opposed spread is slower in general and a steady state can be achieved more readily. Due to its relative experimental and theoretical simplicity, most research has been conducted on opposed spread of laminar flames over thin fuels. 


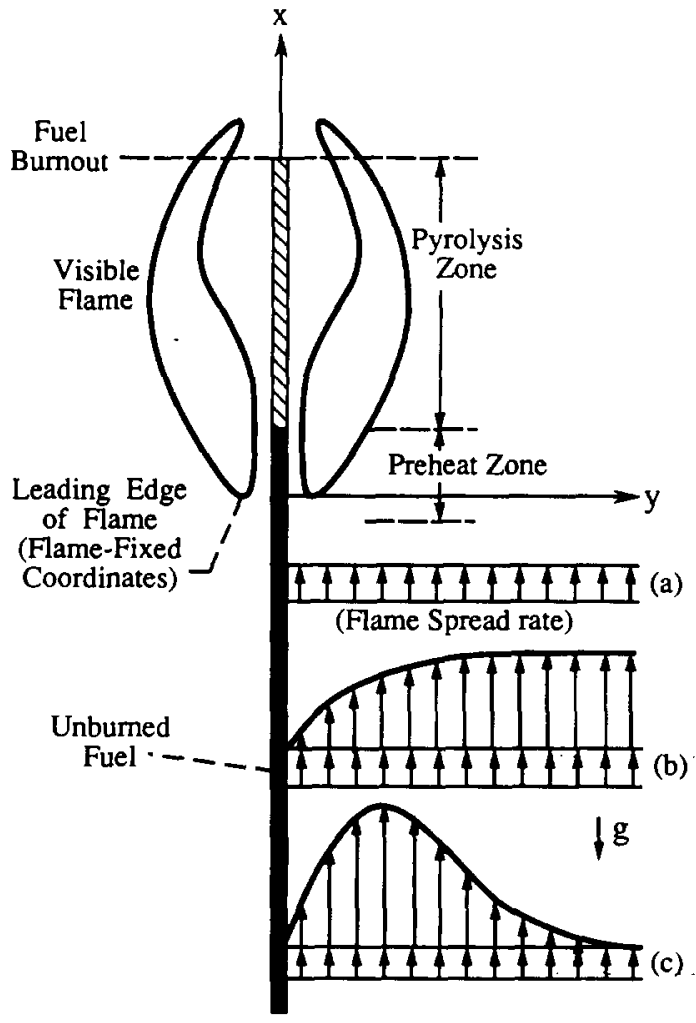

FIG. 26. Schematic of flame propagation with different opposed flow velocity profiles in the flame-stationary reference frame: (a) $\mu \mathrm{g}$ stagnant environment, (b) $\mu \mathrm{g}$ forcedconvection environment, and (c) stagnant buoyant environment.

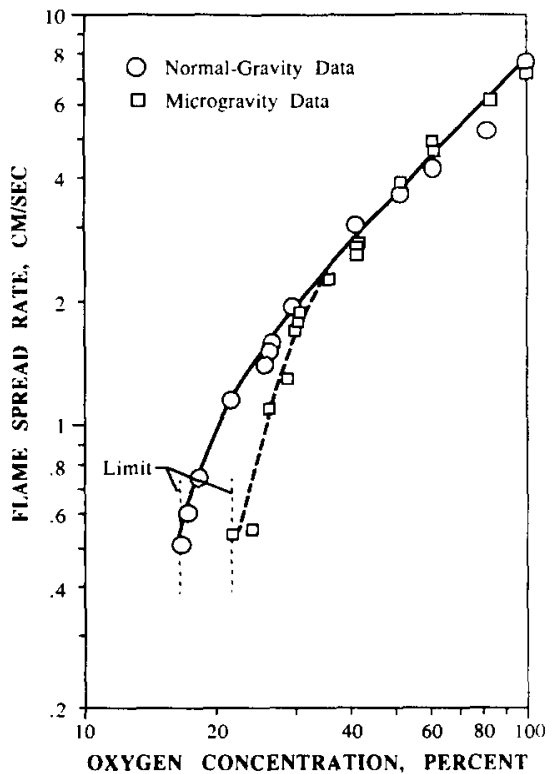

Fig. 27. Flame spread rates at $\mathrm{ng}$ and $\mu \mathrm{g}$ as a function of ambient oxygen concentration for a thin solid fuel. From Olson. ${ }^{152}$
Recently, however, work has been initiated on flame spread over thick fuels, ${ }^{147,148}$ concurrent spread, ${ }^{147.149}$ and turbulent flames. ${ }^{150}$ There is a growing body of literature on flame spread related to fire research (see Refs 146-163, and references cited therein, for additional information).

Figure 26 is a more detailed schematic showing an opposed spread configuration. Recognizing that the flame has a finite spreading speed, Fig. 26 shows that, in the flame-stationary reference frame, the flame experiences different upstream velocities against its motion if it is situated in (i) a zero-gravity, stagnant environment, (ii) a zero-gravity, forced convective environment, and (iii) a stagnant, buoyant environment. Spreading is accomplished through highly coupled convective-diffusive heat and mass transport, as well as radiative heat transport, near the leading segment of the flame. Here the forward diffusive and radiative heat transfer from the flame heats and pyrolyzes the solid fuel ahead and in the vicinity of the leading edge of the flame. The pyrolyzed fuel vapor then mixes with the fresh oxidizing gas from the freestream, forming a combustible mixture which subsequently reacts. Since the mixture around the leading edge of the flame is premixed, this flame segment resembles a premixed flame. Thus, spreading of such a global diffusion flame is achieved through propagation of this premixed flame segment that forms the leading portion of the flame. Fundamentally, we also recognize the similarity of flame spread to the stabilization of jet diffusion flames by a premixed flame segment. A comprehensive theory, yet to be formulated, should be able to describe both phenomena.

Microgravity experiments have been conducted in order to study flame spread without the complications from heat and mass transport processes associated with the induced buoyant flow. ${ }^{151-155} \mathrm{It}$ is also of particular interest to assess the influence of the convective environment on fire safety, especially under limit conditions. In general, it is found that as the external convective flow is reduced to values near zero, the flame temperature is reduced, and the flame becomes thicker and is located farther away from the surface. Figure 27 is an illustration of measurements of the flame spread rate over a thin paper sample as a function of the ambient oxygen concentration at ng and $\mu \mathrm{g}$ for a stagnant environment. ${ }^{152}$ It is seen that while the flame spread rate is basically not affected by buoyancy in highly-enriched oxygen environments, as the oxygen concentration is reduced the flame spreads more slowly at $\mu \mathrm{g}$. Consequently, the flame fails to spread at a comparatively higher oxygen concentration at $\mu \mathrm{g}$. The substantial difference between the spread rate at $\mu \mathrm{g}$ and ng also indicates the need to conduct these experiments at $\mu \mathrm{g}$, as well as other intermediate gravity levels, in order to accurately assess the influence of buoyancy.

Figure 28 is an illustration of the flame spread velocity over thin paper samples as a function of the 


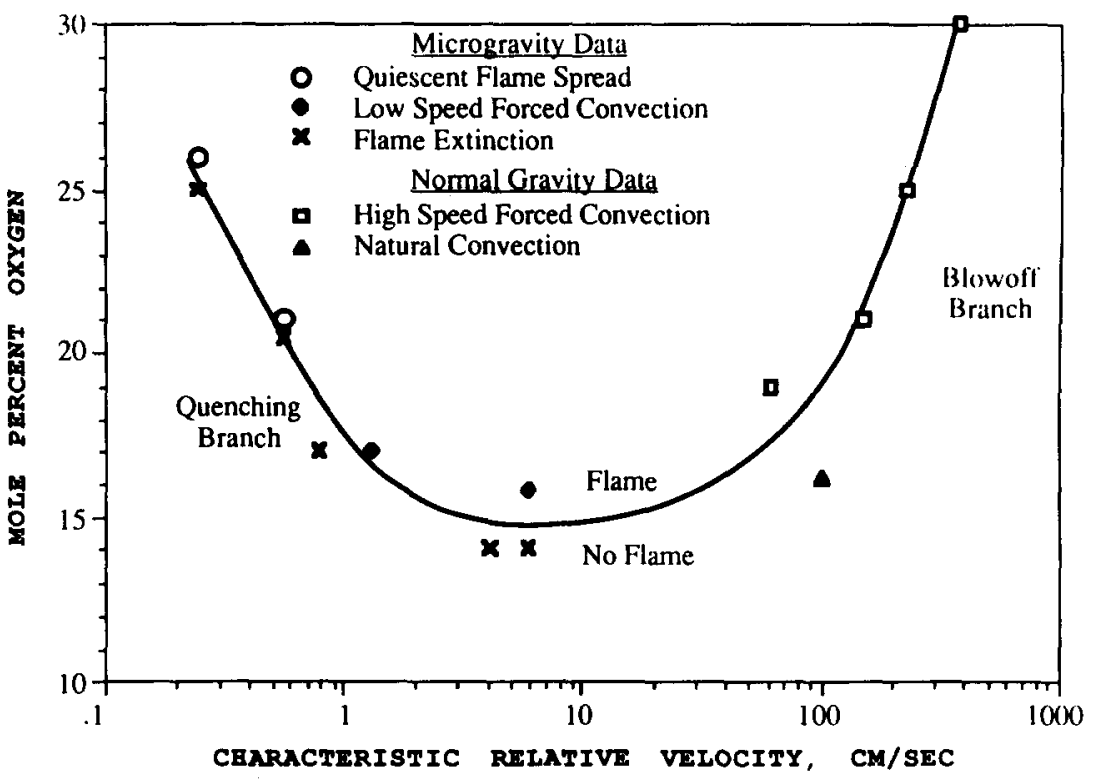

Fig. 29. Extinction boundary for flame spread over a thin fuel. From Olson. ${ }^{152}$

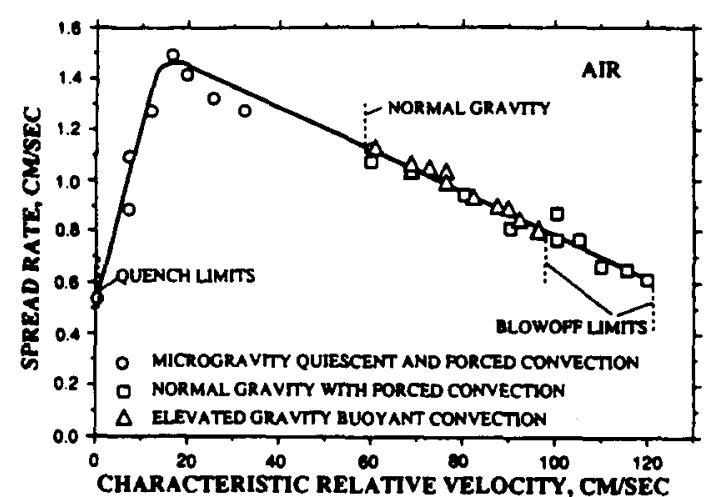

FIG. 28. Effect of opposed flow on the flame spread rate for a thin fuel. From Olson. ${ }^{152}$

characteristic relative velocity experienced by the flame. ${ }^{152}$ The correlation considers all possible modes of convection, including quiescent and forced convection at $\mu \mathrm{g}$, with and without forced convection at $\mathrm{ng}$, and buoyant convection at elevated gravity. It is seen that the spreading response is nonmonotonic, with the spread rate exhibiting a peak value at a certain characteristic relative velocity. Such a nonmonotonic behavior is further demonstrated in Fig. 29, which is a plot of the limit of flame spread in terms of the oxygen concentration and the characteristic relative velocity. The results demonstrate that spreading is inhibited beyond a low and a high limit of the relative velocity. It is suggested ${ }^{152}$ that in the high velocity limit, relevant to buoyant or highly forced convective situations, the flame is simply blown off because a balance cannot be maintained between the local flow velocity and flame propagation speed at the leading edge of the flame. In the low velocity limit, relevant to stagnant $\mu \mathrm{g}$ situations, the reduced convective rate of oxygen supply causes the burning rates, and thereby the heat release rates, to be too slow relative to that of the radiative heat flow, and the flame is quenched. The possible existence of such a dual extinction behavior was originally suggested by T'ien and Foutch and T'ien, ${ }^{156-158}$ based on numerical solutions of counterflow diffusion flames. Recent analytical studies of nonpremixed and premixed flames with flame and surface radiation ${ }^{159,160}$ also substantiate such a phenomenon.

The above results demonstrate that the complete suppression of convective flows does not necessarily lead to the most favorable situation to retard flame spread. In fact, it is seen that flame spread can be significantly promoted in a $\mu \mathrm{g}$ environment having a gentle breeze, somewhat lower than the lowest possible characteristic velocity for opposed-flow flame spread at ng, which is typical of the working environment in spacecraft. It is, however, also shown that an absolute minimum oxygen concentration of about $15 \%$ exists, below which opposed-flow flame spreading is not possible, at least for the materials used in the experiments of Fig. 29. These results are highly significant for fire prevention considerations and will be discussed again in Section 7.2.

The opposed-flow spreading of flames over thin fuels has also been numerically simulated. ${ }^{154,161-163}$ The predictions appear to quantitatively agree well with measurements at $\mu \mathrm{g}$, especially at the leading edge. ${ }^{154}$ Such agreement emphasizes the importance of the leading edge region and radiative transfer on opposed-flow flame spread.

A schematic diagram illustrating flame spread over a pool of liquid fuel appears in Fig. 30. The reference frame in Fig. 30 is the flame, so that both air and liquid approach the flamefront, with local modifications of surface tension and effects of buoyancy 


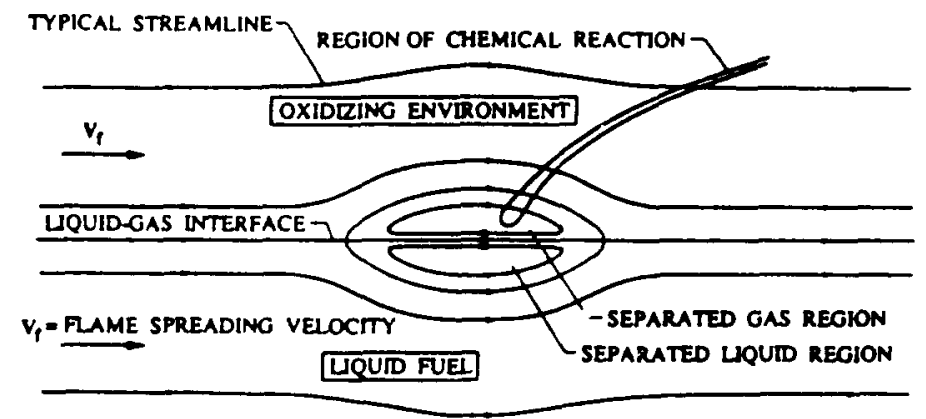

FIG. 30. Schematic showing flame spread over a liquid surface in the flame-stationary reference flame, with spreading being aided by surface tension. From Sirignano. ${ }^{164}$

contributing to the formation of recirculation or separated-flow zones in both the gas and liquid. In this reference frame, the region near the leading edge of the flame resembles the flame attachment point of gaseous jet diffusion flames, discussed earlier. Thus, the leading edge involves a small premixed region fed by vapor leaving the fuel surface in its vicinity, in the same manner as that of flame spread over a solid surface discussed previously.

Flame spreading over the surface of a pool of liquid fuel (Fig. 30) possesses several distinctive characteristics which are different from the behavior of flames for solid fuels. First of all, since liquid fuels are more volatile than solid fuels, substantial amounts of fuel vapor can be generated in the region near the leading edge of the flame which controls the flame spread rate. Flame propagation is therefore sensitive to the vapor pressure (and thus the temperature) of the liquid, leading to the use of the flash point of the liquid fuel as an indicator of the different modes of spreading. It is reasonable to expect that with a moderate increase of the fuel vapor concentration, the premixture at the leading edge will be rendered more combustible and hence will propagate a flame faster when compared with a solid fuel. However, excessive enrichment could make the leading edge too fuel rich and consequently retard the spreading rate. Such a dependence has not been sufficiently studied.

There are two main reasons for the study of flame spreading over liquid pools at $\mu \mathrm{g}$. First, since the surface tension in the flame region is now much smaller than that far upstream of the flame, because of the higher liquid temperature in the flame region, thermocapillary forces induce a surface velocity in the direction of flame propagation. ${ }^{164}$ This effect subsequently increases the overall flame spread rate. Since the inherent flame spread rate in a stagnant $\mu \mathrm{g}$ environment is very small, as just shown, this surface tension-induced flow can become the controlling factor in flame spreading. The second consideration is that if the pool is sufficiently deep, then buoyancy will also affect the fluid motion within the liquid, and thus the flame spread rate. A complete understanding of the flame propagation process will therefore involve studies of both gas- and liquidphase processes.

Microgravity experiments using both shallow and moderately deep pools ${ }^{165,166}$ have shown that when flames at ng spread uniformly, the spreading rates at $\mu \mathrm{g}$ are almost identical to those at $\mathrm{ng}$. This implies a minimal influence of buoyancy on the motion in either liquid or gas phases for this horizontally-oriented fuel surface. The spreading behavior, however, is markedly different under limit conditions of, say, low liquid temperatures. For these situations, spreading assumes a pulsating mode at $\mathrm{ng}$, and is not possible at $\mu \mathrm{g}$. It is reasoned that at $\mathrm{ng}$ a gas-phase recirculation cell is present ahead of the leading edge, being formed by the concurrent gas flow next to the liquid surface due to the no-slip boundary conditions and the opposed flow above it induced by buoyancy. ${ }^{167}$ The gas-phase recirculation cell also induces a liquid-phase recirculation cell. The gasphase recirculation cell facilitates fuel-air mixing, especially near limit conditions, and therefore promotes combustion. At $\mu \mathrm{g}$, such a recirculation cell may not exist (due to hot gas expansion) and flame spreading is therefore not possible under the same limit conditions. However, when an opposed flow is externally applied at $\mu \mathrm{g}$, the flame is sustained under otherwise extinguished conditions. ${ }^{166}$

\subsection{Droplets}

Droplet vaporization and combustion is an essential process during spray combustion in liquid-fueled engines and combustors. It is also a classical model problem of heterogeneous combustion because, by assuming quasisteadiness and spherical symmetry, the mathematical aspects of the problem can be greatly simplified.

The basic droplet combustion model, ${ }^{168}$ depicted in Fig. 31, describes the gasification of the liquid fuel at the droplet surface and its subsequent outward transport to meet inwardly-diffusing oxidizing gas in a thin flame region. The classical $d^{2}$ law, derived by assuming spherical symmetry (Fig. 31a), quasisteadiness, and flame-sheet combustion, then predicts that 


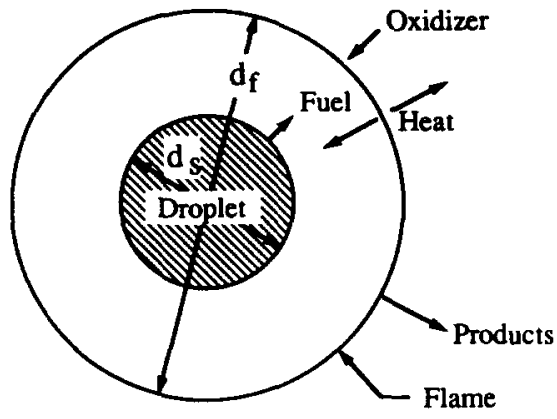

(a)

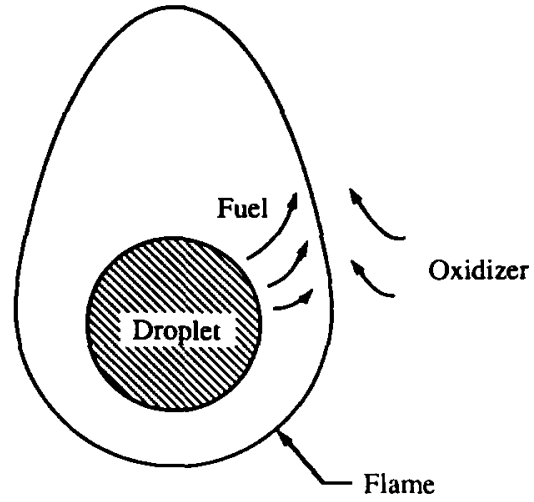

(b)

Fig. 31. Schematic of drop envelope flames at (a) $\mu \mathrm{g}$, and (b) ng.

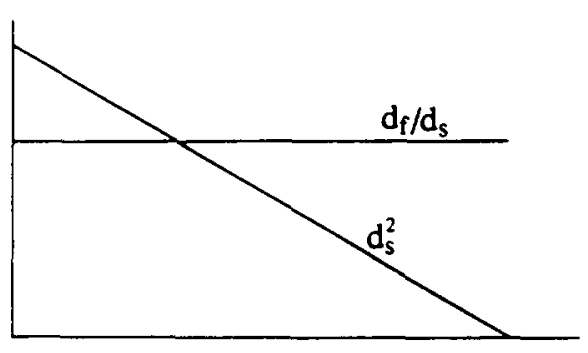

TIME

FIG. 32. Theoretical predictions of spherically symmetric drop combustion according to the $d^{2}$ law.

the square of the droplet diameter, $d_{s}^{2}$, decreases linearly with time, and that the ratio of the flame diameter, $d_{f}$, to the droplet diameter, $d_{f} / d_{s}$, is a constant, as illustrated in Fig. 32.

Numerous attempts have been made to verify the $d^{2}$ law. Normal gravity experimental results show that $d_{\mathrm{s}}^{2}$ indeed varies approximately linearly with time, with the deviation from linearity depending on the extent of second-order influences. Attempts to quantify the behavior of the flame size, however, proved futile because it is meaningless to define a flame diameter when the flame is severely elongated by the presence of buoyant flow (Fig. 31b). Furthermore, since the intensity of buoyancy continuously changes because of the steadily decreasing droplet size, an unsteady effect is also introduced. Thus, $\mu \mathrm{g}$ experiments are needed to better understand droplet combustion.

Kumagai and coworkers ${ }^{169,170}$ pioneered the use of the drop tower to study droplet combustion at $\mu \mathrm{g}$. A spherically-symmetric droplet combustion configuration was observed during these experiments. The period of free-fall in Kumagai's experiments, however, was fairly short and therefore only covered the early portion of the droplet lifetime.
An alternative approach to minimize buoyancy during droplet burning is to conduct the experiment in $\mathrm{ng}$ environments at reduced pressure, ${ }^{8}$ down to about 0.1 atm., as mentioned earlier. Since droplet burning is a diffusion-controlled process, and since the density-weighted mass diffusivities are pressure insensitive, this approach is suitable to study certain small-scale (say $1 \mathrm{~mm}$ or less), low-velocity, steadilyburning diffusion flame phenomena. The reduced chemical reactivity can also be partially compensated by using oxygen-enriched environments, which have the additional advantage of reducing the flame size and hence the extent of buoyancy experienced by the flame. Results from such a study show that while $d_{s}^{2}$ still varies approximately linearly with time, the behavior of the flame diameter completely disagrees with the $d^{2}$ law prediction. ${ }^{8}$ Specifically, the flamefront standoff ratio $d_{f} / d_{s}$ continuously increases with time for low to moderate ambient oxygen concentrations, but increases and levels off for higher ambient oxygen concentrations (Fig. 33). This behavior has recently been substantiated by experiments conducted at $\mu \mathrm{g} .{ }^{171,172}$ Theoretical results ${ }^{8}$ showed that this behavior is caused by transient phenomena, that have been called "fuel vapor accumulation effects." That is, at the moment of ignition, the amount of fuel vapor in the region interior to the flame is low compared with the $d^{2}$ law value, being constrained by the amount which existed for the vaporizing droplet prior to ignition. Thus, subsequent to ignition, only part of the fuel that is gasified is used to support burning at the flame, the rest is used to build up the fuel vapor concentration in the inner region of the flame. The flame diameter consequently grows with increasing amounts of fuel vapor accumulation. The growth of $d_{\mathrm{f}} / d_{\mathrm{s}}$ continues with time for low ambient oxygen levels where the flame is relatively large, while it levels off for higher ambient oxygen levels where the flame is relatively small and 


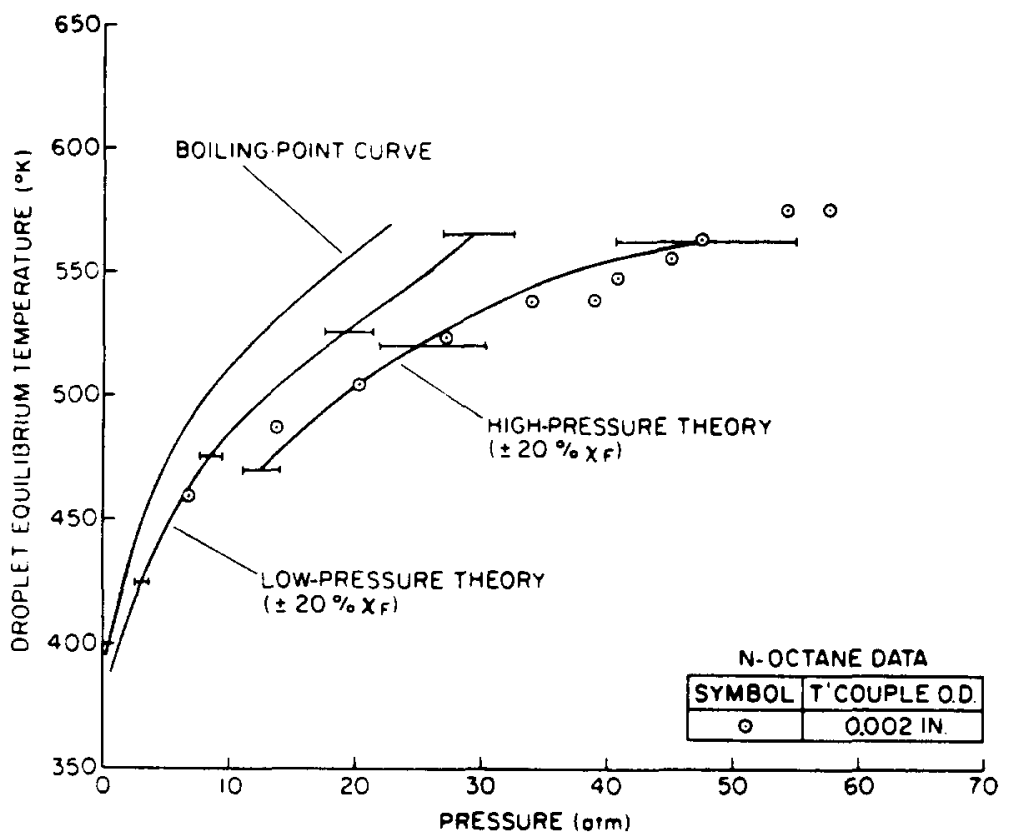

FIG. 34. Theoretical and experimental steady-burning temperatures of $n$-octane drops burning in air at low gravity conditions. From Lazar and Faeth. ${ }^{174}$

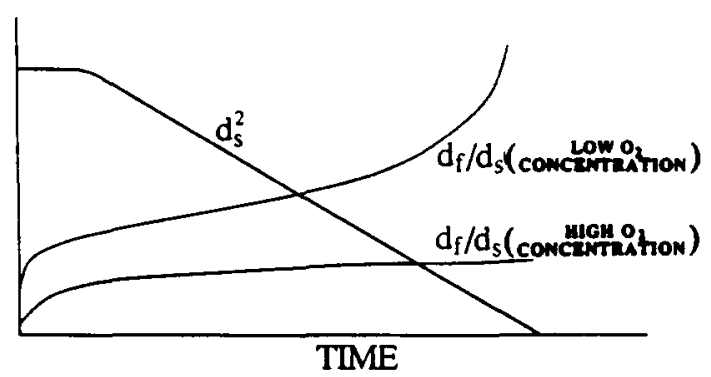

FIG. 33. Behavior of spherically symmetric drop combustion demonstrating the effect of fuel vapor accumulation on flame sheet location.

there is less need for fuel vapor accumulation. The phenomenon can be completely described by considering gas-phase quasisteadiness, treating the fuel vapor accumulation process at the same slow timescale as that of droplet surface regression. Indeed, by suppressing fuel vapor accumulation, through the use of the $d^{2}$ law concentration profile as the initial condition, a separate analysis ${ }^{173}$ allowing for gasphase transient diffusion shows that fuel vapor accumulation has only minor influence on the flame response. Further discussion of this effect can be found in Ref. 168.

Gas-phase unsteadiness is also important during droplet vaporization and combustion in high-pressure environments when effects of forced convection are absent, because the droplet approaches its thermodynamic critical point where the liquid and gas densities are comparable. When the liquid reaches or exceeds its critical point, liquid properties are lost, the droplet acts like a puff of gas, and it is meaningless to talk of droplet combustion. Experiments at low gravity have been used to identify droplet properties at high pressures and the conditions for the onset of supercritical combustion. ${ }^{174}$ These experiments involved igniting droplets within a pressure vessel at various ambient oxygen concentrations and using a free-fall facility to provide low-gravity conditions. It was found that the increased solubility of the liquid to gases at its surface at high pressures has an important effect on droplet surface properties and the conditions required for supercritical combustion. Some typical results are illustrated in Fig. 34, which is a plot of the liquid temperatures during the steady burning phase (where the droplet has reached its wet bulb temperature) as a function of the ambient pressure for $n$-octane droplets burning in air. The plot includes measured liquid temperatures, the standard boiling point curve and predictions both ignoring (low-pressure theory) and considering (high-pressure theory) effects of dissolved gases in the liquid. The plots are terminated at high pressures at the point where supercritical combustion conditions are reached. The high-pressure theory is in reasonably good agreement with the measurements, and shows that the dissolved gases tend to reduce liquid temperatures at each pressure. Additionally, the dissolved gases also tend to increase the ambient pressure required for the droplet to exceed its thermodynamic critical point, beyond both the critical pressure of the pure fuel and the predictions of the low-pressure theory. ${ }^{174}$

Effects of unsteady combustion in convection-free environments at high pressures have also been stud- 


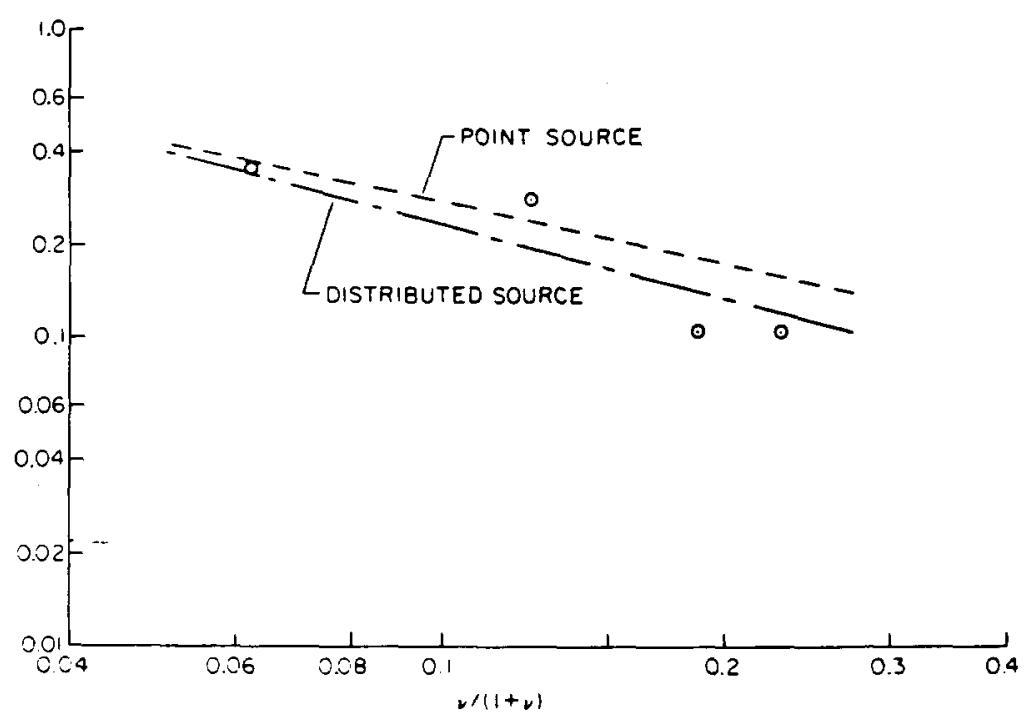

FIG. 35. Supercritical combustion lifetimes of $n$-decane at $68 \mathrm{~atm}$, as a function of stoichiometric parameter (corrected to an initial drop diameter of $0.875 \mathrm{~mm}$ ). From Faeth et al. ${ }^{175}$

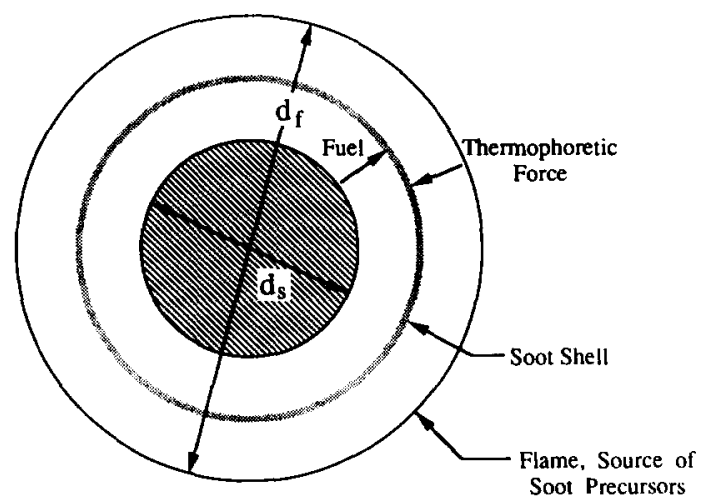

FIG. 36. Schematic showing the soot formation phenomenon during combustion at $\mu \mathrm{g}$.

ied at low-gravity conditions, using a pressure vessel in a free-fall facility. ${ }^{175}$ Combustion lifetimes (defined as the time between the droplet exceeding its thermodynamic critical condition and the end of combustion) were measured at high pressures where most of the combustion process occurs after the droplet exceeds its thermodynamic critical point. These measurements were compared with predictions of Spalding ${ }^{176}$ and Rosner, ${ }^{177}$ who treated unsteady combustion from point and distributed sources of fuel vapor, respectively. Predicted and measured results for $n$-decane droplets at $68 \mathrm{~atm}$. and various ambient oxygen concentrations are illustrated in Fig. 35, where $\nu=Y_{\mathrm{O}_{\infty}} / \sigma$, and $\sigma$ is the stoichiometric mixture ratio. The distributed source theory yields better agreement with the measurements, but there is little to choose between the two in view of uncertainties in estimating transport properties in flame environments. Additionally, predictions of the maximum flame radius during combustion were in good agreement with measurements for various ambient oxygen concentrations and pressures. ${ }^{175}$ Subsequently, additional experiments on high-pressure droplet combustion at $\mu \mathrm{g}$ have been completed, as well as the development of advanced theories allowing for unsteady and real-gas effects in both cases (see Shuen et al. ${ }^{178}$ and Faeth $^{179}$ for discussion of this work). These reviews indicate that much remains to be done to resolve the thermochemical and transport issues of droplet vaporization and combustion at the near-critical and supercritical conditions that are relevant to numerous high-pressure combustion processes. Thus, significant opportunities remain to exploit the demonstrated capabilities of combustion at $\mu \mathrm{g}$ for studies of high-pressure droplet combustion phenomena.

Recent $\mu \mathrm{g}$ experiments ${ }^{180-182}$ have also revealed an unexpected, interesting aspect of droplet combustion, namely the formation of a soot layer between the droplet and the flame (Fig. 36). This phenomenon is caused by the back-diffusion of soot particles that are formed near the flame toward the droplet as a result of thermophoresis. Since this back-diffusion is opposed by the outwardly-transported fuel vapor, the soot particles eventually stagnate before reaching the droplet surface. The continuous accumulation of these soot particles eventually forms the shell as observed. The role of gravity here is apparent: soot layer formation, as seen at $\mu \mathrm{g}$, has not been observed at $\mathrm{ng}$ for envelope flames, with such 'clean-burning' hydrocarbons as $n$-heptane in the presence of even very weak convective motion. Apparently the weak convection continuously sweeps the soot precursors and particles towards the flame segment in the wake on the leeward side of the droplet, causing their burnout. ${ }^{183}$ This phenomenon can have a profound 
influence on our understanding of soot formation with and without external convection. It is also of interest to reassess the sooting tendencies of those fuels which are usually considered to be nonsooty.

Another interesting phenomenon observed during recent $\mu \mathrm{g}$ single-component droplet combustion is that the droplet burning rate appears to be substantially lower than previously observed. Specifically, the classical result of Kumagai et al. ${ }^{170}$ showed that the burning rate constant of $n$-heptane droplets in air is $0.78 \mathrm{~mm}^{2} / \mathrm{s}$, while the recent determination ${ }^{181}$ showed a lower value of around $0.6 \mathrm{~mm}^{2} / \mathrm{s}$, which also decreases with increasing initial droplet size. ${ }^{184}$ The tentative explanation for this burning rate retardation is that soot formation acts as a chemical heat sink in reducing the total amount of fuel mass to be oxidized, and that the soot shell could also act as a partial barrier for heat transfer from the flame to the droplet surface. The fact that Kumagai et al. ${ }^{170}$ obtained a higher burning rate, and indeed did not observe any soot shell at all in their $\mu$ g experiments, was postulated to be caused by the dispersion of the soot particles by the convective motion formed when the suspension fiber was abruptly pulled at the start of their particular experiment. Results of this nature demonstrate the sensitivity of $\mu \mathrm{g}$ experiments to small currents of air movement and the care needed to prevent their occurrence.

Spherically-symmetric droplet combustion also serves as a good model problem for the study of diffusion flame reaction kinetics. ${ }^{185-188}$ Recently there has been considerable effort to extract fundamental kinetic information by comparisons between theoretical and experimental results for certain flame processes. The accuracy of these comparisons, however, is frequently compromised by inaccurate descriptions of the flow field. This difficulty does not exist for the simple spherically-symmetric droplet combustion configuration. Since droplet burning is basically diffusion controlled, kinetic effects are best manifested by the ignition and extinction events. In particular, recent studies at $\mu \mathrm{g}$ have made frequent observations of drop extinction before all the liquid has evaporated. ${ }^{172,182,187,188}$

A complication that can result from droplet studies of flame kinetics is the potential influence of liquidphase processes on gas-phase behavior. For example, when methanol is used as the fuel, it can potentially dissolve the water generated at the flame. ${ }^{190,191}$ Thus, shortly after ignition, the droplet becomes a bicomponent mixture, whose amount and spatial distribution are not only unknown but also vary with time. While these quantities could conceivably be determined by numerical simulation, it is difficult to be quantitatively accurate due to the uncertainties of liquid-phase transport properties. Due to the complications as a result of water dissolution, the reliability of determining the gas-phase kinetics is correspondingly compromised.

A droplet ignition study at $\mu \mathrm{g}$ has also been con- ducted by rapidly submerging a drop in a heated gas within a furnace, with the apparatus contained in a free-fall facility, yielding ignition delay times for various liquid fuels and ambient conditions. ${ }^{192}$ This test configuration provides a convection-free environment that simplifies both kinetic analysis and the interpretation of measurements which deserves additional consideration.

Several $\mu \mathrm{g}$ multicomponent droplet combustion programs are also currently underway. The most important factors which distinguish multicomponent droplet combustion from pure liquid droplet combustion are that the volatility differentials among the various components are an essential factor, and that liquid-phase mass diffusion can be very slow compared with either the surface regression rate or liquid-phase thermal conduction. ${ }^{168.193 .194}$ The parameter which characterizes the efficiency of liquidphase mass diffusion is a Peclet number, $P e$, defined as the ratio of the surface regression rate to the liquid mass diffusivity. For droplet combustion, $P e$ is usually a large number because liquid-phase mass diffusivities are small. Consequently, after the initiation of gasification of an originally uniform droplet consisting of, say, two components having different volatilities, there exists an initial period when the volatile component in the surface layer is preferentially gasified and the droplet temperature is controlled by the boiling point of this volatile component. This preferential gasification, however, will eventually slow down due to the reduction of the volatile concentration in the surface layer and the extremely slow rate with which it can be replenished from the core of the droplet. A steady state will then be reached at which the rate of supply of the components is equal to the rates with which they are vaporized. Furthermore, since the surface is now more concentrated with the less volatile, higher-boilingpoint component, the droplet temperature will also become correspondingly higher. It is therefore clear that between the initial and the steady states a transition droplet heating period must exist, during which the droplet temperature increases while the droplet gasification rate becomes slower because most of the heat it receives is now diverted to effect droplet heating.

Experimental results at ng, but for weakly-convective situations, substantiate this three-stage behavior. ${ }^{195.196}$ Figures 37 and 38 respectively show the variations of $d_{\mathrm{s}}^{2}$ and the normalized flame diameter with time for a bicomponent droplet initially consisting of $70 \%$-heptane and $30 \%$-hexadecane. The existence of the transition heating period, characterized by a slow gasification rate and a simultaneous shrinking of the flame diameter, is particularly noteworthy. The above behavior has also been observed during recent microgravity experiments. ${ }^{197}$

The combustion of multicomponent droplets is sometimes accompanied by a microexplosion phenomenon, which involves either mild fragmentation 


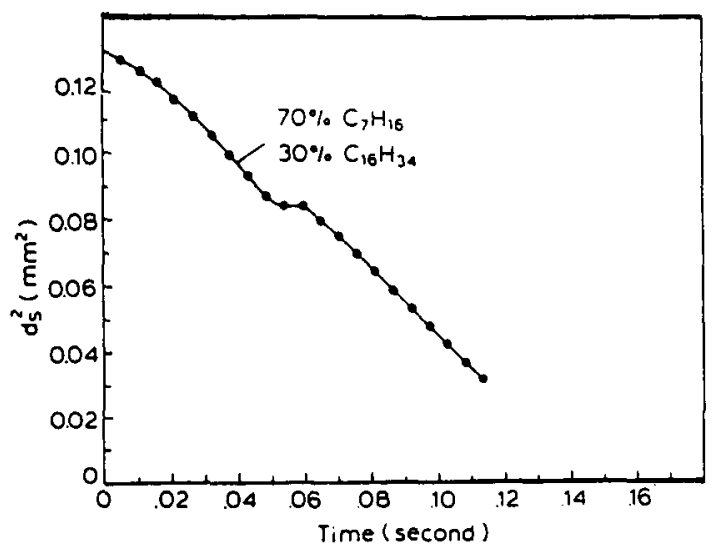

FIG. 37. Temporal variation of the droplet diameter for heptane-hexadecane droplets burning in air. From Wang et al. ${ }^{195}$

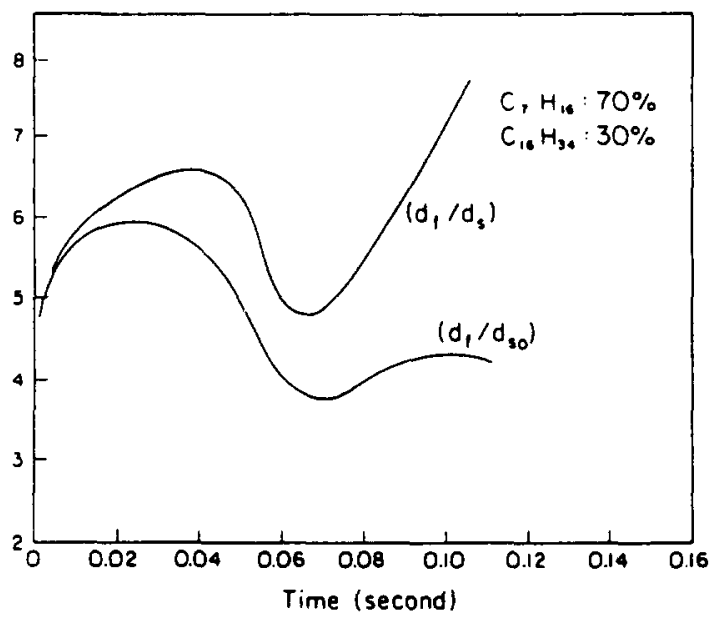

FIG. 38. Temporal variations of normalized flame-diameter $\left(d_{\mathrm{f}} / d_{\mathrm{so}}\right)$ and the flame-front standoff ratio $\left(d_{\mathrm{f}} / d_{\mathrm{s}}\right)$ for a $70 \%$ heptane- $30 \%$ hexadecane droplet burning in air. From Wang et al. ${ }^{195}$

or violent rupturing of the droplet as it burns. The fundamental cause of microexplosion is the superheating of the more volatile components trapped in the inner core of the droplet whose temperature is controlled by the higher boiling points of the less volatile components. Thus, when these more volatile components are locally heated to the limit of superheat, instantaneous gasification and thereby droplet rupturing occurs. The tendency to microexplode has been experimentally observed at ng, but with weakly-convective environments, ${ }^{198}$ to increase with increasing system pressure, due to the corresponding increase of the liquid boiling point and the nonideality of the mixture. These results were again recently confirmed by $\mu \mathrm{g}$ experiments. ${ }^{199}$

A heterogeneous burning problem which is somewhat similar to droplet combustion is the candle flame, ${ }^{200,201}$ in which a diffusion flame is established between the inwardly-diffusing oxidizer gas and the outwardly-diffusing vaporized wax. Since the length of the wick is fixed, the phenomenon is basically steady, in contrast with quasisteady droplet burning situations in which the droplet size continuously shrinks. At $\mu \mathrm{g}$, the flame appears to be somewhat spherical, in spite of the axisymmetric nature of the fuel source, probably due to the large flame size in comparison with the length of the wick. However, the soot shell which was present for the droplet flame was not observed for the $\mu \mathrm{g}$ candle flame. More experiments are needed to draw conclusions about the characteristics of these flames.

The combustion of metals at $\mu \mathrm{g}$ has also received some attention, motivated by concerns about hazards associated with high-pressure oxygen systems in space applications. ${ }^{202}$ This work involved the combustion of rods of aluminium alloy, stainless steel alloy, iron and titanium, as well as sheets and meshes of stainless steel alloy. Combustion was studied in pure oxygen at various pressures. The experiments involved upward propagation at $\mathrm{ng}$, in order to avoid irreproducible results due to molten metal flowing along the sample surface, as well as tests at $\mu \mathrm{g}$. The combustion of these materials involves the formation of molten balls at the end of the sample, which serve as the fuel source for the flame. It was found that the regression rate of the melting interface was significantly greater at $\mu \mathrm{g}$ than $\mathrm{ng}$ and that some sample shapes, such as thin sheets, that extinguish at $\mathrm{ng}$ burn to completion at $\mu \mathrm{g}$. Much remains to be done, however, in order to exploit the use of $\mu \mathrm{g}$ to study metal combustion: in particular, the high melting and boiling points of metals and their combustion products, their capabilities to form complex condensed phase mixtures, and the variety of combustion mechanisms for various metal-oxidant combinations, provides a host of theoretical and experimental problems.

The combustion of solid materials other than metals has received only limited attention at microgravity, for example, the study of the combustion of carbon rods by Spunkler, ${ }^{203}$ and additional work should be encouraged. In particular, investigation of solid particle combustion, analogous to drop combustion, should provide valuable background information needed to gain an understanding of more complex processes such as flame spread along surfaces and heterogeneous flame propagation through suspensions.

\section{SPACECRAFT FIRE SAFETY}

\subsection{Introduction}

The previous discussion has amply demonstrated that the flame spread rates and flammability limits at $\mu \mathrm{g}$ and $\mathrm{ng}$ are not the same, and that information gained during ng studies may not be accurately transferable to $\mu$ g situations even as limiting case 
criteria. For example, no solid or liquid material has yet been studied to find the lean flammability limits (or the limiting oxygen concentration for flame propagation) in all the obvious configurations, for example, upward and downward flame spread at ng, and quiescent, opposed and concurrent flow at $\mu \mathrm{g},{ }^{204}$ therefore, it has not been possible to quantitatively demonstrate the relationship between fire safety properties at $\mathrm{ng}$ and $\mu \mathrm{g}$. Furthermore, $\mu \mathrm{g}$ flame sizes are expected to be large while the environment on board manned space facilities such as the space station is compact, both of which tend to aggravate the consequence of a fire. Thus, specific information relevant to spacecraft fire safety is discussed in the following, treating flame-inhibiting atmospheres, fire detection and fire extinguishment, in turn.

\subsection{Flame-Inhibiting Atmospheres}

The control of fires within isolated inhabited compartments such as spacecraft, aircraft cabins, submarines, medical chambers, etc. involves novel problems in comparison with conventional systems. $^{205-218}$ In particular, any fire must be prevented or extinguished in a way that does not endanger the occupants, interfere with operations, or damage operating systems in a very confined environment. This is particularly critical for spacecraft operations because the occupants may have to live and function in the postfire environment for a considerable period of time. Some of the problems of fire control for these circumstances will be considered subsequently; the following discussion will address available tactics for the prevention of fires, emphasizing the potential use of flame-inhibiting atmospheres that might be able to entirely eliminate fire hazards in spacecraft.

The most common method of fire control is to eliminate potential ignition sources and to select materials that minimize the risk of incidence of fires, for example, 'design to preclude' fire. ${ }^{207,211}$ This is effective up to a point, however, the potential for fires cannot be completely eliminated in this manner and the required modifications of system design and materials are costly and inevitably involve excessive compromises of performance and flexibility of spacecraft operations. ${ }^{205,207}$ These problems will only increase as the exploitation of space proceeds and a greater range of manned spacecraft operations are undertaken. Thus, more effective alternatives must be sought.

The fact that the environment within spacecraft is completely under human control offers a novel approach toward avoiding fires by using flame-inhibiting, or 'fire-safe,' atmospheres as an approach toward design to preclude. In particular, a property of fire-related phenomena is that they tend to be functions of the fractional amount of oxygen in the atmosphere. In contrast, human comfort and performance seem to depend mainly on the absolute amount of oxygen in the atmosphere (or the oxygen partial pressure). Thus, the potential exists to find a composition of the atmosphere that will not support combustion but that will support normal human activities indefinitely. This approach has been advocated by Carhart, ${ }^{208}$ based on experience with undersea systems such as submarines and Sealab. ${ }^{3}$

Underwater systems provide several examples of fire-safe atmospheres. ${ }^{207,208.210}$ For example, the atmosphere within Sealab was rendered completely fire safe by pressurizing the vehicle to 7 atm., while keeping the partial pressure of oxygen at the standard sea level value of $0.21 \mathrm{~atm}$. This reduced the oxygen mole fraction to only $3 \%$, which is well below flammability limits, both on Earth and in space. This was a very natural solution for Sealab because normal operations required the pressurized atmosphere in any event; however, this specific technique is not immediately transferrable to spacecraft, where similar pressure increases would cause substantial structural weight penalties. Nevertheless, it seems likely that similar fire-safe atmospheres, having operationally acceptable properties, can be found for spacecraft. They certainly should be sought due to the enormous advantages of eliminating fire hazards for manned space activities, with minimal limitations on materials properties.

Fire-safe atmospheres for spacecraft would be unique from other applications; nevertheless, existing information on flammability limits, studies of firesafety parameters such as minimum oxygen indices, and specific studies of flame-inhibiting atmospheres, can provide some general guidelines.,205-211 For example, the flame spread limit illustrated in Fig. 29 for thin fuels at $\mu \mathrm{g}$ is roughly $15 \%$ oxygen by volume. On the other hand, it is generally agreed that an oxygen partial pressure of $16.5 \mathrm{kPa}$, equivalent to an altitude of $1800 \mathrm{~m}$, is acceptable for long-term human activities, ${ }^{211}$ for example, such conditions are comparable with those of high-altitude cities such as Mexico City and Denver. Thus, satisfying both requirements with an oxygen-nitrogen atmosphere would imply a total pressure of $118 \mathrm{kPa}$. Another reduced oxygen atmosphere was identified by studies sponsored by the Navy that showed acceptable performance of spacecraft crews in an atmosphere having an oxygen partial pressure and mole fraction of $16.0 \mathrm{kPa}$ and $11 \%{ }^{212}$ This mole fraction is thought to retard most fires, based on ng data, and would require a total pressure of $145 \mathrm{kPa}$. These reduced-oxygen atmospheres are not major departures from the atmosphere planned for space stations; namely, air at atmospheric pressure $(101.3 \mathrm{kPa}) .^{213}$ Naturally, these prescriptions are only suggestive because limited data for a single material and ignition mode, etc. such as the results of Fig. 29, or test results limited to ng, are certainly not sufficient to make a judgement concerning fire-safe ambient oxygen mole fraction levels at 
TABLE 2. Fire-safe atmosphere tests at atmospheric pressure

\begin{tabular}{|c|c|c|c|c|}
\hline $\begin{array}{l}\mathrm{O}_{2} \\
(\% \text { by vol })\end{array}$ & $\begin{array}{c}\text { Inert } \\
\text { (\% by vol) }\end{array}$ & $\underset{\left(\mathrm{kJ} / \mathrm{kg} \mathrm{O} \mathrm{O}_{2} \mathrm{~K}\right)}{C_{\mathrm{p}}}$ & Fuel & Remarks \\
\hline 40.5 & $59.5 \mathrm{C}_{2} \mathrm{~F}_{6}$ & 5.77 & filter paper & ignition flame only \\
\hline 21.1 & $20.2 \mathrm{C}_{2} \mathrm{~F}_{6}, 58.9 \mathrm{He}$ & 5.91 & $\begin{array}{l}\text { filter paper } \\
\text { raw cotton } \\
\text { polyurethane foam }\end{array}$ & ignition flame only \\
\hline 21.0 & $10.0 \mathrm{C}_{4} \mathrm{~F}_{6}, 69.0 \mathrm{He}$ & 5.68 & filter paper & ignition flame only \\
\hline $21.0^{\mathrm{b}}$ & $21.0 \mathrm{C}_{2} \mathrm{~F}_{6}, 69.0 \mathrm{~N}_{2}$ & 6.68 & $\begin{array}{l}\text { filter paper } \\
\text { cotton cloth } \\
\text { polyurethane foam } \\
\text { kerosene }\end{array}$ & ignition flame only \\
\hline 16.9 & $19.0 \mathrm{CF}_{4}$ in air & 6.49 & cotton flannel & no combustion \\
\hline 18.4 & $12.0 \mathrm{C}_{2} \mathrm{~F}_{6}$ in air & 6.49 & cotton flannel & no combustion \\
\hline 19.0 & $9.0 \mathrm{C}_{3} \mathrm{~F}_{8}$ in air & 6.51 & cotton flannel & no combustion \\
\hline 17.8 & $15.0 \mathrm{CF}_{4}$ in air & 5.95 & kerosene & no combustion \\
\hline 19.2 & $8.0 \mathrm{C}_{2} \mathrm{~F}_{6}$ in air & 5.72 & kerosene & no combustion \\
\hline 19.4 & $7.0 \mathrm{C}_{3} \mathrm{~F}_{8}$ in air & 5.99 & kerosene & no combustion \\
\hline
\end{tabular}

"From Huggett. ${ }^{205}$

${ }^{b}$ Electrically heated solid rocket propellant as ignition source; remainder ignited using an electricallyfired match.

$\mu \mathrm{g}$. Additionally, there are numerous human factors, and spacecraft design and operational requirements, that must be taken into account. Nevertheless, these very preliminary results do suggest that potentially fire-safe atmospheres may not be particularly unusual or hard to provide.

Research carried out by Huggett ${ }^{205,206}$ provides other general guidelines for selecting fire-safe atmospheres. In particular, he found that flame spread over solid surfaces could be correlated with the heat capacity of the gaseous environment per mole of oxygen, and that when this heat capacity reached the range $5-6 \mathrm{~kJ} / \mathrm{kg} \mathrm{O} \mathrm{O}_{2} \mathrm{~K}\left(40-50 \mathrm{cal} / \mathrm{g} \mathrm{mol} \mathrm{O}_{2} \mathrm{~K}\right)$ organic fuels ceased to burn at atmospheric pressure. This prompted the study of fully fluorinated compounds of carbon as diluents for suppressing combustion because they have unusually high heat capacities among known inert gases. ${ }^{205}$ Table 2 gives a summary of data on atmospheres that did not support combustion for various fuel samples ignited by either an electrically fired match, or a small piece of solid propellant, placed at the bottom of the sample at atmospheric pressure. All of these mixtures are characterized by a specific heat capacity in the range 5.7$6.7 \mathrm{~kJ} / \mathrm{kg} \mathrm{O} \mathrm{O}_{2} \mathrm{~K}$, while mixtures having lower specific heats sustained combustion. The results also indicate flexibility for meeting the specific heat criterion: some mixtures involved $\mathrm{O}_{2}$ concentrations greater than normal atmospheric levels, while the use of helium as a diluent yielded overall molecular weights and densities similar to normal air. Additionally, limited testing with animals-mice, rats, rabbits and dogsdid not indicate significant physiological problems when subjected to at least some of these environments. ${ }^{205}$ Other saturated fluorine compounds, such as sulfur hexaftuoride, offer similar advantages. ${ }^{207} \mathrm{~A}$ potential problem with fully fluorinated compounds, similar to those listed in Table 2, however, involves potentially harmful emissions of $\mathrm{HF}$ in the confined fire environments of spacecraft. ${ }^{215}$
The previous results suggest that there is potential for fire-safe atmospheres with acceptable properties for spacecraft operations. However, available information is woefully inadequate in view of the importance of this selection. Obvious test variables such as fuel type, fuel configuration, method of ignition, ignition energy, flow properties, the presence of a $\mu \mathrm{g}$ environment, and the effect of total pressure have not been examined. Furthermore, fundamental understanding of flammability is incomplete so that extrapolation of limited data is unreliable, as discussed earlier. Finally, effects of fire-safe atmospheres on the performance and health of humans and other biological systems, on the quality of voice communications due to changed acoustic properties, and on spacecraft design and operations, certainly have not been adequately evaluated. In view of the potential importance of fire-safe atmospheres to manned space flight, however, this problem clearly merits a comprehensive interdisciplinary research program involving specialists in combustion, space medicine, human performance, and spacecraft design and operations, in order to resolve these issues. This task represents long-term research and it is doubtful that the results could apply to current plans for Space Station Freedom where the decision to use air at atmospheric pressure was made some time ago, based on a desire to have an atmosphere similar to sea level air so that ng ground data can be compared directly with $\mu \mathrm{g}$ flight data (see J. H. Kimzey in Appendix C of Ref. 218). Nevertheless, it would be desirable to gain a better understanding of fire-safe atmospheres for application to manned space activities in the future.

\subsection{Fire Detection and Extinguishment}

Problems of fire detection and extinguishment in spacecraft have been recognized for some time, 
prompting several recent studies and reviews of this technology (see Refs 207 and 214 and references cited therein). Methods of fire detection have progressed from the crew serving as fire detectors during the first manned space programs, to multiple ionization smoke detectors in the Space Shuttle, to proposals for multiple smoke, UV flame and thermal detectors for Space Station Freedom. ${ }^{207}$ The main concerns are the slow rate of response of detectors at $\mu \mathrm{g}$ (except for radiation sensors), the modified convection patterns of flames at $\mu \mathrm{g}$ as opposed to $\mathrm{ng}$, and the requirements for high sensitivity to compensate for the relatively slow response of $\mu \mathrm{g}$ environments to smoldering and flames. Locating detectors to exploit the spacecraft ventilation system helps to mitigate these difficulties to some extent, but fault conditions where the ventilation system is inoperative, must still be addressed. Finally, the technology base for fire detection in spacecraft is very limited due to the difficulties and costs of arranging full-scale tests at $\mu \mathrm{g}$.

Problems of fire extinguishment in the confined environment of spacecraft were mentioned earlier in connection with fire-safe atmospheres. Thus, the use of techniques developed for underwater applications, by temporarily flooding the environment with an inert atmosphere, deserve consideration. ${ }^{207,208,210}$ For example, Halon 1301 effectively prevents flammability at concentrations less than $6 \%$. Additionally, Navy applications, where fluorinated compounds are not acceptable due to problems with the life support system, have used nitrogen flooding for years. ${ }^{208.210}$ A better understanding of systems of this type for spacecraft at $\mu \mathrm{g}$ is closely related to research on firesafe atmospheres, and merits study on the same basis.

Fire extinguishing systems on early manned spacecraft were primitive, involving the backup use of the water dispenser and aqueous gels. ${ }^{207}$ This has evolved to multiple Halon 1301 dispensers on the Space Shuttle, similar to aircraft fire protection systems. ${ }^{207,214}$ Unfortunately, Halon 1301 is less effective for smoldering fires (which are a common scenario for fires in spacecraft) and presents environmental problems due to emissions during groundbased activities (alternatives are being sought for aircraft as a result), as well as potentially harmful postfire emissions of $\mathrm{HBr}$ and $\mathrm{HF}^{215}$ The use of other gases, such as carbon dioxide which has been proposed for the space station, and venting the space where combustion is occurring, are being studied. Problems with less effective extinguishing agents, or venting, involve enhanced combustion, at least for a short time, due to increased convection from forced flows associated with the operation of these systems. ${ }^{207}$ Thus, much remains to be done in order to establish a proper technology base for fire extinguishment on board spacecraft, even for relatively near-term applications such as the Space Station.

\section{MICROGRAVITY FACILITIES}

\subsection{Introduction}

Experimental research under controlled gravity conditions is constrained in many ways. The most obvious constraints are the small number of facilities that can provide low gravity conditions, the long development times required to prepare experiments for these facilities, the large costs associated with the use of the most flexible facilities, the limitations concerning the instrumentation that can be used, the available test times at low gravity, and the availability of the facility to experimenters. These issues, as well as the capabilities of available facilities, will be discussed in the following sections, considering drop towers, aircraft facilities, sounding rockets and spacecraft, in turn.

\subsection{Drop Towers}

Drop towers provide the easiest access to a $\mu \mathrm{g}$ environment and many facilities of this type have been developed by individual workers. These facilities generally involve test times less than $1 \mathrm{~s}$, which require free-fall distances less than $5 \mathrm{~m}$. The capabilities of drop towers to sustain low-gravity conditions varies with the specific design, but it is not difficult to achieve values smaller than $10^{-3} \mathrm{~g}$. Improved performance can be obtained by using a drag shield, where the actual test chamber falls within an outer freely falling chamber so that the relative velocities of the test chamber, and thus the drag forces, are minimized. A simpler approach, acceptable when only short test times are needed, is a short-drop tower where a drop shield is often not needed, for example, a $1.2 \mathrm{~m}$ free-fall distance that involves relatively small drag forces can provide $0.5 \mathrm{~s}$ test times at good low-gravity levels.

Longer test times require more sophisticated facilities with drop towers at NASA Lewis and elsewhere in the United States and Europe providing 2-5 $\mathrm{s}$ at $\mu \mathrm{g}$ down to $10^{-4}-10^{-6} \mathrm{~g}$, and a new facility in Japan providing $10 \mathrm{~s}$ test times at similar conditions (see Lekan $^{216}$ for a detailed description of major droptower facilities available in the United States). Additionally, these facilities can provide substantial test chamber volumes $(10-1000 \mathrm{~L})$. A disadvantage of most free-fall facilities having longer test times, however, is that the test apparatus is subject to a considerable shock load, of the order of $100 \mathrm{~g}$, at the end of a drop test. The $10 \mathrm{~s}$ drop tower in Japan is an exception, however, and has relatively modest deceleration rates.

The facilities at NASA Lewis are representative of drop-tower technology for test times in excess of $2 \mathrm{s.}^{5,216}$ Designs of test chambers, plumbing systems, data acquisition and control electronics, and filmand video-based imaging equipment are mature for 
this environment, and a number of somewhat standard test rigs are being used in both 2.2 and $5 \mathrm{~s}$ drop towers. Quiescent chambers with volumes of $\sim 40 \mathrm{~L}$ are available in which various atmospheric mixtures up to more than $2 \mathrm{~atm}$. pressure can be formulated. These chambers have optical access principally designed for photography and video records and have electrical connections for conventional transducers. A combustion tunnel is being used in the $2.2 \mathrm{~s}$ drop tower. The tunnel provides an unvitiated blowdown flow of preformulated atmospheres at $1 \mathrm{~atm}$. pressure, and flat inlet velocity profiles having velocities of $0-300 \mathrm{~mm} / \mathrm{s}$. The tunnel has been used for flame spreading experiments with solid fuels, but could be adapted for experiments in other combustion systems. The tunnel provides orthogonal views across the $200 \mathrm{~mm}$ diameter test section, which have been used for visualizing flames and cold forced flow. Development of a tunnel for the $5 \mathrm{~s}$ drop tower has been initiated.

Due to the rather severe impact loads, adapting common optical diagnostic methods to drop-tower experiments has been slow. Currently, workers at NASA Lewis are attempting to introduce a rainbow schlieren technique into a drop-tower package. Similar to conventional schlieren photography, refractive index gradients are detected, but are encoded here as variations in visible wavelength rather than the lesssensitive variation in monochromatic intensity. Rainbow schlieren methods will provide a visualization technique for the refractive index fields of $\mu \mathrm{g}$ flames. If constituent, and temperature influences on density can be distinguished, then the method could be used as a quantitative measure of temperature fields. Measurement of sooting characteristics of $\mu \mathrm{g}$ flames are being pursued in drop-tower experiments at NASA Lewis with the introduction of simultaneous absorption-scattering measurements and cold-probe thermophoretic sampling of soot particles. These measurements are intended to provide spatially distributed measurements of soot particle number density and size distributions.

Velocimetry at $\mu \mathrm{g}$ is being attempted in drop-tower experiments at NASA Lewis that will use particle imaging velocimetry (PIV) methods. In PIV, a sequence of computer enhanced images of thin, laserilluminated sheets from within a flowfield are correlated to establish the path of seed particles and thereby their velocities. This method is limited in its ability to measure large velocities by the intensity of the illumination source and the sensitivity of the image detector. Current source and detector technologies were vulnerable to the impact loads experienced in the past in drop towers, which limited this measurement scheme to low-velocity flows (up to $100 \mathrm{~mm} / \mathrm{s}$ ) in, for example, liquid-fuel pools. Recently, however, drop rigs outfitted with shock isolation platforms have been developed, which reduce landing loads to $30 \mathrm{~g}$, a level that a wide array of commercial instrumentation can sustain without damage. Thus, a broader range of application of PIV, and other shock-sensitive instruments such as rainbow schlieren deflectometers, can be anticipated in the future.

Thus, at the current time, an interesting array of test facilities and instrumentation are available for $\mu \mathrm{g}$ combustion tests in drop towers, with more advanced laser diagnostics in the offing. A frustrating feature of these facilities, however, is that $2-10 \mathrm{~s}$ is a perilously short time to develop combustion processes and to achieve the steady-state conditions for combustion experiments that are easiest to interpret. This has prompted the development of aircraft and space facilities-in spite of their attendant costs and more limited availability.

\subsection{Aircraft}

Aircraft-based experiments provide longer durations for experiments without the impact loads seen in drop towers. However, aircraft are normally not able to execute adequately precise free-fall trajectories, and buoyant motion and other accelerative disturbances are usually not entirely suppressed. Thus, while aircraft experimentation is a valuable source of low-gravity test time, the test results generally only indicate trends with reduced buoyancy, and are not representative of true $\mu \mathrm{g}$ behavior. With the exception of a multiuser chamber developed by the European Space Agency, aircraft-based combustion experiments have generally been performed in test apparatus tailored to single programs. See Lekan ${ }^{216}$ for a description of aircraft $\mu \mathrm{g}$ facilities in the United States.

Perhaps because of the cost of operations and of designing man-rated experimental hardware for the aircraft, these facilities are just beginning to be exploited by combustion experimenters. While fundamental studies of all types may benefit from the extended test time available in aircraft, a major use involves the development of diagnostic techniques in order to extend initial work being done in the drop towers. The PIV method of quantifying two-dimensional flow fields can be enhanced by the introduction of intensified detector arrays for the low-g loads of aircraft, so that higher velocity flows can be observed. The intensified array cameras will also provide improved visualization of dim, near-limit flames, as well as potential for measurements of species concentrations when fitted with bandpass filters.

Another aspect of aircraft-based facilities that has been used to some extent by combustion workers is the ability to free-float experiment payloads within the cabin volume, and thereby reduce the ambient accelerations by at least an additional order of magnitude. Unfortunately, this advantage has been limited by problems of free-floating test containers striking objects during free flight due to the limited space available in the aircraft cabins. If this problem can 
be resolved, the aircraft facilities could provide an effective test platform for fundamental combustion studies. For the present, however, these facilities are best suited for the development of experimental techniques to be used during space-based tests. In particular, access to these facilities is reasonably good with each flight providing up to 40 test periods of $15-20 \mathrm{~s}$ duration.

\subsection{Sounding Rockets}

Sounding rockets can provide $200-900 \mathrm{~s}$ test times at low gravity, ca. $10^{-4} \mathrm{~g}$, which is sufficient to achieve steady-state conditions for most combustion systems. ${ }^{217}$ Facilities of this type have been exploited by the European Space Agency and are just coming into use in the United States for combustion experiments, with two experiments involving flame spread across liquids and solids, respectively, currently under development at NASA Lewis. Available test volumes are in the range $0.5-0.8 \mathrm{~m}^{3}$ with payloads of $200-300 \mathrm{~kg}$; however, generally only a portion of the space and weight is allocated to any one user. The available test period with sounding rockets is attractive but the experiment must withstand significant $\mathrm{g}$ forces $(10-40 \mathrm{~g})$ during takeoff and landing which places limitations on available instrumentation. There is also concern that acceleration levels will be impulsively raised by the rate control systems of the spin-stabilized rockets. Thus, while development of sounding rockets is to be encouraged as a possibly less expensive and more accessible facility than spacecraft, the value of this approach for $\mu \mathrm{g}$ combustion experiments has not been established at this time.

\subsection{Spacecraft}

Many combustion processes demonstrate the most interesting effects when the propagation velocities are at their lowest. This often occurs near the limit of flammability in terms of either fuel-air or oxygen-inert gas ratio. While ground-based experimenters have been creative in identifying systems that propagate quickly enough to observe lowgravity behavior in very short duration tests, most combustion processes will not be fully explored without the longer test times of low Earth orbit.

Condensed-phase fuels are limited during groundbased tests to very thin or shallow fuels, because conducted heat into the depth of the fuel retards the progress of the spreading flame. Consequently, experiments directed toward understanding the spreading of flames over thermally thick fuels, which represent nearly all engineering materials, cannot be attempted under any near-limit conditions in the ground-based facilities. While a series of engineering tests were conducted during the 1973-1974 Skylab era, ${ }^{218}$ the first flight experiments to provide extended duration flame spreading data compatible with modeling efforts have involved several solid-surface combustion experiments during recent Space Shuttle missions. The apparatus involves a quiescent chamber having a volume of $40 \mathrm{~L}$. The test samples consist of thermally thin ashless filter paper and thermally thick polymethylmethacrylate (PMMA), ignited by a hotwire filament coated with nitrocellulose, in selected gaseous environments. The facility is instrumented with two cameras to provide side and top views of the combustion process, thermocouples on and near the sample to measure solid and gas temperatures, and temperature and pressure sensors to monitor the chamber environment. The results are being used to evaluate theories emphasizing the mechanism of flame propagation. ${ }^{153,161-163}$

A second series of experiments on the space shuttle were flown in connection with the United States Microgravity Laboratory (USML) in July 1992 (USML-1), using a glove box facility. This arrangement provides a working and storage volume of $25 \mathrm{~L}$ and allows considerable interaction between the experiment operator and the apparatus using two glove ports. Instrumentation consists of video and film visualization, and pressure, temperature and gas composition sensors. Three combustion experiments were flown, as follows: smoldering combustion of polyurethane, the ignition and combustion of electrical wire insulation, and the combustion of candle flames. All three experiments were operated successfully but results at this stage are preliminary and further experience with the $\mu \mathrm{g}$ environment will be required to fully exploit the glove box facility.

Other experiments are being developed for flight testing in the late 1990s, involving gaseous premixed and diffusion flames, and drop diffusion flames. Developing experiments of this type for the manned space environment, however, is a long, complex and costly process. Additionally, flight opportunities are limited so that each experiment involves substantial risk. Thus, much remains to be done to achieve a more or less conventional laboratory environment allowing full exploitation of the long duration $\mu \mathrm{g}$, and the experiment-operator interaction, of manned space flight. As a result, the potential of reducedgravity environments to clarify fundamental concepts of combustion will remain incomplete for some time.

In summary, we feel that long-duration experiments at $\mu \mathrm{g}$ offer great potential for developing a fundamental understanding of combustion phenomena, and the technology base needed for fire-safe spacecraft operations. To achieve this potential, however, efforts need to be made to increase access to space for combustion experiments, which could involve the use of sounding rockets, Space Shuttle facilities involving minimal crew interaction, and unmanned orbiting spacecraft. In this regard, recent interest in exploiting sounding rockets by various space agencies-worldwide-should provide an opportunity to assess the potential of this resource for 
combustion experiments. The advantages of using such intermediate facilities with greater frequency would be to provide a means of developing combustion experiments for the unfamiliar $\mu \mathrm{g}$ environment, and thus reduce the risk and enhance the impact of the more complex and costly experiments using manned spacecraft.

\section{CONCLUDING REMARKS}

Historically, progress in combustion research can be divided into several periods. In the pre-1950s period, many of the basic combustion phenomenadeflagration and detonation waves, diffusion flames, flame quenching, flamefront instability, and chemical kinetic effects - were observed and attempts were made to describe them. The 1950 s was a truly robust period when the theory of aerothermochemistry was formulated and systematic study of various combustion phenomena was undertaken by a dedicated group of researchers. Combustion became a separate scientific discipline during this period. The period from the early 1960 s to the mid-1970s involved continued exploitation of this technology, with notable progress in environment and aerospace-related research. From the mid-1970s and throughout the 1980 s, combustion research was unusually active. These intensified activities were motivated by concerns about energy efficiency and environmental quality, and facilitated by the appearance of the various 'tools' needed for rigorous study. These tools included activation-energy asymptotics for analytical studies, computational advances for numerical studies, and laser-based diagnostics for experimental studies.

While sophisticated tools have been developed for combustion research, truly significant progress has been hindered by the lack of 'clean' and well-defined combustion and flame phenomena, through which individual processes can be isolated and studied in depth. A major cause of difficulty has been buoyancy. It is therefore not unrealistic to anticipate that the current interest in $\mu \mathrm{g}$ combustion, if sustained, could usher in the fifth period of combustion research, during which many of the fundamental issues of combustion and fire safety are finally resolved in a rigorous manner. The extremely interesting $\mu \mathrm{g}$ results reported here provide a strong indication of the potential. In order to accomplish this goal, however, experimental investigations will have to be conducted nonintrusively, most likely via optical diagnostics. For certain experiments sufficient run time also is needed in order to achieve a steady state and to perform an adequate number of tests to achieve statistically significant results. These requirements suggest that many more combustion experiments will have to be conducted on board sounding rockets, the Space Shuttle and future space stations, in order to fully realize the potential benefits of $\mu \mathrm{g}$ combustion research.
Finally, while $\mu \mathrm{g}$ offers new opportunities for fundamental studies of combustion phenomena, there now is ample evidence that our current understanding of fire and explosion hazards at ng has questionable relevance at $\mu \mathrm{g}$ conditions. This is a serious matter due to the extraordinary value of spacecraft facilities and the high visibility of accidents in space. Thus, there is strong motivation for a comprehensive program of fire research for spacecraft environments, to avoid both fire-related accidents and overly stringent fire safety regulations that could excessively increase the cost of spacecraft operations and limit capabilities for the beneficial exploitation of space. Among the fire safety issues that need to be addressed, the possibility of providing fire-safe spacecraft environments deserves greater priority than in the past. In particular, there may be a potential to leave Earth-bound fire hazards behind in the controlled environment of spacecraft, which has substantial implications for manned space activities. The feasibility of this potential must be understood by wideranging interdisciplinary research involving the effects of various environments on flame properties as well as the health and performance of humans and other organisms in these environments.

Acknowledgements-It is a pleasure to acknowledge useful inputs from H. D. Ross and K. Sacksteder of the NASA Lewis Research Center, M. K. King of the NASA Headquarters, P. D. Ronney of the University of Southern California and M. Y. Bahadori of the SAI Corporation. The authors' research in areas discussed in this paper has been sponsored by the NASA Microgravity Science and Applications Division (through the Lewis Research Center), the National Science Foundation, the Department of Energy, the Army Research Office, the Air Force Office of Scientific Research, the Office of Naval Research and the National Institute of Standards and Technology. The U.S. Government is authorized to reproduce and distribute copies of this article for governmental purposes notwithstanding any copyright notation thereon.

\section{REFERENCES}

1. Microgravity Combustion Science: A Program Overview, NASA TM 101424 (1989).

2. Microgravity Combustion Science: Progress, Plans and Opportunities, NASA TM 105410 (1992).

3. LAW, C. K., AIAA Paper No. 90-0120 (1990).

4. FAETH, G. M., AIAA/IKI Microgravity Science Symposium, Moscow, pp. 281-293, AIAA, Washington (1991).

5. SACKSTEDER, K., 23rd Symposium (International) on Combustion, pp. 1589-1596, The Combustion Institute, Pittsburgh (1990).

6. PoPE, S. B., 23rd Symposium (International) on Combustion, pp. 591-612, The Combustion Institute, Pittsburgh (1990).

7. Ostrach, S., Adv. Heat Trans. 8, 161 (1972).

8. Law, C. K., Chung, S. H. and Srinivasan, N., Combust. Flame 38, 173 (1980).

9. Kawakami, T., OKajima, S. and Iinuma, K., 23rd Symposium (International) on Combustion, pp. 16631667, The Combustion Institute, Pittsburgh (1990).

10. WU, M.-S., Kwon, S., Driscoll, J. F. and FAeTh, G. M., Combust. Sci. Technol. 73, 327 (1990). 
11. Wu, M.-S., Kwon, S., Driscoll, J. F. and Faeth, G. M., Combust. Sci. Technol. 78, 69 (1991).

12. Kwon, S., Wu, M.-S., Driscoll, J. F. and Faeth, G. M., Combust. Flame 88, 221 (1992).

13. Bray, K. N. C., Turbulent Reacting Flows, P. A. Libby and F. A. Williams (Eds), pp. 115-183, Springer-Verlag, Berlin (1980).

14. Peters, N., 21st Symposium (International) on Combustion, pp. 1231-1250, The Combustion Institute, Pittsburgh (1986)

15. LAW, C. K., 22nd Symposium (International) on Combustion, pp. 1381-1402, The Combustion Institute, Pittsburgh (1988).

16. Abraham, J., Williams, F. A. and Bracco, F. V. SAE Paper No. 850345 (1985).

17. Karlovitz, B., Denniston, D. K., Knappchafer, D. H. and WelLs, F. E., 4th Symposium (International) on Combustion, pp. 613-620, The Combustion Institute, Pittsburgh (1952).

18. Clavin, P., Prog. Energy Combust. Sci. 11, 1 (1985).

19. Tseng, L.-K, and FAETH, G. M., Combust. Flame, submitted.

20. Sivashinsky, G. I., Acta Astronautica 4, 1177 (1977)

21. Matalon, M. and Matkowsky, B. J., J. Fluid Mech. 124, 239 (1982)

22. Pelce, P, and Clavin, P., J. Fluid Mech. 124, 219 (1982).

23. Chung, S. H. and Law, C. K., Combust. Flame 75, 309 (1989)

24. Williams, F. A., Combustion Theory, 2nd edn, p. 135, Benjamin/Cummings, Menlo Park, CA (1985).

25. Kwon, S., Tseng, L.-K. and Faeth, G. M., Combust. Flame 90, 230 (1992).

26. Tseng, L.-K., Ishmall, M. and Faeth, G. M., Combust. Flame 95, 410 (1993).

27. Palm-leis, A. and Strehlow, R. A., Combust. Flame 13, 111 (1969).

28. Markstein, G. H., Non-Steady Flame Propagation, p. 22, MacMillan, New York (1964).

29. Fristrom, R. M., Phys. Fluids 8, 273 (1965).

30. Deshaies, B. and Cambray, P., Combust. Flame 82, 361 (1990).

31. TAYlor, S. C., Ph.D. Thesis, University of Leeds, 1991; see also, Dowdy, D. R., Smith, D. B., Taylor, S. C. and Williams, A., 23rd Symposium (International) on Combustion, pp. 325-332, The Combustion Institute, Pittsburgh (1990).

32. WU, C. K. and LAW, C. K., 20th Symposium (International) on Combustion, pp. 1941-1949, The Combustion Institute, Pittsburgh (1984).

33. LAW, C. K., ZHU, D. L. and YU, G., 21st Symposium (International) on Combustion, pp. 1419-1421, The Combustion Institute, Pittsburgh (1986).

34. ZHU, D. L., Egolfopoulos, F. N. and LAw, C. K., 22nd Symposium (International) on Combustion, pp. 1539-1545, The Combustion Institute, Pittsburgh (1988).

35. Law, C. K., Reduced Kinetic Mechanisms for Application in Combustion, B. Rogg and N. Peters (Eds), pp. 15-26, Springer-Verlag, Berlin (1993).

36. YamaOKA, I., and Tsuj, H., 20th Symposium (International) on Combustion, pp. 1883-1892, The Combustion Institute, Pittsburgh (1984).

37. Andrews, G. E., and Bradley, D. Combust. Flame 20, 77 (1973).

38. Searby, G. and Quinard, J., Combust. Flame 82, 298 (1990).

39. Warnatz, J. 24th Symposium (International) on Combustion, pp. 553-579, The Combustion Institute, Pittsburgh (1992).

40. ENG, J. A., ZHU, D. L. and LAw, C. K., 2nd Microgravity Combustion Workshop, NASA CP 10113, pp. 177-
182 (1993); see also, Eng, J. A., Law, C. K. and Zhu, D. L., AIAA Paper No. 94-057I (1994).

41. Lewis, B. and voN Elbe, G., Combustion, Flames and Explosions of Gases, p. 315, Academic Press, New York (1961).

42. Strehlow, R. A., Combustion Fundamentals, 2nd edn, p. 380, McGraw-Hill, New York (1984).

43. Sivashinsky, G. I., Ann. Rev. Fluid Mech. 15, 179 (1983).

44. Grofr, E. G., Combust. Flame 48, 51 (1982).

45. ZEL'Dovich, Y. B., The Theory of Combustion and Detonation, Academy of Sciences, Moscow (1944).

46. BarenblatT, G. I., Zel'Dovich, Y. B. and Istratov, A. G., Zh. Prikl. Mekh. Tekh. Fiz. 4, 21 (1962).

47. Sivashinsky, G. I., Combust. Sci. Technol. 15, 137 (1977).

48. Manton, J., von Elbe, G. and Lewis, B., J. Chem Phys. 20, 153 (1952).

49. Bregon, B., Gordon, A. S. and Williams, F. A., Combust. Flame 33, 33 (1978)

50. RaKib, Z. and Sivashinsky, G. I., Combust. Sci. Technol. 54, 69 (1987).

51. Вöнм, G. and Cuusius, K., Z. Naturforsch. A3, 386 (1948).

52. Kailasanath, K., Patnaik, G. and Oran, E. S., Paper No. IAF-88-354, 39th Congr. of Int. Astro. Fed., Bangalore (1988)

53. Patnaik, G., Kallasanath, K., Lasky, K. J. and ORAN, E. S., 22nd Symposium (International) on Combustion, pp. 1517-1526, The Combustion Institute, Pittsburgh (1988).

54. Patnaik, G. and Kailasanath, K., 23rd Symposium (International) on Combustion, pp. 1641-1647, The Combustion Institute, Pittsburgh (1990).

55. Patnaik, G. and Kailasanath, K., AIAA Paper No. 91-0784 (1991).

56. Patnaik, G. and Kailasanath, K., 24th Symposium (International) on Combustion, pp. 189-195, The Combustion Institute, Pittsburgh (1992).

57. Kailasanath, K., Patnaik, G. and Oran, E. S., NASA Contractors' Report 191051 (1993).

58. Kailasanath, K., Ganguly, K. and Patnaik, G., Prog. Aero. Astro. 151, 247 (1993).

59. Strehlow, R. A., Noe, K. A. and Wherley, B. L., 21st Symposium (International) on Combustion, pp. 1899-1908, The Combustion Institute, Pittsburgh (1986).

60. Kee, R. J., Miller, J. A., Evans, G. H. and DixonLeWIS, G., 22nd Symposium (International) on Combustion, pp. 1479-1494, The Combustion Institute, Pittsburgh (1988).

61. Dunsky, C. and Fernandez-Pello, A., 23rd Symposium (International) on Combustion, pp. 1657-1662, The Combustion Institute, Pittsburgh (1990).

62. Dunsky, C. M., 24th Symposium (International) on Combustion, pp. 177-187, The Combustion Institute, Pittsburgh (1992).

63. Durox, D., 24th Symposium (International) on Combustion, pp. 197-204, The Combustion Institute, Pittsburgh (1992).

64. Ronney, P. D. and Wachman, H. Y., Combust. Flame 62, 107 (1985).

65. Ronney, P. D., Combust. Flame 62, 121 (1985).

66. RoNNEY, P. D., 22nd Symposium (International) on Combustion, pp. 1615-1623, The Combustion Institute, Pittsburgh (1988).

67. RonNey, P. D., Combust. Sci. Technol. 59, 123 (1988)

68. ABBUD-MADRID, A. and RonNEY, P. D., 23rd Symposium (International) on Combustion, pp. 423-431, The Combustion Institute, Pittsburgh (1990).

69. Whaling, K. N., AbBUd-Madrid, A. and Ronney, P. D., Fall Technical Meeting, Western States Section, The Combustion Institute, Pittsburgh (1990) 
70. Ronney, P. D., Combust. Flame 82, 1 (1990).

71. Ronney, P. D. and Sivashinsky, G. I., SIAM J. Appl. Math. 49, 1029 (1989).

72. Farmer, J. R. and Ronney, P. D., Combust. Sci. Technol. 73, 555 (1990).

73. LAW, C. K. and Egolfopoulos, F. N., 23rd Symposium (International) on Combustion, pp. 413-421, The Combustion Institute, Pittsburgh (1990).

74. Law, C. K. and Egolfopoulos, F. N., 24th Symposium (International) on Combustion, pp. 137-144, The Combustion Institute, Pittsburgh (1992).

75. Buckmaster, J. and Weeratunga, S., Combust. Sci. Tech. 35, 287 (1984).

76. Buckmaster, J. D., Joulin, G. and Ronney, P. D., Combust. Flame 79, 381 (1990); lbid. 84, 411 (1991).

77. Buckmaster, J., Gessman, R. and Ronney, P., 24th Symposium (International) on Combustion, pp. 53-59, The Combustion Institute, Pittsburgh (1992).

78. Buckmaster, J., RonNey, P. D. and SMOOKe, M., AIA A Paper No. 93-0712 (1993).

79. Buckmaster, J., Smooke, M. and Gioivangigli, V., Combust. Flame 94, 113 (1993).

80. Hawthorne, W. R., Weddell, D. S. and Hottel, H. C., 3rd Symposium on Combustion, Flame and Explosion Phenomena, pp. 266-288, The Combustion Institute, Pittsburgh (1949).

81. Burke, S. P. and Schumann, T. E. W., Ind. Eng. Chem. 20, 998 (1928)

82. Bilger, R. W., Prog. Energy Combust. Sci. 1, 87 (1976).

83. Bilger, R. W., Combust. Flame 30, 277 (1977).

84. GORE, J. P. and FAETH, G. M., 21st Symposium (International) on Combustion, pp. 1521-1531, The Combustion Institute, Pittsburgh (1986).

85. Gore, J. P. and Faeth, G. M., J. Heat Trans. 110, 173 (1988).

86. Sivathanu, Y. R. and Faeth, G. M., Combust. Flame 82, $150(1990)$.

87. Faeth, G. M., Gore, J. P., Chuech, S. G. and Jeng, S.-M., Ann. Rev. Num. Fluid Mech. Heat Trans. 2, 1 (1989).

88. LAW, C. K. and Chung, S. H., Combust. Sci. Technol. 29, $129(1982)$

89. Chung, S. H. and LAw, C. K., Combust. Flame 52, 59 (1983).

90. Faeth, G. M. and Samuelson, G. S., Prog. Energy Combust. Sci. 12, 305 (1986)

91. BILGer, R. W., 22nd Symposium (International) on Combustion, pp. 475-488, The Combustion Institute, Pittsburgh (1988).

92. Spalding, D. B., Combustion and Mass Transfer, Chapter 10, Pergamon Press, New York (1979).

93. Cochran, T. H. and Masica, W. J, NASA TN D$5872(1970)$

94. Cochran, T. H. and Masica, W. J., 13th Symposium (International) on Combustion, pp. 821-829, The Combustion Institute, Pittsburgh (1970).

95. Edelman, R. B., Fortune, O. F., Weilerstein, G., Cochran, T. H. and Haggard, J. B., Jr, 14 th Symposium (International) on Combustion, pp. 399-412, The Combustion Institute, Pittsburgh (1972).

96. Haggard, J. B., Jr and Cochran, T. H., Combust. Sci. Technol. 5, 291 (1972).

97. Haggard, J. B., Jr, NASA TN D-6523 (1972).

98. Haggard, J. B., Ir and Cochran, T. H., NASA TN D-7165 (1973)

99. HAGgaRD, J. B., Jr, NASA TP1841 (1981)

100. KlajN, M. and OPPENHEIM, A. K., 19th Symposium (International) on Combustion, pp. 223-235, The Combustion Institute, Pittsburgh (1982).

101. Edelman, R. B. and Bahadori, M. Y., Acta Astronautica 13, 681 (1986).

102. Edelman, R. B., Bahadori, M. Y., Olson, S. L. and Stocker, D. P., AIAA Paper No. 88-0645 (1988).

103. Bahadori, M. Y., Stocker, D. P. and Edelman, R. B., AIA A Paper No. 90-0651 (1990).

104. Bahadori, M. Y., Edelman, R. B., Stocker, D. P. and Olson, S. L., AIAA J. 28, 236 (1990).

105. Bahadori, M. Y., Edelman, R. B, Sotos, R. G. and Stocker, D. P., Ala A Paper No. $91-0719$ (1991).

106. Bahadori, M. Y., Edelman, R. B., Stocker, D. P., Sotos, R. G. and Vaughan, D. F., AIAA Paper No. 92-0243 (1992).

107. Bahadori, M. Y., Stocker, D. P., Vaughan, D. F. and ZHOU, L., 2nd International Microgravity Combustion Workshop, pp. 91-105, NASA CP 10113 (1993).

108. Mortazavi, S., Sunderland, P. B., Jurng, J., Köylü, Ü. Ö. and FAeth, G. M., AIAA Paper No. 93-0708 (1993)

109. Köylü, Ü. Ö., Sunderland, P. B., Mortazavi, S. and FaETH, G. M., AIAA Paper No. 94-0428 (1994).

110. EllzeY, J. L. and ORAN, E. S., 23rd Symposium (International) on Combustion, pp. 1635-1640, The Combustion Institute, Pittsburgh (1990).

111. Bahadori, M. Y., Vaughan, D. F., Stocker, D. P., Weiland, K. J. and Edelman, R. B., Spring Technical Meeting, pp. 75-79, Central States Section, The Combustion Institute, Pittsburgh (1992).

112. Viskanta, R. and Mengüc, M. P., Prog. Energy Combust. Sci. 13, 97 (1987).

113. Tien, C. L. and Lee, S. C., Prog. Energy Combust. Sci. 8, 41 (1982).

114. Köylü, Ü. Ö. and Faeth, G. M., Combust. Flame 87, $61(1991)$

115. Köylü, Ü. Ö., Sivathanu, Y. R. and Faeth, G. M., 3rd International Symposium on Fire Safety Science, pp. 625-634, Elsevier, London (1991)

116. Friedman, R., Ist International Symposium on Fire Safety Science, pp. 349-359, Hemisphere, Washington (1986).

117. Glassman, I., 22nd Symposium (International) on Combustion, pp. 295-311, The Combustion Institute, Pittsburgh (1988).

118. HAYNeS, B. S. and WaGner, H. G., Combust. Sci. Technol. 7, 229 (1981).

119. Sivathanu, Y. R. and Faeth, G. M., Combust. Flame 81, 133 (1990).

120. Schug, K. P., Manheimer-Timnat, Y., Yaccarino, P. and Glassman, I., Combust. Sci. Technol. 22, 235 (1980).

121. Sunderland, P. B., Mortazavi, S., Faeth, G. M. and Urban, D. L., Combust. Flame 96, 97 (1994).

122. Flower, W. L. and Bowman, C. T., 20th Symposium (International) on Combustion, pp. 1035-1044, The Combustion Institute, Pittsburgh (1984).

123. Flower, W. L. and Bowman, C. T., 21st Symposium (International) on Combustion, pp. 1115-1124, The Combustion Institute, Pittsburgh (1986).

124. Lee, J. H. S., Peraldi, O. and Knystautas, R., 2nd International Microgravity Combustion Workshop, $\mathrm{pp}$. 189-195, NASA CP 10113 (1993).

125. Ross, H. D., Facca, L. T., Berlad, A. and TangiRALA, V., NASA TM 101371 (1989).

126. Berlad, A., Ross, H., Facca, L. and Tangirala, V., AIAA Paper 89-0500 (1989)

127. Berlad, A. L., Ross, H., Facca, L. and Tangirala, V., Combust. Flame 82, 448 (1990).

128. Berlad, A. L., Ross, H., Facca, L. and Tangirala V., J. Prop. Power 7, 5 (1991).

129. Berlad, A. L. and Tangirala, V., Prog. Astron. Aero. 132, 59 (1991).

130. Kumar, R. K., Bowles, E. M. and Mintz, K. J., Combust. Flame 89, 320 (1992)

131. Seshadri, K., Berlad, A. L. and Tangirala, V. Combust. Flame 89, 333 (1992) 
132. RAYLEIGH, LORD, The Theory of Sound, Dover (1945).

133. Hegde, U., Ross, H. D. and FACCA, L. T., Combust. Sci. Technol. 94, 279 (1993).

134. Buckmaster, J. and Clavin, P., 24th Symposium (International) on Combustion, pp. 29-36, The Combustion Institute, Pittsburgh (1992).

135. Dosanjh, S., Peterson, J., Fernandez-Pello, A. C. and PAGNi, P. J., Acta Astronautica 13, 689 (1986).

136. Dosanjh, S. S., Pagni, P. J. and Fernandez-Pello, A. C., Combust. Flame 68, 131 (1987).

137. Torero, J. L., Fernandez-Pello, A. C. and Urban, D., AIAA Paper No. 93-0829 (1993).

138. Fernandez-Pello, A. C. and PAGNi, P. J., 2nd International Microgravity Combustion Workshop, pp. 251256, NASA CP 10113 (1993).

139. Howard, J. B., 2nd International Microgravity Combustion Workshop, pp. 73-79, NASA CP 10113 (1993).

140. Munir, Z. A. and Anselmi-Tamburi, U., Mater. Sci. Rep. 3, 277 (1989).

141. Holt, J. B. and Dunmead, S. D., Annu. Rev. Mater. Sci. 21, 305 (1991).

142. Varma, A. and Lebrat, J.-P., Chem. Eng. Sci. 47, 2179 (1992).

143. Glassman, I., Brezinsky, K. and Law, C. K., Combustion Synthesis of Materials in Microgravity, proposal to NASA (1991).

144. Makino, A. and LAw, C. K., 24th Symposium (International) on Combustion, pp. 1883-1891, The Combustion Institute, Pittsburgh (1992).

145. Moore, J. J., AIAA Paper No. 93-0830 (1993).

146. Fernandez-Pello, A. C. and Hirano, T., Combust. Sci. Technol. 32, 1 (1983).

147. Di Blasi, C., Crescitelli, S. and Russo, G., Combust Flame 72, 205 (1988).

148. West, J., Bhattacharjee, S. and Altenkirch, R. A., Fire and Combustion Systems, HTD-Vol. 199, A. M. Kanury and M. Q. Brewster (Eds), pp. 151-157, ASME, New York (1992).

149. Ferkul, P. V. and T'ien, J. S., AIA A Paper No. 930827 (1993).

150. Zhou, L. and Fernandez-Pello, A. C., 24th Symposium (International) on Combustion, pp. 1721-1728 The Combustion Institute, Pittsburgh (1992).

151. Olson, S. L., Ferkul, P. V. and T'IEN, J. S., 22nd Symposium (International) on Combustion, pp. 12131221, The Combustion Institute, Pittsburgh (1988).

152. Olson, S. L., Combust. Sci. Technol. 76, 233 (1991).

153. Altenkirch, R. A., Bhattacharjee, S., Olson, S. L. and WEST, J., IKI/AIAA Microgravity Science Symposium, Moscow, pp. 305-313, AIAA, Washington (1991).

154. Bhattacharjee, S. and Altenkirch, R. A, 24th Symposium (International) on Combustion, pp. 1669-1676, The Combustion Institute, Pittsburgh (1992).

155. Bonneau, L., Joulain, P., MOST, J. M. and Fernandez-Pello, A. C., AIAA Paper No. 93-0826 (1993).

156. T'IEN, J. S., Combust. Flame 65, 31 (1986).

157. Foutch, D. W. and T'IEN, J. S., $A I A A$ J. 25, 972 (1987)

158. T'IEN, J. S., Combust. Flame 80, 355 (1990).

159. Chao, B. H., Law, C. K. and T'IEN, J. S., 23rd Symposium (International) on Combustion, pp. 9-18, The Combustion Institute, Pittsburgh (1990).

160. Chao, B. H., Law, C. K., Combust. Flame 92, 1 (1993)

161. Bhattacharjee, S., Altenkirch, R. A., SrikantaRiah, N. and Vedha-Nayagam, M., Combust. Sci. Technol. 69, 1 (1990).

162. Altenkirch, R. A. and Bhattacharjee, S., alaA Prog. Astro. Aero, 130, 723 (1990).

163. Bhattacharjee, S. and AltenkirCh, R. A., 23rd Symposium (International) on Combustion, pp. 1627-1633,
The Combustion Institute, Pittsburgh (1990).

164. Sirignano, W. A., Combust. Sci. Technol. 6, 95 (1972).

165. Ross, H. D. and Sotos, R. G., 23rd Symposium (International) on Combustion, pp. 1649-1655, The Combustion Institute, Pittsburgh (1990).

166. Miller, F. J. and Ross, H., 24th Symposium (International) on Combustion, pp. 1703-1711, The Combustion Institute, Pittsburgh (1992)

167. Schiller, D. N. and Sirignano, W. A., AlaA Paper No. 93-0825 (1993).

168. Law, C. K., Prog. Energy Combust. Sci. 8, 171, 1982.

169. Kumagal, S. and Isoda, H., 6th Symposium (International) on Combustion, pp. 726-731, The Combustion Institute, Pittsburgh (1956).

170. Kumagai, S., Sakai, T. and OKajima, S., 13th Symposium (International) on Combustion, pp. 779-785, The Combustion Institute, Pittsburgh (1970).

171. Chauveau, C. and GöKalP, I., 7th European Symposium on Materials and Fluid Sciences in Microgravity (1989).

172. Hara, H. and KumagaI, S., 23rd Symposium (International) on Combustion, pp. 1605-1610, The Combustion Institute, Pittsburgh (1990).

173. Matalon, M. and Law, C. K., Combust. Flame 50, 219 (1983); Ibid, 59, 213 (1985).

174. LAzar, R. S. and FaETH, G. M., 13th Symposium (International) on Combustion, pp. 801-811, The Combustion Institute, Pittsburgh (1970).

175. FaETH, G. M., Dominicis, D. P., Tulpinsky, J. F. and OLSON, D. R., 12th Symposium (International) on Combustion, pp. 9-18, The Combustion Institute, Pittsburgh (1968).

176. Spalding, D. B., ARS J. 29, 828 (1959).

177. ROSNER, D. E., AIAA J. 5, 163 (1967).

178. Shuen, J. S., Yang, V. and Hsiao, C. C., Combust. Flame 89, 286 (1992).

179. FaEth, G. M., Prog. Energy Combust. Sci. 3, 191 (1977).

180. Shaw, B. D., Dryer, F. L., Williams, F. A. and HaGGard, J. B., Acta Astronautica 17, 1195 (1988).

181. ChoI, M. Y., Dr YeR, F. L. and HaGGaRd, J. B., Jr, 23rd Symposium (International) on Combustion, $\mathrm{pp}$. 1597-1604, The Combustion Institute, Pittsburgh (1990).

182. Choi, M. Y., Dryer, F. L., Green, G. J. and SangiovanNI, J. J., AlAA Paper No. 93-0823 (1993)

183. Randolph, A. L. and Law, C. K., Combust. Flame 64, 267 (1986).

184. JACKSON, G. and Avedisian, C. T., AIAA Paper 93OI30 (1993).

185. Williams, F. A., Prog. Aero. Astro. 73, Chap. 2 (1981).

186. Chung, S. H. and Law, C. K., Combust. Flame 64, 237 (1986)

187. Cho, S. Y., Chol, M. Y. and Dryer, F. L., 23rd Symposium (International) on Combustion, pp. 16111617, The Combustion Institute, Pittsburgh (1990).

188. Cho, S. Y., YetTer, R. A. and DRYer, F. L., J. Comp. Phys. 102, 160 (1992).

189. YANG, J. C., JACkson, G. S. and Avedisian, C. T., 23rd Symposium (International) on Combustion, pp. 1619. 1625, The Combustion Institute, Pittsburgh (1990).

190. LeE, A. and LAW, C. K., Combust. Sci. Technol. 86, 253 (1992).

191. Chol, M. Y., Cho, S. Y., Stein, Y. S. and Dryer, F. L., Fall Technical Meeting of the Eastern States Section, The Combustion Institute, Pittsburgh (1990).

192. FAETH, G. M. and Olson, D. R., SAE Trans. 1793 (1968).

193. LAW, C. K., AIChE J. 24, 626 (1978)

194. Makino, A. and LAw, C. K., Combust. Flame 73, 331 (1988). 
195. Wang, C. H., LiU, X. Q. and LaW, C. K., Combust. Flame 56, 175 (1984).

196. LAW, C. K. and LAW, H. K., Modern Developments in Energy, Combustion and Spectroscopy, F. A. Williams, A. K. Oppenheim, D. B. Olfe and M. Lapp (Eds), Pergamon Press, New York, in press.

197. JACKSON, G. S. and Avedisian, C. T., 2nd International Microgravity Combustion Workshop, pp. 331-337, NASA CP 10113 (1993).

198. WANG, C. H. and LAW, C. K., Combust. Flame 59, 53 (1985).

199. Yang, J. C., Jackson, G. S. and Avedisian, C. T., 23rd Symposium (International) on Combustion, pp. 1619-1625, The Combustion Institute, Pittsburgh (1990).

200. Carleton, F. B. and Weinberg, F. J., Nature 330, $635(1987)$

201. Ross, H. D., Sotos, R. G. and T'IEN, J. S., Combust. Sci. Technol. 75, 155 (1991).

202. Steinberg, T. A., Wilson, D. B. and Benz, F., Combust. Flame 88, 309 (1992); Ibid. 91, 200 (1992).

203. SPUNKLER, C. M., NASA TM 81728 (1981).

204. Ross, H. D., 2nd Microgravity Combustion Workshop, pp. 9-19, NASA CP 10113 (1993).

205. Huggett, C., Aerosp. Med. 40, 1176 (1969).

206. HugGett, C., Combust. Flame 20, 140 (1973).

207. Friedman, R. and Sacksteder, K. R., NASA TM 100944 (1988).
208. Carhart, H. W., Spacecraft Fire Safety, J. M. Margle (Ed.), pp. 51-57, NASA CP-2476 (1987).

209. McAleVey, R. F., III and Magee, R. S., J. Spacecraft Rockets 4, 1390 (1967).

210. Gann, R. G., Stone, J. P., Tatem, P. L., Williams, F. W. and Carhart, H. W., Combust. Sci. Technol. 18, $155(1978)$.

211. Horrigan, D. J., The Physiological Basis for Spacecraft Environmental Limits, J. M. Waligora (Ed.), pp. 1-15, NASA RP-1045 (1979).

212. KNIGHT, D. R., Spacecraft Fire Safety, J. M. Margle (Ed.), pp. 59-64, NASA CP-2476 (1987).

213. WILLENBERG, H. J. AIAA/IKI Microgravity Science Symposium, Moscow, pp. 317-323, AIAA, Washington (1991).

214. Youngblood, W. W. and Vedha-Nayagam, M., NASA CR 185147 (1989).

215. DE RIS, J., Spacecraft Fire Safety, J. M. Margle (Ed.), pp. 43-49, NASA CP-2476 (1987).

216. LekAN, J., NASA TM 101397 (1989); also AIAA Paper No. 89-0236 (1989).

217. Wessling, F. C. and Maybee, G. W., AIAA/IKI Microgravity Science Symposium, Moscow, pp. 356-366, AIAA, Washington (1991).

218. Kimzey, J. H., Proceedings of the Third Space Processing Symposium on Skylab Results, Vol. 1, pp. 115-130, NASA TM X-70252 (1974). 